\begin{tabular}{|c|c|c|}
\hline (ATINER) & $\begin{array}{l}\text { The Athens Journal of } \\
\text { Business \& Economics }\end{array}$ & (ATINER) \\
\hline \multicolumn{3}{|c|}{$\begin{array}{r}\text { Volume 5, Issue 1, J } \\
\text { Articles }\end{array}$} \\
\hline \multicolumn{3}{|c|}{ Front Pages } \\
\hline \multicolumn{3}{|c|}{ SÉVERINE MENGUY } \\
\hline \multicolumn{3}{|c|}{ Economic Growth in a Framework of Wages Rigidity } \\
\hline \multirow{2}{*}{\multicolumn{3}{|c|}{$\begin{array}{l}J E A N R O Y \\
\text { Optimal Pricing of Deposit Insurance: Aiming at Fairness } \\
\text { and Stability }\end{array}$}} \\
\hline & & \\
\hline \multicolumn{3}{|c|}{ ARTHUR KORUS } \\
\hline Spillover & Effects from the ECB's Unco & iventional \\
\hline \multicolumn{3}{|c|}{ Monetary Policies: The Case of Denmark, Norway and } \\
\hline \multicolumn{3}{|c|}{ Sweden } \\
\hline $\begin{array}{l}\text { AYLA OĞL } \\
\text { Monetary }\end{array}$ & $\begin{array}{l}\text { SINATLI E NILOUFER SOHRABJI } \\
\text { olicy Transmission in the Euro Zone }\end{array}$ & \\
\hline
\end{tabular}




\section{Mission}

ATINER is a World Non-Profit Association of Academics and Researchers based in Athens. ATINER is an independent Association with a Mission to become a forum where Academics and Researchers from all over the world can meet in Athens, exchange ideas on their research and discuss future developments in their disciplines, as well as engage with professionals from other fields. Athens was chosen because of its long history of academic gatherings, which go back thousands of years to Plato's Academy and Aristotle's Lyceum. Both these historic places are within walking distance from ATINER's downtown offices. Since antiquity, Athens was an open city. In the words of Pericles, Athens"... is open to the world, we never expel a foreigner from learning or seeing". ("Pericles' Funeral Oration", in Thucydides, The History of the Peloponnesian War). It is ATINER's mission to revive the glory of Ancient Athens by inviting the World Academic Community to the city, to learn from each other in an environment of freedom and respect for other people's opinions and beliefs. After all, the free expression of one's opinion formed the basis for the development of democracy, and Athens was its cradle. As it turned out, the Golden Age of Athens was in fact, the Golden Age of the Western Civilization. Education and (Re)searching for the 'truth' are the pillars of any free (democratic) society. This is the reason why Education and Research are the two core words in ATINER's name. 
The Athens Journal of Business \& Economics ISSN NUMBER: 2241-794X- DOI: 10.30958/ajbe

Volume 5, Issue 1, January 2019

Download the entire issue ( $\underline{\mathrm{PDF}})$

Front Pages

Efficiency of Cuts in Various Taxation Rates to Foster 1 Economic Growth in a Framework of Wages Rigidity

Séverine Menguy

Optimal Pricing of Deposit Insurance: Aiming at 37 Fairness and Stability

Jean Roy

Spillover Effects from the ECB's Unconventional

53

Monetary Policies: The Case of Denmark, Norway and $\underline{\text { Sweden }}$

Arthur Korus

Monetary Policy Transmission in the Euro Zone

Ayla Oğuş Binatli \& Niloufer Sohrabji 


\section{Athens Journal of Business \& Economics Editorial and Reviewers' Board}

\section{Editors}

- Dr. Christos Sakellariou, Associate Professor of Economics, Nanyang Technological University, Singapore \& Vice President of Administration and Finance, Athens Institute for Education and Research (ATINER).

- Dr. Gregory T. Papanikos, Honorary Professor, University of Stirling, UK \& President of ATINER.

- Dr. Peter Yannopoulos, Professor, Brock University, Canada \& Vice President of Global Communications, ATINER.

- Dr. Julia Underwood, Professor, Azusa Pacific University, USA \& Academic Member, ATINER.

- Dr. Nektarios Tzempelikos, Senior Lecturer in Marketing, Anglia Ruskin University, UK.

\section{Editorial Board}

- Dr. Panagiotis Petratos, Vice President of ICT, ATINER \& Professor, Department of Computer Information Systems, California State University (Stanislaus), USA.

- Dr. Michael P. Malloy, Director, Business \& Law Research Division, ATINER \& Distinguished Professor of Law, University of the Pacific, USA.

- Dr. Peter Koveos, Head, Accounting \& Finance Research Unit, ATINER \& Professor of Finance, Syracuse University, USA.

- Dr. Sharon Claire Bolton, Head, Management Research Unit, ATINER \& Professor, The Management School, University of Stirling, Scotland.

- Dr. Cleopatra Veloutsou, Head, Marketing Research Unit, ATINER \& Professor of Brand Management, University of Glasgow.

- Dr. John Thanopoulos, Professor of International Business (IB), and Dean, Business and Economics, IST

College \& Emeritus Professor, University of Piraeus, Greece.

- Dr. Elyas Elyasiani, Professor Finance and Economics, Fox School of Business and Management, Temple University, USA.

- Dr. Eduardo Segarra, Academic Member, ATINER \& Professor, Department of Agricultural \& Applied Economics, Texas Tech University, USA.

- Dr. Samuel Seaman, Academic Member, ATINER \& Professor of Decision Sciences, Graziadio School of Business and Management, Pepperdine University, USA.

- Dr. Hercules Haralambides, Academic Member, ATINER \& Professor of Maritime Economics and Logistics, Department of Econometrics, Erasmus University Rotterdam, The Netherlands.

- Dr. Steven Dellaportas, Academic Member, ATINER \& Professor of Accounting, RMIT (Royal Melbourne Institute of Technology) University, Australia.

- Dr. George V. Priovolos, Professor, Iona College, USA.

- Dr. George Saridakis, Director of Doctoral Programmes, Kingston Business School, Kingston University \&

Professor of Small Business and Entrepreneurship, Kingston Hill, Kingston Upon Thames, UK.

- Dr. Liliana Costa, Tutor, Department of Communication and Art, University of Aveiro, Portugal.

- Dr. Gilles Chemla, Academic Member, ATINER \& Professor, Imperial College Business School, UK.

- Dr. Nathalie Homlong, Associate Professor, University College Volda, Norway.

- Dr. Tatyana Boikova, Associate Professor, Business Administration Department, Baltic International Academy, Latvia.

- Dr. Zubin Sethna, Associate Professor of Entrepreneurial Marketing, Regent's University London, UK.

- General Managing Editor of all ATINER's Publications: Ms. Afrodete Papanikou

- ICT Managing Editor of all ATINER's Publications: Mr. Kostas Spyropoulos

- Managing Editor of this Journal: Ms Fani Balaska (bio)

\section{Reviewers' Board}




\section{President's Message}

All ATINER"s publications including the e-journals are open access without any costs (submission, processing, publishing, open access paid by authors, open access paid by readers etc) and are independent of the presentations made at any of the many small events (conferences, symposiums, forums, colloquiums, courses, roundtable discussions) organized by ATINER throughout the year. The intellectual property rights of the submitted papers remain with the author.

Before you submit, please make sure your paper meets some basic academic standards, which include proper English. Some articles will be selected from the numerous papers that have been presented at the various annual international academic conferences organized by the different divisions and units of the Athens Institute for Education and Research.

The plethora of papers presented every year will enable the editorial board of each journal to select the best ones, and in so doing, to produce a quality academic journal. In addition to papers presented, ATINER encourages the independent submission of papers to be evaluated for publication.

The current issue of the Athens Journal of Business and Economics (AJBE) is the first issue of the fifth volume (2019). The reader will notice some changes compared with the previous issues, which I hope is an improvement. An effort has been made to include papers which fall within in one of the subfields of business and economics.

This issue includes papers on macroeconomic policy. In total, four papers are included. The first is a theoretical paper on fiscal policy; the second on optimal pricing of deposit insurance and the next two on monetary policy. The AJBE is truly an international journal; this is also reflected in this issue both in terms of authors and empirical content of the papers.

Gregory T. Papanikos, President

Athens Institute for Education and Research 


\section{Athens Institute for Education and Research}

\section{A World Association of Academics and Researchers}

\section{$14^{\text {th }}$ Annual International Symposium on Economic Theory, Policy and Applications 1-4 July 2019, Athens, Greece}

The Economics Unit of ATINER, will hold its $14^{\text {th }}$ Annual International Symposium on Economic Theory, Policy and Applications 1-4 July 2019, Athens, Greece sponsored by the Athens Journal of Business \& Economics. The aim of the conference is to bring together academics and researchers of all areas of economics and other related disciplines. You may participate as panel organizer, presenter of one paper, chair a session or observer. Please submit a proposal using the form available (https:// www.atiner.gr/2019/FORM-ECO.doc).

\section{Academic Members Responsible for the Conference}

- Dr. Gregory T. Papanikos, President, ATINER \& Honorary Professor, University of Stirling, UK.

- Dr. Chris Sakellariou, Head, Economics Unit \& Associate Professor of Economics, Nanvang Technological University, Singapore.

- Abstract Submission: 4 March 2019

- Acceptance of Abstract: 4 Weeks after Submission

- Submission of Paper: 3 June 2019

\section{Social and Educational Program}

The Social Program Emphasizes the Educational Aspect of the Academic Meetings of Atiner.

- Greek Night Entertainment (This is the official dinner of the conference)

- Athens Sightseeing: Old and New-An Educational Urban Walk

- Social Dinner

- Mycenae Visit

- Exploration of the Aegean Islands

- Delphi Visit

- Ancient Corinth and Cape Sounion

\section{Conference Fees}

Conference fees vary from $400 €$ to $2000 €$ Details can be found at: https://www.atiner.gr/2019fees 


\section{Athens Institute for Education and Research}

A World Association of Academics and Researchers

\section{$6^{\text {th }}$ Annual International Conference on Business, Law \& Economics 6-9 May 2019, Athens, Greece}

The Business, Economics and Law Division (BLRD) of ATINER is organizing its $6^{\text {th }}$ Annual International Conference on Business, Law \& Economics, 6-9 May 2019, Athens, Greece in collaboration with the MLC Management \& Law College of Ljubljana, sponsored by the Athens Journal of Business \& Economics and the Athens Journal of Law. In the past, the six units of BLRD have organized more than 40 annual international conferences on accounting, finance, management, marketing, law and economics. This annual international conference offers an opportunity for cross disciplinary presentations on all aspects of business, law and economics. Please submit an abstract (email only) to: atiner@atiner.gr, using the abstract submission form (https:/ / www.atiner.gr/2019/FORM-BLE.doc)

\section{Important Dates}

- Abstract Submission: 25 March 2019

- Acceptance of Abstract: 4 Weeks after Submission

- Submission of Paper: 8 April 2019

\section{Academic Member Responsible for the Conference}

- Dr. Gregory T. Papanikos, President, ATINER.

- Dr. Michael P. Malloy, Director, Business, Economics and Law Division, ATINER \& Distinguished Professor \& Scholar, University of the Pacific, USA.

- Dr. David A. Frenkel, LL.D., Head, Law Research Unit, ATINER \& Emeritus Professor, Law Area, Guilford Glazer Faculty of Business and Management, Ben-Gurion University of the Negev, Beer-Sheva, Israel.

\section{Social and Educational Program}

The Social Program Emphasizes the Educational Aspect of the Academic Meetings of Atiner.

- Greek Night Entertainment (This is the official dinner of the conference)

- Athens Sightseeing: Old and New-An Educational Urban Walk

- Social Dinner

- Mycenae Visit

- Exploration of the Aegean Islands

- Delphi Visit

- Ancient Corinth and Cape Sounion

More information can be found here: https://www.atiner.gr/social-program

\section{Conference Fees}

Conference fees vary from $400 €$ to $2000 €$

Details can be found at: https://www.atiner.gr/2019fees 



\title{
Efficiency of Cuts in Various Taxation Rates to Foster Economic Growth in a Framework of Wages Rigidity
}

\author{
By Séverine Menguy*
}

\begin{abstract}
We use a simple DSGE model with prices and wages rigidities to evaluate the efficiency of various fiscal policies intended to sustain economic activity and growth. We show that a fiscal policy aiming at reducing the tax burden would be all the more efficient as wages are more flexible. Besides, a decrease of the capital taxation rate appears as the most efficient fiscal policy. Indeed, it would decrease the capital cost, and it would foster private and public investment, but also private and public consumption. Wages rigidities would then reduce the inflationary tensions due to this economic growth. In comparison, a decrease of the consumption taxation rate increases private consumption, and all other components of global demand; however, economic growth is then more limited than with a decrease of the capital taxation rate. Finally, a decrease of the labor taxation rate would increase private investment and consumption and public expenditure exactly in the same proportions, but it would be much less efficient than the previous policies in order to sustain economic growth. Besides, it would favor public consumption expenditure, whereas the decrease of consumption or capital taxation rates would mainly promote the most productive public investment expenditure.
\end{abstract}

Keywords: Budgetary Policy, Capital Taxation Rate, Consumption Taxation Rate, DSGE Model, Labor Taxation Rate, Wages Rigidity.

\section{Introduction}

Is public expenditure growth enhancing (positive fiscal multiplier in Keynesian models), or can fiscal consolidation be expansionary? The question has been largely studied in the economic literature, without having a clear-cut answer. Indeed, these results strongly depend on the initial fiscal situation of the country: fiscal consolidations can increase private investment and economic growth, especially if the country is initially excessively indebted. They also depend on the structure of the fiscal consolidation: spending cuts (government wage bills, welfare payments, or unproductive expenditure) usually seem to be more growthenhancing Alesina and Ardagna (2010). So, after the 1970s, the efficiency of public expenditure in order to sustain economic growth by the way of budgetary multipliers higher than one has strongly been challenged. The latter could even negative, if the public debt is excessive and if the sustainability of public finances is put into question. Besides, consolidations based on spending cuts could imply non-Keynesian effects: adjustment on the labor market and decrease in production costs could increase profits and private investment.

\footnotetext{
*Associate Professor, Université Paris Descartes, France.
} 
More precisely, in New-Keynesian models, an increase in public expenditure increases global demand, labor demand, real wages, economic activity and private consumption. Using a DSGE model, Forni et al. (2009) underline the prevalence of empirical mild Keynesian effects of public expenditure. In particular, government purchases of goods and services, compensations for public employees or transfers to households would have small and short-lived expansionary effects on private consumption. The effects would be more significant on the revenue side: decreases in labor income and consumption tax rates would have sizeable effects on consumption and output, while a reduction in capital income taxation rate would favor investment and output in the medium run. Furthermore, Fatas and Mihov (2001) find that increases in public expenditure (particularly regarding wages of public employees) are followed by strong and persistent empirical increases in consumption and employment.

In the same way, Pappa (2004) shows that shocks to government consumption and investment increase real wages and employment contemporaneously both in US aggregate and in US state data. Indeed, a government consumption shock, financed by a higher budgetary deficit, increases global demand (absorption effect), and thus also labor demand, real wages, employment and output. Moreover, this positive effect on economic activity is the highest in case of an investment shock. Pappa (2009) also identifies fiscal shocks in the United-States, between 1969 and 2001, with a VAR methodology, using the hypothesis that fiscal shocks raise output and the budgetary deficit. Then, she shows that an increase in the public deficit as well as in public consumption or investment empirically increases real wages and employment (the evidence for public employment shocks is mixed).

On the contrary, Real Business Cycles models anticipate that increases in government spending should imply a decrease in labor productivity and in real wages; indeed, more resources are then absorbed by the government. Besides, the standard negative wealth effect implies that households feel poorer because of the decrease in their permanent income. Therefore, economic agents should increase their work effort and their labor supply, whereas they should reduce their consumption. Burnside et al. (2004) show that fiscal shocks (increase in military purchases) increase capital and labor income tax rates and aggregate hours worked, but decrease real wages. They are also associated with short lived rises in aggregate investment and small declines in private consumption. Edelberg et al. (1999) also show that an exogenous increase in US government purchases increases the present value of the tax burden for the representative household, implies a negative wealth effect, and increases labor supply. So, employment, output, the real interest rate and nonresidential investment (capital substitutable to labor in the production process) rise, while real wages, residential investment and private consumption expenditures fall.

Therefore, the question of the size and even of the sign of the budgetary multiplier is not clear cut, neither theoretically nor empirically.

To contribute to this debate, the current paper uses a DSGE model with a detailed fiscal block, in order to study the effect of the structure of public expenditures and resources. Indeed, public spending has various degrees of 
productivity, as some public expenditure can strongly enhance economic growth, whereas some public expenditure is quite inefficient and unproductive. Different types of public expenditure have various impacts on private factors (capital and labor) marginal productivity. Some are highly productive, in particular investment in capital: highways, airports, electric and gas facilities, water systems, etc. Some are moderately productive (education, healthcare), whereas others are quite weakly productive (entertainment, culture, national defense and environment, social transfers). Besides, regarding fiscal resources, we must also distinguish between various types of distortionary taxes: on consumption, on capital or on labor. Thanks to this detailed fiscal framework, we will then be able to shed light on the efficiency of various fiscal instruments and of variations in different taxes in order to really sustain economic growth.

The contribution of the current paper is also to introduce the stylized fact of wages rigidity on the labor market. Indeed, empirically, we can observe a high degree of wage stickiness in the economy; trade-unions have the power to avoid large wage variations and contractions. So, Christiano et al. (2005) find strong evidence in favor of sticky wages and estimate a degree of nominal wage rigidity much higher than the degree of price rigidity. The average duration of price and wage contracts in the estimated model is roughly two and three quarters, respectively, in the US between 1965 and 1995. Therefore, the authors find that wage rigidity is quantitatively at least as important as price rigidity for explaining the effects of monetary shocks and more generally, for explaining cyclical fluctuations.

Indeed, empirical wage rigidity has important implications regarding the efficiency of fiscal policies to promote economic growth. For example, Furlanetto (2007) studies the impact of a government spending shock on aggregate consumption. He shows that the model of Gali et al. (2007) implies a counterfactual increase in the real wage, the interest rate and the inflation rate. However, the introduction of sticky wages solves these problems and preserves the main result of the model, i.e. the positive response of consumption. In the context of sticky nominal wages, even without increase in the real wage, an increase in public expenditure can crowd-in and implies a positive multiplier on private consumption. Indeed, the consumption of rule of thumb consumers then increases less. However, marginal costs and inflation is also more moderate, and therefore, the interest rate increases less, and the consumption of optimizing consumers is less reduced. So, the aim of the current paper is to study the implications of a fiscal policy decreasing taxation rates on economic variables and on economic growth, but in the framework of nominal wages rigidities.

The rest of the paper is organized as follows. The second section reminds the numerous factors affecting the efficiency of the fiscal policy in order to sustain economic growth mentioned in the economic literature. The third section describes our DSGE model: economic agents, monetary and budgetary policies. The fourth, fifth and sixth sections study respectively the consequences of variations of the consumption taxation rate, of the capital taxation rate, and of the labor taxation rate. Finally, the seventh section concludes the paper. 


\section{Economic Literature}

The first parameter affecting the efficiency of an expansionary budgetary policy is the nature of the global policy-mix: the budgetary policy is all the more efficient as monetary policy is more constrained and less active. For example, Sims and Wolff (2013) study the state-dependence of the output and welfare effects of shocks to government purchases in a DSGE model with real and nominal frictions and a rich fiscal financing structure. Then, they show that the output multiplier is quite high: from 1 to 1.5 , it would reach about 2 in a Zero Lower Bound (ZLB) framework (inactive monetary policy). In the same way, with a medium scale DSGE model, Zubairy (2014) estimates the effects of a discretionary fiscal policy. The multiplier for government spending would be 1.07, as higher public spending is able to boost private consumption in the short run, but its effect would be quickly decreasing in the long run. The size of this multiplier is also increased if monetary policy is more accommodative and if it is less contractionary after an increase in public expenditure. Furthermore, a cut in capital tax or labor tax of $1 \%$ would imply an increase in GDP of $0.34 \%$ and $0.13 \%$ respectively, but the stimulating effect on investment would take more time.

Davig and Leeper (2011) also underline that an increase in government purchases is all the more detrimental to economic growth as monetary policy is active. Indeed, the nominal interest rate then increases more than proportionally to inflationary expectations, and the increase in the real interest rate crowds-out private consumption. In the same way, Leeper et al. (2011) show that fiscal multipliers are larger if monetary policy is more accommodative, and in a ZLB framework where monetary policy is constrained to be more passive. They are also larger if the economy is more closed, and if the proportion of non-savers (non-Ricardian and constrained consumers) is higher. Bianchi and Ilut (2017) also interpret the policy-mix in light of the possibility of regimes changes regarding the balance of power between the monetary and fiscal authorities (whether they are active or passive, and whether a conflict of goals arises). They show that regime changes imply breaks in the persistence and volatility of inflation, as well as in the trend and accommodation of the public debt level.

Another parameter affecting the budgetary policy efficiency is the nature of the representative household, and the possibility to take into account nonRicardian and constrained consumers. For example, Galí et al. (2007) introduce the existence of rule-of-thumb consumers in a New-Keynesian model, and they also consider sticky prices to study the effect of government spending on consumption. So, in the framework of an inter-temporal budgetary constraint of infinity-lived Ricardian households, if the budgetary deficit must later be financed, public spending crowds-out private consumption. On the contrary, in the framework of non-Ricardian households constrained to consume their current income, the budgetary multiplier can be higher than one. Besides, the authors mention that empirical evidence according to quarterly US data over the period 1954-2003 would mainly support this hypothesis (multiplier around 1.74 at the end of the second year). Therefore, the authors underline the necessity to take into account this existence of non-Ricardian consumers, in order to reconcile the 
theoretical results with the empirically observed expansionary consequences of higher public expenditure.

Drautzberg and Uhlig (2011) or Forni et al. (2009) also find that the fraction of transfers given to rule-of-thumb consumers improves the efficiency of an increase in public expenditure to sustain economic activity. However, Coenen and Straub (2005) revisit the effects of government spending shocks on private consumption within an estimated New-Keynesian DSGE model of the euro area. They show that the presence of non-Ricardian households (consuming current income and liquidity constrained) is in general conducive to raising the level of consumption in response to government spending shocks. Nevertheless, the latter would usually not crowd-in private consumption, because the estimated share of non-Ricardian households is relatively low, and because the highly persistent nature of government spending shocks induces large negative wealth effects, inducing households to work more but to consume less.

Another important parameter is the nature of the expansionary budgetary policy conducted by the government. Indeed, cuts in taxation rates are often found to be more expansionary than increases in public expenditure. Alesina and Ardagna (2010) examine the evidence on episodes of large stances in fiscal policy (politically motivated modification in the budgetary deficit), both in cases of fiscal stimuli (to increase GDP) and in cases of fiscal adjustments (to reduce the public debt-to-GDP ratio) in OECD countries from 1970 to 2007. They find that fiscal stimuli based upon tax cuts are more likely to increase growth than those based upon spending increases. In the same way, Ardagna (2004) uses data from a panel of OECD countries, and shows that a fiscal adjustment is more or less expansionary according to its composition. In particular, stabilizations implemented by cutting public spending would imply higher GDP growth rates.

Coenen et al. (2008) use the ECB's New Area-Wide Model to model fiscal consolidation as a permanent reduction in the targeted government debt-to-output ratio. Then, they find that fiscal consolidation has positive long-run effects on key macroeconomic aggregates such as output and consumption, but that it gives rise to noticeable short-run adjustment costs. Mertens and Ravn (2011) also show that, in the framework of a DSGE model, 'anticipated' tax cuts may be contractionary. However, after their implementation, 'surprise' and effective exogenous tax cuts have expansionary and persistent effects on output, consumption, investment and hours worked. In the same way, according to Ludvigson (1996), deficit financed cuts in distortionary income taxation may stimulate investment and be expansionary, even if agents expect future taxes on capital income to be higher. Indeed, the fiscal shock implies a substitution from leisure to labor increasing output. Besides, higher future capital taxes decrease the returns on sparing and increase consumption levels. Furthermore, Blanchard and Perotti (2002) characterize the dynamic effects of shocks in government spending and taxes on economic activity in the United States between 1947 and 1997, using a mixed structural VAR/event study approach. They show that positive government spending shocks have a positive effect on output, and positive tax shocks have a negative effect, even if the multipliers are moderate, often close to one. Nevertheless, both increases in taxes and in government spending have a strong 
negative effect on investment spending, which underlines the benefits of a tax consolidation policy.

For G7 economies (excluding Italy) between the 1970's and 2010, Baum et al. (2012) show that fiscal multipliers differ across countries. Besides, the position in the business cycle affects the impact of fiscal policy on output: on average, government spending, and revenue multipliers tend to be larger in downturns than in expansions. Indeed, under a negative output gap, excess capacities are available in the economy, making the crowding out of private investment lower. Moreover, revenue multipliers would be smaller than spending multipliers; they would be particularly small in the United-States and in the United-Kingdom, whereas their impact would be statistically significant for Canada, France, Germany, and Japan. Stähler and Thomas (2012) use a DSGE model with a two-country monetary union structure, calibrated for Spain and the rest of the monetary union. They find that, in terms of output and employment losses, fiscal consolidation is the least damaging when achieved by reducing the public sector wage bill, whereas it is most damaging when carried out by cutting public investment. Besides, an increase in indirect taxation (the consumption tax rate: the VAT) to finance public expenditure, compensated by a decrease in social security contributions and in direct taxation, would be beneficial in terms of output and employment.

Finally, in the framework of a DSGE model, Bhattarai and Trzeciakiewicz (2017) show that in the United-Kingdom, between 1987 and 2010, the most stimulating fiscal policy instrument is the consumption tax cut in the short term, the capital tax cut in the medium term, and the government investment expenditure in the long term. Nevertheless, the implications of fiscal policy depend significantly on the size of nominal and real frictions. In particular, higher levels of price rigidity increase government expenditure multipliers and tax multipliers. In addition, higher nominal wage rigidity tends to decrease tax multipliers in the long term.

\section{The Model}

In the framework of this abundant economic literature, the current paper aims at shedding light on the consequences of various fiscal policies in order to sustain economic growth. We consider a standard DSGE model, with a representative household and a representative firm. Regarding the budgetary authority, the contribution of the current paper is to take into account a developed fiscal block, where public consumption expenditure is distinguished from public investment expenditure, in order to study the consequences of the productivity of public spending on economic activity. Besides, we also distinguish between the use of various fiscal resources and distortionary taxes: on consumption, capital or labor, in order to affect economic activity. As previously mentioned, we also precisely model prices and wages rigidities. In the rest of the paper, all lower-case letters denote variables in logarithms and in variations from their long run equilibrium values. 


\section{Households}

Aggregate demand results from the log-linearization of the Euler equation, which describes the representative household's expenditure decisions. In a given period $(\mathrm{T})$, the representative household/consumer maximizes an inter-temporal utility function:

$\max \sum_{t=T}^{\infty} \beta^{t-T} E_{T}\left[U_{t}\right]$

Where: $E_{t}()$ is the rational expectation operator conditional on information available at date $(\mathrm{t})$, and $(\beta)$ is the time discount factor. Prices of goods, interest rates, taxation rates and wages are taken as given by the representative household.

We suppose that the utility function of a representative household is as follows:

$U_{t}=\alpha_{c} \frac{\theta}{(\theta-1)}\left(C_{t}\right)^{\frac{(\theta-1)}{\theta}}+\alpha_{g} \frac{\theta}{(\theta-1)}\left(G_{t}\right)^{\frac{(\theta-1)}{\theta}}-\alpha_{l} \frac{1}{(1+\varphi)} L_{t}^{s(1+\varphi)}$

The indices $\left(0<\alpha_{\mathrm{c}}<1\right),\left(0<\alpha_{\mathrm{g}}<1\right)$ and $\left(0<\alpha_{1}<1\right)$ are the respective weights given to consumption of private goods, consumption of public goods and leisure in the utility function.

So, utility is an increasing and concave function of $\left(\mathrm{C}_{\mathrm{t}}\right)$, an index of the household's consumption of all goods that are supplied; $(\theta)$ is the elasticity of intertemporal substitution. Utility is also an increasing and concave function of real public goods and services provided in the home country $\left(\mathrm{G}_{\mathrm{t}}\right)$. Finally, utility is also a decreasing and convex function of the hours worked $\left(L_{t}^{S}\right)$, where $(\varphi \geq 0)$ is the inverse of the Frisch elasticity of labor supply, the inverse of the elasticity of the work effort with respect to the real wage.

This maximization is subject to a life time and inter-temporal nominal budget constraint, for whatever date (T) considered at which the actualization is realized. Regarding its expenditure, the representative household consumes goods (including taxes), it realizes investments in physical capital and it purchases government bonds. Capital is rented by households to firms, for which they receive a rental rate as well as profits which are all redistributed. Regarding its resources, the representative household receives labor and capital revenues (physical capital and profits), as well as gains from government bonds holding from the previous period. For simplicity, we suppose that these financial assets are only riskless one-period nominal government bonds. Besides, capital is not fully taxed, as we suppose that physical capital depreciation is exempted from taxation. So, if we suppose complete financial markets, a household flow budget constraint for each period $(\mathrm{T})$ takes the form: 


$$
\begin{aligned}
& \left(1+\tau_{c, T}\right) P_{T} C_{T}+P_{T} I N V_{T}+B_{T} \\
= & \left(1-\tau_{l, T}\right) W_{T} L_{T}+\left(1-\tau_{k, T}\right) R_{T}^{k} K_{T}+\delta \tau_{k, T} P_{T} K_{T}+P_{T} \Xi_{T}+\left(1+i_{T-1}\right) B_{T-1}
\end{aligned}
$$

With, in period $(t)$ : $\left(C_{t}\right)$ : real consumption; $\left(\mathrm{INV}_{\mathrm{t}}\right)$ : real investment in new physical capital; $\left(\mathrm{K}_{\mathrm{t}}\right)$ : stock of physical capital; $\left(\mathrm{P}_{\mathrm{t}}\right)$ : level of consumer prices; $\left(\mathrm{W}_{\mathrm{t}}\right)$ : nominal hourly wage; $\left(\tau_{1, t}\right)$ : taxation rate on labor income; $\left(\tau_{\mathrm{c}, t}\right)$ : taxation rate on consumption; $\left(\tau_{\mathrm{k}, \mathrm{t}}\right)$ : taxation rate on capital; $\left(R_{t}^{k}\right)$ : nominal rental rate for capital services rented out to firms; $(\delta)$ : depreciation rate of physical capital; $\left(\mathrm{L}_{\mathrm{t}}\right)$ : hours worked by the household; $\left(\mathrm{i}_{\mathrm{t}}\right)$ : nominal interest rate; $\left(\mathrm{B}_{\mathrm{t}}\right)$ : nominal value of riskless one period bonds (portfolio of all claims on the government) at the end of period $(\mathrm{t}) ;\left(\Xi_{t}\right)$ Nominal profits distributed to households by firms (dividends).

Furthermore, the capital stock varies according to the following equation:

$K_{t+1}=(1-\delta) K_{t}+I N V_{t}$

So, in logarithms and in terms of variations, the capital stock adjusts according to the following equation:

$k_{t+1}=(1-\delta) k_{t}+\left(\frac{I N V}{K}\right) \operatorname{inv}_{t}=(1-\delta) k_{t}+\delta i n v_{t}$

Besides, the value of the real interest rate on capital is:

$\left(\frac{R_{t}^{k}}{P_{t}}\right)=\left(\frac{1-\beta}{\beta}\right) \frac{1}{\left(1-\tau_{k, t}\right)}+\delta$

which implies: $\left(r_{t}^{k}-p_{t}\right)=-\log \left(1-\widehat{\tau_{k, t}}\right) \sim \widehat{\tau_{k, t}}$

in logarithms and in variations, where a circumflex denotes a variation in the taxation rate.

In this context, the result of the maximization of equation (1) under the constraint (3) implies the following first order Euler condition, regarding timing of expenditure decisions and inter-temporal substitution, for whatever period $(\mathrm{T})$ :

$\frac{1}{\left(1+\tau_{c, T}\right) P_{T}} \frac{\partial U_{T}}{\partial C_{T}}=\frac{\beta\left(1+i_{T}\right)}{\left(1+\tau_{c, T+1}\right) P_{T+1}} \frac{\partial E_{T}\left(U_{T+1}\right)}{\partial C_{T+1}}$

Furthermore, by combining equations (2) and (8), (VT), we have:

$$
C_{T}=\left[\frac{\left(1+\tau_{c, T+1}\right) E_{T}\left(P_{T+1}\right)}{\beta\left(1+\tau_{c, T}\right)\left(1+i_{T}\right) P_{T}}\right]^{\theta} E_{T}\left(C_{T+1}\right)
$$


So, in logarithms and in variations from their long run equilibrium values, with: $\log (1+\mathrm{x}) \sim \mathrm{x}$ provided $(\mathrm{x})$ is sufficiently small; with $\left[\pi_{t}=\frac{P_{t}-P_{t-1}}{P_{t-1}} \sim p_{t}-p_{t-1}\right]$ : inflation rate; we have:

$\left.c_{T}=E_{T}\left(c_{T+1}\right)-\theta\left[i_{T}-E_{T}\left(\pi_{T+1}\right)\right]-\theta \mid \widehat{\tau_{c, T}}-E_{T}\left(\widehat{\tau_{c, T+1}}\right)\right]$

Besides, for the representative agent in the country (i), we obtain the following optimal substitution between private consumption, public consumption and working time ${ }^{1}$ :

$$
\frac{\partial U_{T}}{\partial C_{T}}=-\frac{\left(1+\tau_{c, T}\right) P_{T}}{W_{T}\left(1-\tau_{l, T}\right)} \frac{\partial U_{T}}{\partial L_{T}^{S}}=\tau_{c, T} \frac{\partial U_{T}}{\partial G_{T}}
$$

Therefore, a higher real wage net of taxes reduces the marginal utility of leisure and increases the one of labor.

Besides, regarding labor supply, according to equations (2) and (11), in logarithms and in variations from their long run equilibrium values, we obtain ${ }^{2}$ :

$$
l_{T}^{S}=\frac{1}{\varphi}\left(w_{T}-p_{T}\right)-\frac{1}{\varphi}\left(\widehat{\tau_{l, T}}+\widehat{\tau_{c, T}}\right)-\frac{1}{\varphi \theta} c_{T}
$$

So, labor supply increases with the real wage, but it decreases with taxation rates $\left(\tau_{1, \mathrm{t}}\right.$ and $\left.\tau_{\mathrm{c}, \mathrm{t}}\right)$ reducing the purchasing power and with the disutility of working time $(\varphi)$.

Besides, regarding the variation in consumption, according to equations (2) and (11), in logarithms and in variations from their long run equilibrium values, we obtain ${ }^{3}$ :

$$
g_{T}=c_{T}+\theta \widehat{\tau_{c, T}}
$$

Therefore, private consumption increases less than global public expenditure and the budgetary multiplier is smaller than one if the consumption taxation rate increases. However, the rest of the paper will allow distinguishing between the various components of this budgetary expenditure.

\footnotetext{
${ }^{1}$ Here, we suppose that according to the budgetary constraint of the government, fiscal resources and expenditures vary in phase.

$2 \frac{\partial U_{T}}{\partial L_{T}^{s}}=-\alpha_{l}\left(L_{T}^{s}\right)^{\varphi}=-\frac{W_{T}\left(1-\tau_{l, T}\right)}{\left(1+\tau_{c, T}\right) P_{T}} \frac{\partial U_{T}}{\partial C_{T}}=-\frac{W_{T}\left(1-\tau_{l, T}\right)}{\left(1+\tau_{c, T}\right) P_{T}} \alpha_{c}\left(C_{T}\right)^{-\frac{1}{\theta}}$.

$3 \frac{\partial U_{T}}{\partial G_{T}}=\alpha_{g}\left(G_{T}\right)^{-\frac{1}{\theta}}=\frac{1}{\tau_{c, T}} \frac{\partial U_{T}}{\partial C_{T}}=\frac{\alpha_{c}}{\tau_{c, T}}\left(C_{T}\right)^{-\frac{1}{\theta}}$.
} 


\section{Firms}

The representative firm produces a differentiated good in a monopolistic competition setting. It defines prices in order to maximize its profit, taking other variables as given. The firm rents capital and labor on perfectly competitive markets. Capital is defined according to equation (4). Wages are fixed by unions, whereas labor adjusts according to labor demand by firms. Monopolistic competition gives to goods suppliers a market power regarding price-setting, while at the same time fitting the empirical evidence of a large number of firms in the economy. So, the production function of the representative firm, including the utilization of capital and labor, has the following form:

$$
\begin{aligned}
& Y_{t}=A_{t} K_{t}^{v} L_{t}^{D(1-v)} G_{\text {inv }, t}^{z_{1}} G_{c, t}^{z_{2}} \quad 0<v<1 \quad 0<\mathrm{z}_{2}<\mathrm{z}_{1}<1 \\
& y_{t}=a_{t}+v \mathrm{k}_{t}+(1-v) l_{t}^{D}+\mathrm{z}_{1} \mathrm{~g}_{\text {inv }, t}+\mathrm{z}_{2} \mathrm{~g}_{c, t}
\end{aligned}
$$

With $\left(\mathrm{Y}_{\mathrm{t}}\right)$ : real production level; $\left(\mathrm{A}_{\mathrm{t}}\right)$ : technology or productivity shock; $(v)$ : share of capital in the production function; $\left(\mathrm{z}_{1}\right)$ or $\left(\mathrm{z}_{2}\right)$ : productivity of public expenditure.

Besides, we introduce the fact that public expenditure is made freely available by the government, and can be more ( $\mathrm{z}_{1}$ is high) or less $\left(\mathrm{z}_{2}\right.$ is small) efficient and productive in increasing the productivity of private factors. So, investment public expenditure $\left(G_{i n v, t}\right)$ is supposed to be more productive than consumption public spending $\left(\mathrm{G}_{\mathrm{c}, \mathrm{t}}\right)$, which implies $\left(\mathrm{z}_{1}>\mathrm{z}_{2}\right)$, whereas: $\left(G_{t}=G_{\text {inv }, t}+G_{c, t}\right)$.

The firm maximizes its nominal profit: $\Xi_{t}=P_{t} Y_{t}-W_{t} L_{t}^{D}-R_{t}^{k} K_{t}$. So, this implies ${ }^{1}$ :

$$
\frac{R_{t}^{k} K_{t}}{W_{t} L_{t}^{D}}=\frac{v}{(1-v)}
$$

The capital-labor ratio is thus defined by the returns in the production function. So, in logarithms and in variations, we have:

$k_{t}-l_{t}^{D}+r_{t}^{k}-w_{t}=0$

Let's consider a Calvo-type framework of staggered priced, where a fraction $(0<\alpha<1)$ of goods prices remain unchanged each period, whereas prices are adjusted for the remaining fraction (1- $\alpha)$ of goods. Monopolistically competitive firms choose their nominal prices to maximize profits subject to constraints on the frequency of future price adjustments, taking into account that prices may be fixed for many periods. So, they minimize the loss function:

$$
\overline{\frac{\partial g_{t}}{\partial K_{t}}=v P_{t} A_{t} K_{t}^{v-1}\left(L_{t}^{D}\right)^{1-v} G_{i n v, t}^{z_{1}} G_{c, t}^{z_{2}}-} R_{t}^{k}=0 ; \quad \frac{\partial g_{t}}{\partial L_{t}^{D}}=(1-v) P_{t} A_{t} K_{t}^{v}\left(L_{t}^{D}\right)^{-v} G_{i n v, t}^{z_{1}} G_{c, t}^{z_{2}}-W_{t}=0 .
$$


$\operatorname{Min}_{p_{t}^{r}} \sum_{k=0}^{\infty}(\alpha \beta)^{k} E_{t}\left(p_{t}^{r}-\widetilde{p_{t+k}^{r}}\right)^{2}$

Where $\left(\widetilde{p_{t}^{r}}\right)$ is the logarithm of the optimal price that the representative firm will set in period (t) if there were no price rigidity.

Thus, by deriving in function of the reset price $\left(p_{t}^{r}\right)$, we have:

$p_{t}^{r}=(1-\alpha \beta) \sum_{k=0}^{\infty}(\alpha \beta)^{k} E_{t}\left(\widetilde{p_{t+k}^{r}}\right)$

Therefore, the representative firm sets the optimal reset price $\left(p_{t}^{r}\right)$ to the level of a weighted average of the prices that it would have expected to reset in the future if there weren't any price rigidities.

The optimal strategy of the firm is to fix prices at marginal costs: $\left(\widetilde{\mathrm{p}_{\mathrm{t}}^{\mathrm{r}}}=m c_{t}\right)$, where $\left(m c_{t}\right)$ is the nominal marginal production cost of the representative firm. Furthermore, prices in period $(\mathrm{t})$ are an average of past prices and reset prices:

$p_{t}=\alpha p_{t-1}+(1-\alpha) p_{t}^{r}$

So, by combining equations (19) and (20), we obtain:

$$
\mathrm{p}_{\mathrm{t}}^{\mathrm{r}}=\frac{\alpha \beta}{(1-\alpha)} \mathrm{E}_{\mathrm{t}}\left(p_{t+1}\right)-\frac{\alpha^{2} \beta}{(1-\alpha)} p_{t}+(1-\alpha \beta) m c_{t}
$$

Therefore, we have the following inflation rate:

$\pi_{t}=\beta E_{t}\left(\pi_{t+1}\right)+\frac{(1-\alpha)(1-\alpha \beta)}{\alpha}\left(m c_{t}-p_{t}\right)$

Inflation depends on expected future inflation, and on the gap between the frictionless optimal price level and the current price level, i.e.: on the real marginal cost. Indeed, inflationary pressures can be due to the fact that prices which can be reset by firms are increased.

Let's now clarify the expression of the real marginal production cost for the representative firm. According to equation (14), the production costs of the quantity $\left(\mathrm{Y}_{\mathrm{t}}\right)$ are:

$$
W_{t} L_{t}=W_{t}\left(\frac{Y_{t}}{A_{t} K_{t}^{v} G_{i n v, t}^{z_{1}} G_{c, t}^{z_{2}}}\right)^{\frac{1}{1-v}} \text { and } R_{t}^{k} K_{t}=R_{t}^{k}\left(\frac{Y_{t}}{A_{t} L_{t}^{1-v} G_{i n v, t}^{z_{1}} G_{c, t}^{z_{2}}}\right)^{\frac{1}{v}}
$$

So, differentiating these expressions, and using equations (14) and (16), the nominal marginal production cost of the quantity $\left(\mathrm{Y}_{\mathrm{t}}\right)$ is: 
$M C_{t}=\frac{\partial\left(W_{t} L_{t}\right)}{\partial Y_{t}}=\frac{\partial\left(R_{t}^{k} K_{t}\right)}{\partial Y_{t}}=\frac{\left(R_{t}^{k}\right)^{v} W_{t}^{1-v}}{v^{v}(1-v)^{1-v} A_{t} G_{i n v, t}^{z_{1}} G_{c, t}^{z_{2}}}$

In logarithms, we obtain the following variation in the real marginal production cost:

$$
\left(m c_{t}-p_{t}\right)=(1-v)\left(w_{t}-p_{t}\right)+v\left(r_{t}^{k}-p_{t}\right)-\left(a_{t}+z_{1} g_{i n v, t}+z_{2} g_{c, t}\right)
$$

So, obviously, real marginal production costs increase with the real wage and with the real cost of capital services, whereas they decrease with the productivity of public expenditure. If public expenditure is more productive, inflationary tensions are less accentuated, and the monetary authority increases less the nominal interest rate, which is less detrimental to private consumption and to economic growth.

Therefore, equations (7), (12) (15), (17), (22) and (25) imply the following inflation rate, for a given period $(\mathrm{T})$ :

$$
\begin{gathered}
\pi_{T}=\beta E_{t}\left(\pi_{T+1}\right)+\frac{\varphi \mu_{1}(1-v)}{(1+v \varphi)} y_{T}+\frac{\mu_{1}(1-v)}{\theta(1+v \varphi)} c_{T}-\frac{\mu_{1}(1+\varphi)}{(1+v \varphi)}\left(a_{T}+z_{1} g_{i n v, T}+z_{2} g_{c, T}\right) \\
+\frac{\mu_{1}(1-v)}{(1+v \varphi)}\left(\widehat{\tau_{l, T}}+\widehat{\tau_{c, T}}\right)+\frac{v \mu_{1}(1+\varphi)}{(1+v \varphi)} \widehat{\tau_{k, T}}
\end{gathered}
$$

with: $\mu_{1}=\frac{(1-\alpha)(1-\alpha \beta)}{\alpha}$

In the same way, we can introduce some imperfection on the labor market, avoiding flexibility to fix the wage according to variations in labor demand and supply. Indeed, empirically, we can observe a high degree of wage stickiness in the economy; for example, trade-unions have a monopolistic power to avoid wage contractions. Therefore, as in Gali (2008) for example, we suppose that a fraction $\left(\alpha_{\mathrm{w}}\right)$ of households keep asking for the same wage, whereas the remaining fraction $\left(1-\alpha_{\mathrm{w}}\right)$ re-optimize the wage they desire according their competences (type of labor) and the services they provide. Indeed, households are specialized in a given labor service, monopolistically supplied, and they choose nominal wages in staggered contracts (by the way of trade unions) in order to maximize utility subject to constraints on the frequency of future wage adjustments. Besides, as in Thomas (2008) for example, we suppose that a fraction $(1-\varepsilon)$ of households are able to keep their jobs between two periods, the remaining fraction $(\varepsilon)$ separating from their jobs. More precisely, households minimize the loss function:

$\operatorname{Min}_{W_{t}^{r}} \sum_{k=0}^{\infty}\left[\alpha_{w}(1-\varepsilon) \beta\right]^{k} E_{t}\left(w_{t}^{r}-\widetilde{w_{t+k}^{r}}\right)^{2}$ 
Where $\left(\widetilde{w_{t}^{r}}\right)$ is the logarithm (variation) of the optimal nominal wage that the representative household will set in period $(\mathrm{t})$ if there were no wage rigidity.

By analogy with the method exposed in equations (18) to (22), we have the following variation in the nominal wage $\left(\pi_{t}^{w}\right)$ :

$$
\pi_{t}^{w}=w_{t}-w_{t-1}=\beta(1-\varepsilon) \mathrm{E}_{\mathrm{t}}\left(\pi_{t+1}^{w}\right)+\frac{\left(1-\alpha_{w}\right)\left[1-\alpha_{w} \beta(1-\varepsilon)\right]}{\alpha_{w}}\left(\widetilde{\mathrm{w}_{\mathrm{t}}^{\mathrm{r}}}-w_{t}\right)
$$

So, equation (28) introduces a wedge between the optimal wage and the current one, leading to wage inflation, but with delays and where the adjustment is imperfect. The inflation rate in wages is accentuated if the wage reset by households and targeted for multi-period wage contracts is higher than the current one. Besides, the optimal reset wage $\left(\widetilde{\mathrm{w}_{\mathrm{t}}^{\mathrm{r}}}\right)$ corresponds to the marginal utility of labor in comparison with leisure. So, equations (7), (12) (15) and (17) and (28) imply the following inflation rate in nominal wages, for a period $(\mathrm{T})$ :

$$
\begin{array}{r}
\pi_{T}^{w}=\beta(1-\varepsilon) \mathrm{E}_{\mathrm{T}}\left(\pi_{T+1}^{w}\right)+\frac{\mu_{1}^{w}}{(1-v)} y_{T}+\frac{\mu_{1}^{w}}{\theta(1+\varphi)} c_{T}-\frac{\mu_{1}^{w}(1+\varphi v)}{(1-v)(1+\varphi)} k_{T} \\
-\frac{\mu_{1}^{w}}{(1-v)}\left(a_{T}+\mathrm{z}_{1} \mathrm{~g}_{i n v, T}+\mathrm{z}_{2} \mathrm{~g}_{c, T}\right)+\frac{\mu_{1}^{w}}{(1+\varphi)}\left(\widehat{\tau_{l, T}}+\widehat{\tau_{c, T}}-\widehat{\tau_{k, T}}\right)
\end{array}
$$

with: $\mu_{1}^{w}=\frac{\left(1-\alpha_{w}\right)\left[1-\alpha_{w} \beta(1-\varepsilon)\right]}{\alpha_{w}}$

\section{Global Equilibrium}

We are now going to derive the equilibrium on the goods market regarding global demand. Clearing on the goods market in period $(\mathrm{T})$ requires:

$$
Y_{T}=C_{T}+G_{T}+I N V_{T}
$$

Therefore, in logarithms and in variations, we obtain:

$$
y_{T}=\frac{C_{T}}{Y_{T}} c_{T}+\frac{G_{T}}{Y_{T}} g_{T}+\frac{I N V_{T}}{Y_{T}} \operatorname{inv}_{T}
$$

Besides, profit maximization and equations (4) and (6) imply:

$$
\begin{aligned}
& \frac{I N V_{T}}{Y_{T}}=\left(\frac{I N V_{T}}{K_{T}}\right)\left(\frac{K_{T}}{Y_{T}}\right)=\delta \frac{v P_{T}}{R_{T}^{k}}=\frac{\delta v \beta\left(1-\tau_{k, T}\right)}{\left[(1-\beta)+\delta \beta\left(1-\tau_{k, T}\right)\right]}<1 \\
& \left(i n v_{T}-y_{T}\right)=-\left(r_{T}^{k}-p_{T}\right)=-\widehat{\tau_{k, T}}
\end{aligned}
$$


Let's define the output-gap as the differential between effective and potential output:

$x_{T}=y_{T}-y_{T}^{p}$

By combining equations (10), (13), (30), (31), (32), (33) and (34), we obtain:

$$
\begin{aligned}
& x_{T}= E_{T}\left(x_{T+1}\right)-\theta\left[i_{T}-E_{T}\left(\pi_{T+1}\right)-\overline{r_{T}}\right] \\
& \overline{r_{T}}=-\frac{1}{\theta}\left[y_{T}^{p}-E_{T}\left(y_{T+1}^{p}\right)\right]-\left\{1-\frac{\left[(1-\beta)+\delta \beta\left(1-\tau_{k, T}\right)\right]}{\left[(1-\beta)+\delta \beta(1-v)\left(1-\tau_{k, T}\right)\right]}\left(\frac{G_{T}}{Y_{T}}\right)\right\} \widehat{\tau_{c, T}} \\
&-\frac{\delta v \beta\left(1-\tau_{k, T}\right)}{\theta\left[(1-\beta)+\delta \beta(1-v)\left(1-\tau_{k, T}\right)\right]} \widehat{\tau_{k, T}}+\frac{\delta v \beta\left(1-\tau_{k, T+1}\right)}{\theta\left[(1-\beta)+\delta \beta(1-v)\left(1-\tau_{k, T+1}\right)\right]} E_{T}\left(\widehat{\tau_{k, T+1}}\right) \\
& \quad+\left\{1-\frac{\left[(1-\beta)+\delta \beta\left(1-\tau_{k, T+1}\right)\right]}{\left[(1-\beta)+\delta \beta(1-v)\left(1-\tau_{k, T+1}\right)\right]} E_{T}\left(\frac{G_{T+1}}{Y_{T+1}}\right)\right\} E_{T}\left(\widehat{\tau_{c, T+1}}\right)
\end{aligned}
$$

- $(\theta)$ : real interest rate elasticity of the output-gap, 'inter-temporal elasticity of substitution' of households' expenditure.

- $\overline{r_{T}}$ : Equilibrium or natural real interest rate, which corresponds to the steady-state real rate of return if prices and wages were fully flexible. It is the real interest rate required to keep aggregate demand equal at all times to the natural rate of output. It is a decreasing function of the temporary increase in potential output or in consumption or capital taxation rates.

So, according to equation (35), higher future expected output increases current output and consumption, because households prefer to smooth consumption, and then higher future revenues raise their current consumption and current output. Current output is also a decreasing function of the excess of the real interest rate above its natural level, because of the inter-temporal substitution of consumption.

So, we obtain the following components of global demand:

$y_{T}=x_{T}+y_{T}^{p}$

Equation (33) implies: $\quad$ inv $v_{T}=y_{T}-\widehat{\tau_{k, T}}=x_{T}+y_{T}^{p}-\widehat{\tau_{k, T}}$

Equations (10), (13), (30), (31), (32) and (33) imply:

$$
\begin{aligned}
& c_{T}=g_{T}-\theta \widehat{\tau_{c, T}}=x_{T}+y_{T}^{p}-\frac{\theta\left[(1-\beta)+\delta \beta\left(1-\tau_{k, T}\right)\right]}{\left[(1-\beta)+\delta \beta(1-v)\left(1-\tau_{k, T}\right)\right]}\left(\frac{G_{T}}{Y_{T}}\right) \widehat{\tau_{c, T}} \\
& +\frac{\delta v \beta\left(1-\tau_{k, T}\right)}{\left[(1-\beta)+\delta \beta(1-v)\left(1-\tau_{k, T}\right)\right]} \widehat{\tau_{k, T}}
\end{aligned}
$$


$g_{\text {inv,T }}=x_{T}+y_{T}^{p}+\varepsilon_{T}^{g, i n v}$

if we note $\left(\varepsilon_{T}^{\text {g,inv }}\right)$ the shock on

public investment

$g_{c, T}=x_{T}+y_{T}^{p}+\frac{\delta v \beta\left(1-\tau_{k, T}\right)}{\left[(1-\beta)+\delta \beta(1-v)\left(1-\tau_{k, T}\right)\right]}\left(\frac{G_{T}}{G_{c, T}}\right) \widehat{\tau_{k, T}}$
$-\frac{G_{i n v, T}}{G_{c, T}} \varepsilon_{T}^{g, i n v}+\left\{1-\frac{\left[(1-\beta)+\delta \beta\left(1-\tau_{k, T}\right)\right]}{\left[(1-\beta)+\delta \beta(1-v)\left(1-\tau_{k, T}\right)\right]}\left(\frac{G_{T}}{Y_{T}}\right)\right\}\left(\frac{\theta G_{T}}{G_{c, T}}\right) \widehat{\tau_{c, T}}$

Besides, potential output is the one that would prevail in absence of both price and wage rigidities. So, using equations (26), (29), (37), (39), (40) and (41), the supply functions are as follows, in differential with their long run equilibrium values:

$\pi_{T}=\beta E_{t}\left(\pi_{T+1}\right)+\mu_{1} \mu_{2} x_{T}$

with: $\quad \mu_{2}=\frac{\left[(1+\varphi \theta)(1-v)-\theta(1+\varphi)\left(z_{1}+z_{2}\right)\right]}{\theta(1+v \varphi)}$

$\pi_{T}^{w}=\beta(1-\varepsilon) \mathrm{E}_{\mathrm{T}}\left(\pi_{T+1}^{w}\right)+\mu_{1}^{w} \mu_{2}^{w} x_{T}$

with: $\quad \mu_{2}^{w}=\left[\frac{\left(1-\mathrm{z}_{1}-\mathrm{z}_{2}\right)}{(1-v)}+\frac{1}{\theta(1+\varphi)}\right]$

Equalizing the values of $\left(y_{T}^{p 1}\right)$ in equation (42) and $\left(y_{T}^{p 2}\right)$ in equation (43), we obtain a value for $\left(\varepsilon_{T}^{g, i n v}\right)$, and then also: $\left(y_{T}^{p}=k_{T}+\widehat{\tau_{k, T}}\right)$.

\section{Monetary and Budgetary Policies}

The interest rate reacts to inflation and economic activity deviations according to a simple Taylor rule, but we also introduce a high degree of interest rate smoothing. So, the nominal interest rate is fixed by the central bank as follows:

$i_{T}=\lambda_{i, C B} i_{T-1}+\lambda_{\pi, C B}\left(\pi_{T}-\pi^{o p t}\right)+\lambda_{x, C B}\left(x_{T}-x^{o p t}\right)$

where $\left(\lambda_{i, C B}\right),\left(\lambda_{\pi, C B}\right)$ and $\left(\lambda_{x, C B}\right)$ are the respective weights given by the central bank to interest rate smoothing, stabilizing prices and the output-gap. Therefore, with equations (A7) and (A8) in Appendix A, we obtain:

$i_{T}=f\left(i_{T-1}, \pi^{o p t}, x^{\text {opt }}, \sum_{n=T+1}^{\infty} i_{n}, \sum_{n=T}^{\infty} \tau_{c, n}, \sum_{n=T}^{\infty} \tau_{k, n}\right)$

In the framework of our model, the optimal variation in public expenditure depends on a weighted average of variations in taxation rates, on the technological 
progress, and on the monetary policy (nominal interest rate) conducted by the central bank. Indeed, we suppose that the public indebtedness level remains sustainable, and therefore, that the public debt level doesn't avoid to conduct the optimal budgetary policy. So, according to equations (40), (41), to the value of $\left(\varepsilon_{T}^{\text {g,inv }}\right)$, to $\left(y_{T}^{p}=k_{T}+\widehat{\tau_{k, T}}\right)$ and to equations (A7) and (B2) in Appendixes A and $\mathrm{B}$, we obtain analytical optimal levels of public expenditure:

$$
\begin{aligned}
& g_{\text {inv }, T}=\frac{\theta z_{2} G_{T}}{\left(z_{1} G_{c, T}-z_{2} G_{i n v, T}\right)(1+\theta \varphi)} \widehat{\tau_{l, T}} \\
& \quad+f\left(a_{T},\left(w_{T-1}-p_{T-1}\right), \sum_{n=T}^{\infty} i_{n}, \sum_{n=T}^{\infty} \widehat{\tau_{c, n}}, \sum_{n=T}^{\infty} \widehat{\tau_{k, n}}\right) \\
& g_{c, T}=-\frac{\theta z_{1} G_{T}}{\left(z_{1} G_{c, T}-z_{2} G_{i n v, T}\right)(1+\theta \varphi)} \widehat{\tau_{l, T}} \\
& +f\left(a_{T},\left(w_{T-1}-p_{T-1}\right), \sum_{n=T}^{\infty} i_{n}, \sum_{n=T}^{\infty} \widehat{\tau_{c, n}}, \sum_{n=T}^{\infty} \widehat{\tau_{k, n}}\right)
\end{aligned}
$$

\section{Calibration}

We consider a standard calibration of the parameters of our model, in conformity with the economic literature. The preference for the present $(\beta)$ is usually calibrated at (0.99), and the depreciation rate of capital is usually supposed to be $(\delta=0.025)$. The share of capital in the production function is usually estimated around $(v=0.3)$.

The intertemporal elasticity of substitution $(\theta)$ has a weak value of $(0.5)$ in Leeper et al. (2011) or in Forni et al. (2009), whereas it is assumed to be (1) in Galí et al. (2007) or in papers where consumption appears in logarithm in the utility function (consistent with log preferences). In this paper, we will consider $(\theta=1)$. The calibration of the inverse of the Frisch elasticity of labor supply $(\varphi)$ is very heterogeneous in the economic literature, going from $(0.2)$ in Gali et al. (2007), until (2) in Coenen and Straub (2005) or in Drautzberg and Uhlig (2011). In this paper, we will consider $(\varphi=1)$. Inertia in prices remaining unchanged is around $(\alpha=0.75)$ in most papers, as well as wage stickiness $\left(\alpha_{\mathrm{w}}=0.75\right)$.

The productivity of consumption expenditure is estimated around $\left(\mathrm{z}_{2}=0.05\right)$ in Sims and Wolff (2013) or in Carvalho and Martins (2011), whereas the productivity of public capital investment (highly productive) is $\left(\mathrm{z}_{1}=0.16\right)$ in Finn (1998) or $\left(\mathrm{z}_{1}=0.2\right)$ in Carvalho and Martins (2011). In this paper, we will consider $\left(\mathrm{z}_{1}=0.2\right)$ and $\left(\mathrm{z}_{2}=0.05\right)$. Thomas (2008) calibrates the proportion of workers who lose their job with the following value: $(\varepsilon=0.035)$.

The share of private consumption in output is estimated between $\left(\frac{\mathrm{C}}{\mathrm{Y}}=0.6\right)$ in Smets and Wouters (2003) and $\left(\frac{\mathrm{C}}{\mathrm{Y}}=0.63\right)$ in Bhattarai and Trzeciakiewicz (2017). The share of private investment is estimated between $\left(\frac{\mathrm{INV}}{\mathrm{Y}}=0.15\right)$ in Bhattarai 
and Trzeciakiewicz (2017) and $\left(\frac{\mathrm{INV}}{\mathrm{Y}}=0.22\right)$ in Smets and Wouters (2003). The shares of public investment and consumption $\mathrm{t}$ are estimated between $\left(\frac{\mathrm{G}_{\mathrm{C}}}{\mathrm{Y}}=0.128\right)$ and $\left(\frac{\mathrm{G}_{\text {inv }}}{\mathrm{Y}}=0.032\right)$ in the United-States in Straub and Tchakarov (2007) and $\left(\frac{G_{C}}{Y}=0.153\right)$ and $\left(\frac{G_{\text {inv }}}{Y}=0.04\right)$ in Drautzberg and Uhlig (2011). In this paper, we will take: $\left(\frac{\mathrm{C}}{\mathrm{Y}}=0.64\right),\left(\frac{\mathrm{G}_{\mathrm{C}}}{\mathrm{Y}}=0.15\right),\left(\frac{\mathrm{G}_{\text {inv }}}{\mathrm{Y}}=0.03\right)$.

The steady-state capital income tax rate varies between $\left(\tau_{k}=0.19\right)$ in Forni et al. (2009) and $\left(\tau_{k}=0.43\right)$ in Finn (1998). The labor income tax rate varies between $\left(\tau_{l}=0.20\right)$ in Carvalho and Martins (2011) and $\left(\tau_{l}=0.2844\right)$ in Bhattarai and Trzeciakiewicz (2017). The consumption tax rate varies between $\left(\tau_{c}=0.05\right)$ in Drautzberg and Uhlig (2011) and $\left(\tau_{c}=0.20\right)$ in Bhattarai and Trzeciakiewicz (2017). In this paper, we will consider: $\left(\tau_{k}=0.4\right),\left(\tau_{l}=0.22\right)$, $\left(\tau_{c}=0.20\right)$.

Regarding monetary policy, according to the high degree of interest rate smoothing observed in the empirical behavior of central banks, the persistence of the interest rate varies between $\left(\lambda_{i, C B}=0.7\right)$ in Leeper et al. (2011) and $\left(\lambda_{i, C B}=0.92\right)$ in Drautzberg and Uhlig (2011). The sensibility of the interest rate to the inflation rate varies between $\left(\lambda_{\pi, C B}=0.13\right)$ in Drautzberg and Uhlig (2011) and $\left(\lambda_{\pi, C B}=0.45\right)$ in Leeper et al. (2011). The sensibility of the interest rate to the output-gap varies between $\left(\lambda_{x_{3} C B}=0.01\right)$ in Sims and Wolff (2013) and $\left(\lambda_{x, C B}=0.05\right)$ in Leeper et al. (2011). In this paper, we will consider: $\left(\lambda_{i, C B}=0.8\right),\left(\lambda_{\pi, C B}=0.3\right)$ and $\left(\lambda_{x, C B}=0.02\right)$.

\section{Variation of the Consumption Taxation Rate}

According to the economic literature (see section 2), a decrease in taxation rates could be growth enhancing, and it could improve economic activity. However, what is then the best fiscal instrument? First, the current section 4 studies the consequences of a decrease of the consumption taxation rate.

\section{Consequences on Economic Activity}

If the consumption taxation rate decreases by $(-1 \%)$, according to equations (48) and (49), the expansionary effect on economic activity would be very significant: global economic activity and private investment would increase by around $2.1 \%$ in the first period, whereas private consumption would increase by around $1.9 \%$. Indeed, as prices are reduced by the weaker consumption taxation rate, goods are less expansive, which strongly encourages private consumption and investment (see Figure 1). This economic growth could be sustained by the large increase in labor demand on the labor market (see results below). 
Furthermore, according to equations (48) and (49), in a framework of flexible wages and prices $\left(\alpha_{w} \rightarrow 0\right.$ and $\left.\alpha \rightarrow 0\right)$, global economic activity and private investment could increase until $3.7 \%$ in the first period, whereas private consumption would increase by $3.5 \%$. Indeed, inflationary tensions could then contribute to sustain more strongly economic growth. More precisely, equations (45) and (B5) to (B7) in Appendix B imply:

$$
\begin{gathered}
\frac{\partial y_{T}}{\partial \widehat{\tau_{c, T}}}=\frac{\partial i n v_{T}}{\partial \widehat{\tau_{c, T}}}=-\left\{1+\frac{\left[\theta(1+v \varphi) \mu_{2}+\theta(1+\varphi)+\theta(1+\varphi)(1-v)\left(\mu_{1}^{w} \mu_{2}^{w}-\mu_{1} \mu_{2}\right)\right]}{\left[(1-\delta)+\left(\mu_{1} \mu_{2} \lambda_{\pi, C B}+\lambda_{x, C B}\right) \theta\right](1-v)}\right\} \\
\frac{\theta}{(1+\theta \varphi)}\left\{1-\frac{\left[(1-\beta)+\delta \beta\left(1-\tau_{k, T}\right)\right]}{\left[(1-\beta)+\delta \beta(1-v)\left(1-\tau_{k, T}\right)\right]}\left(\frac{G_{T}}{Y_{T}}\right)\right\} \quad(48) \\
\frac{\partial c_{T}}{\partial \widehat{\tau_{c, T}}}=\frac{\partial y_{T}}{\partial \widehat{\tau_{c, T}}}-\theta \frac{\left[(1-\beta)+\delta \beta\left(1-\tau_{k, T}\right)\right]}{\left[(1-\beta)+\delta \beta(1-v)\left(1-\tau_{k, T}\right)\right]}\left(\frac{G_{T}}{Y_{T}}\right) \quad \text { (49) }
\end{gathered}
$$

Figure 1. Variations in Private and Public Investment and Consumption, after a 1\% Decrease of the Consumption Taxation Rate (Persistence: 0.6)

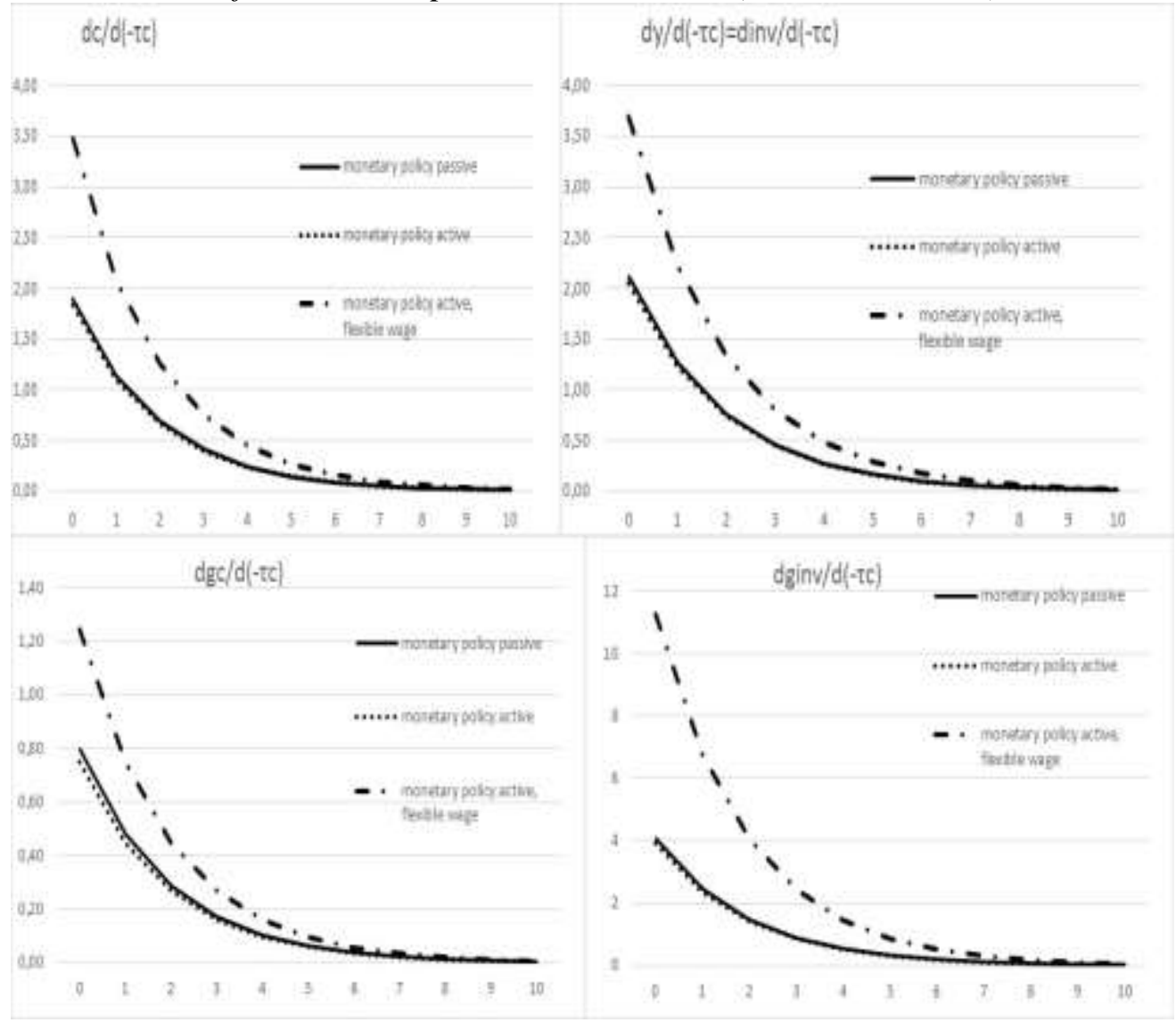


Besides, in the framework of wages rigidity, and according to equations (48) and (49), if the consumption taxation rate decreases, global economic activity, private investment and consumption are more improved if monetary policy is passive (see Figure 1). Indeed, a higher nominal interest rate (see below) would slightly reduce the expansionary consequences of the fiscal shock. More obviously, in a framework of wages flexibility, economic activity (private as well as public, investment as well as consumption expenditure) would decrease with the weight given by the central bank to the stabilization of inflation $\left(\lambda_{\pi, C B}\right)$. Indeed, a higher nominal interest rate would then be necessary in order to reduce the inflationary tensions and the higher potential economic growth. Regarding the robustness of our results to a variation in the calibration of the parameters, global economic activity, private investment and consumption decrease in particular with the share of the public sector in the economy.

Another consequence of a decrease in the consumption taxation rate is to modify the composition of public expenditure [Equations (45), (46) and (47) imply analytical values for $\frac{\partial g_{i n v, T}}{\partial \tau_{c, T}}$ and $\left.\frac{\partial g_{c, T}}{\partial \widehat{\tau_{c, T}}}\right]$. After a decrease of $(-1 \%)$ of the consumption taxation rate, global public expenditure would strongly increase, and mainly in a framework of wages flexibility. Indeed, public investment would increase by $4 \%$ in the first period (until $11.2 \%$ if wages were fully flexible), whereas public consumption expenditure would increase by $0.7 \%$ in the first period (until $1.2 \%$ if wages were fully flexible). Therefore, the decrease of the consumption taxation rate would mainly favor the most productive public investment expenditure.

\section{Variation in Interest Rate and in Prices}

A decrease of the consumption tax rate would increase economic activity, and would create inflationary tensions. However, in a context of wages rigidity, equation (50) shows that if the consumption tax rate decreases by $(-1 \%)$, prices would only increase by $(0.05 \%)$ in the first period, whereas wages would only increase by $(0.11 \%)$ according to equation (51). So, in this context, the variation in nominal wages is a little bit accentuated, but wages and prices rigidities strongly reduce inflationary tensions (see Figure 2).

On the contrary, in a context of wages flexibility, prices could increase by $(2.6 \%)$ and wages by (5.9\%) in the first period, as economic growth is then much higher (see results above). Indeed, according to equations (45), (A8) and (A9) in Appendix A, we obtain:

$$
\begin{aligned}
\frac{\partial \pi_{T}}{\partial \widehat{\tau_{c, T}}}=-\frac{\theta \mu_{1} \mu_{2}}{\left[(1-\delta)+\left(\mu_{1} \mu_{2} \lambda_{\pi, C B}+\lambda_{x, C B}\right) \theta\right]}\{1 & \\
& \left.-\frac{\left[(1-\beta)+\delta \beta\left(1-\tau_{k, T}\right)\right]}{\left[(1-\beta)+\delta \beta(1-v)\left(1-\tau_{k, T}\right)\right]}\left(\frac{G_{T}}{Y_{T}}\right)\right\}
\end{aligned}
$$


$\frac{\partial \pi_{T}^{w}}{\partial \widehat{\tau_{c, T}}}=\frac{\mu_{1}^{w} \mu_{2}^{w}}{\mu_{1} \mu_{2}} \frac{\partial \pi_{T}}{\partial \widehat{\tau_{c, T}}}$

$$
\frac{\partial i_{T}}{\partial \widehat{\tau_{c, T}}}=\frac{\left(\mu_{1} \mu_{2} \lambda_{\pi, C B}+\lambda_{x, C B}\right)}{\mu_{1} \mu_{2}} \frac{\partial \pi_{T}}{\partial \widetilde{\tau_{c, T}}}
$$

Besides, variations in the nominal interest rate are limited, because of the hypothesis of interest rate smoothing conducted by the central bank. So, according to equation (52), after a $1 \%$ decrease of the consumption taxation rate, the nominal interest rate would only slightly increase by $0.03 \%$ in a context of wages rigidity, whereas it would increase by $0.8 \%$ if wages and prices were fully flexible, in order to reduce the inflationary tensions.

Figure 2. Variations in Interest Rate, in Prices and Wages Inflation Rates after a $1 \%$ Decrease of the Consumption Taxation Rate (Persistence: 0.6)
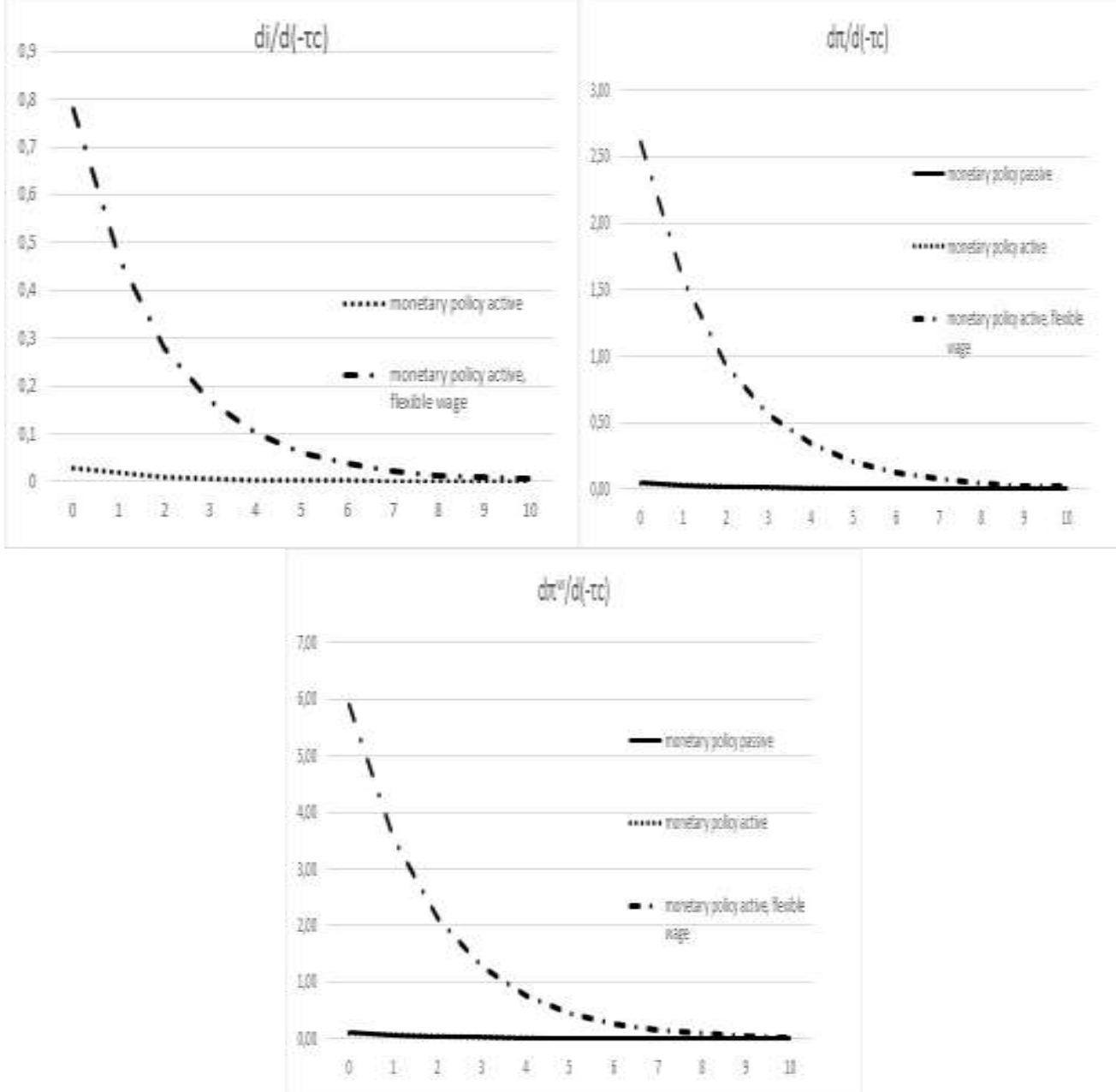

The Labor Market

The decrease of the consumption taxation rate increases the purchasing power of households as well as global demand; so, firms would increase their production levels, which necessitates a higher labor demand. As private demand strongly increases, the real wage, labor supply and demand would decrease with the share 
of public expenditure in the economy. Furthermore, according to equation (54), labor demand by firms would increase by around $(1.2 \%)$ in the first period in a framework of wages rigidity. This increase in labor demand would strongly be accentuated if the intertemporal elasticity of substitution of households' expenditure $(\theta)$ is high, increasing the level of global demand. Indeed, according to equations (45), (B1), (B3) and (B4) in Appendix B, we obtain:

$$
\begin{gathered}
\frac{\partial\left(w_{T}-p_{T}\right)}{\partial \widehat{\tau_{c, T}}}=\frac{-\theta\left(\mu_{1}^{w} \mu_{2}^{w}-\mu_{1} \mu_{2}\right)}{\left[(1-\delta)+\left(\mu_{1} \mu_{2} \lambda_{\pi, C B}+\lambda_{x, C B}\right) \theta\right]}\{1 \\
\left.-\frac{\left[(1-\beta)+\delta \beta\left(1-\tau_{k, T}\right)\right]}{\left[(1-\beta)+\delta \beta(1-v)\left(1-\tau_{k, T}\right)\right]}\left(\frac{G_{T}}{Y_{T}}\right)\right\}(53) \\
\frac{\partial l_{T}^{D}}{\partial \widehat{\tau_{c, T}}}=\frac{\partial y_{T}}{\partial \widehat{\tau_{c, T}}}+\frac{\theta\left(1+\mu_{1}^{w} \mu_{2}^{w}-\mu_{1} \mu_{2}\right)}{\left[(1-\delta)+\left(\mu_{1} \mu_{2} \lambda_{\pi, C B}+\lambda_{x, C B}\right) \theta\right]} \\
\left\{1-\frac{\left[(1-\beta)+\delta \beta\left(1-\tau_{k, T}\right)\right]}{\left[(1-\beta)+\delta \beta(1-v)\left(1-\tau_{k, T}\right)\right]}\left(\frac{G_{T}}{Y_{T}}\right)\right\} \quad(54) \\
\frac{\partial l_{T}^{S}}{\partial \widehat{\tau_{c, T}}}=\frac{\partial y_{T}}{\partial \widehat{\tau_{c, T}}}+\frac{\theta\left[1+\varphi+\varphi\left(\mu_{1}^{w} \mu_{2}^{w}-\mu_{1} \mu_{2}\right)(1-v)+(1+v \varphi) \mu_{2}\right]}{\varphi(1-v)\left[(1-\delta)+\left(\mu_{1} \mu_{2} \lambda_{\pi, C B}+\lambda_{x, C B}\right) \theta\right]} \\
\left\{1-\frac{\left[(1-\beta)+\delta \beta\left(1-\tau_{k, T}\right)\right]}{\left[(1-\beta)+\delta \beta(1-v)\left(1-\tau_{k, T}\right)\right]}\left(\frac{\left.\left.G_{T}\right)\right\} \widehat{\tau_{C, T}}}{Y_{T}}(55)\right.\right.
\end{gathered}
$$

According to equation (53), this higher labor demand would imply a moderate increase of the real wage, by about $(0.07 \%)$ in the first period (see Figure 3 ). Furthermore, the purchasing power of households would be improved by the decrease in prices; so, after a $(-1 \%)$ decrease of the consumption tax rate, labor supply could decrease by around (-1.2\%) [equation (55)].

On the contrary, if wages and prices were fully flexible, if the consumption taxation rate decreases by $(-1 \%)$, the real wage would strongly increase, by around $3.3 \%$ in the first period according to equation (53), in order to sustain labor supply and to meet the stronger economic activity (see Figure 3 ). Labor supply would then increase by around $0.4 \%$, because of the higher attractiveness of this compensation. Labor demand would then increase exactly in the same proportions, in conformity with the stronger global economic activity but also with the higher labor cost [see equation (54)].

So, a decrease of the consumption taxation rate would sustain all parameters of economic growth: private as well as public consumption and investment; besides, this economic growth would be all the more accentuated as wages are more flexible. Labor demand would increase on the labor market, in order to meet the higher global demand, which would create slight inflationary tensions and a small increase of the real wage. Nevertheless, prices and wages rigidities would then avoid the excessive increase of the real wage. They would avoid excessive inflationary tensions, which could necessitate a large increase of the nominal interest rate if wages were fully flexible. 
Figure 3. Labor Supply and Demand, and Real Wage after a 1\% Decrease of the Consumption Taxation Rate (Persistence: 0.6)

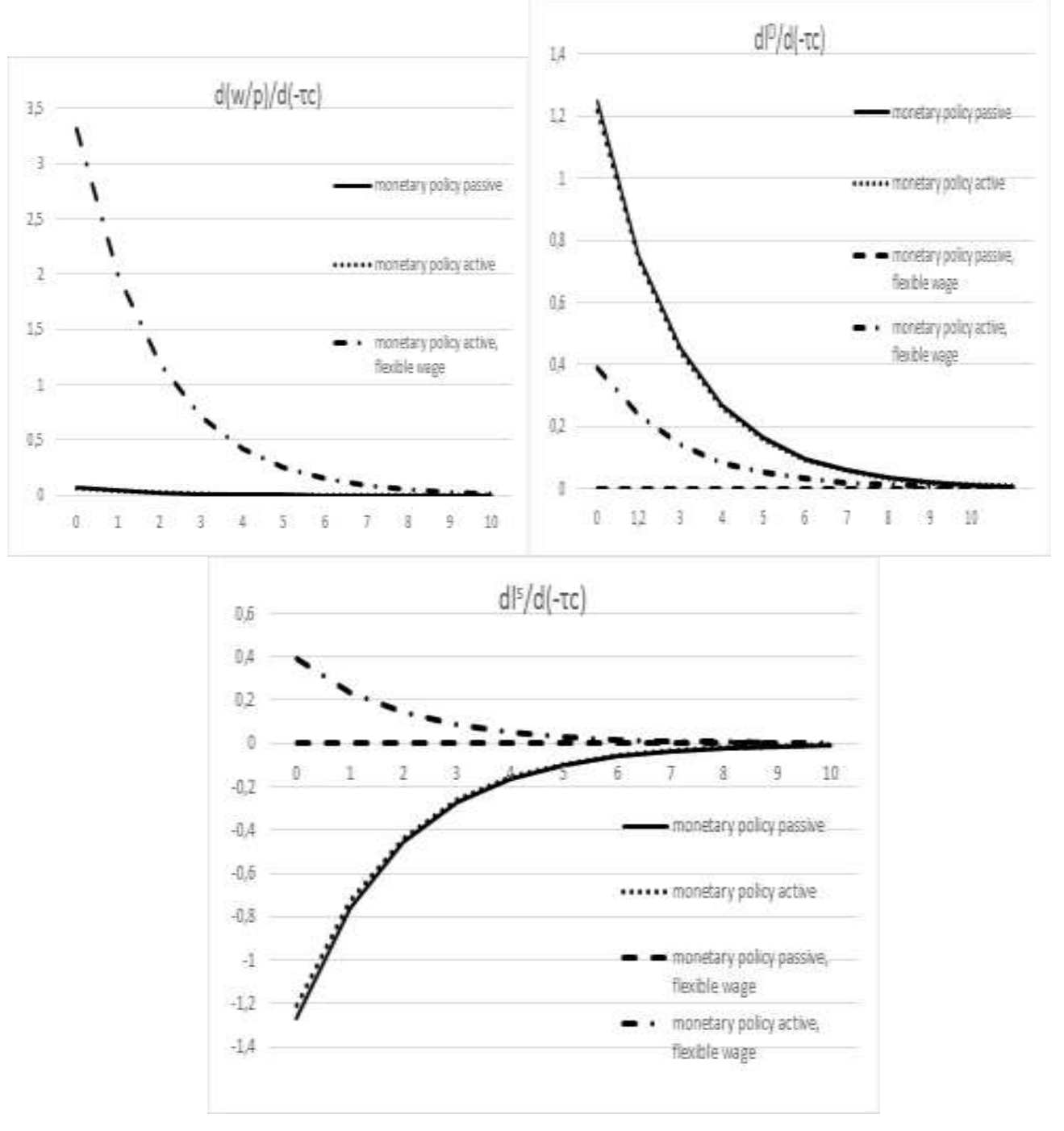

\section{Variation of the Capital Taxation Rate}

Consequences on Economic Activity

What could be the potential consequences of a decrease of the capital taxation rate? If the capital taxation rate decreases by $(-1 \%)$, according to equation (56), the expansionary effect on economic activity would be important: global economic activity would increase by around $2.7 \%$ in the first period. Indeed, the weaker capital cost would strongly foster private investment, which would increase by around $3.7 \%$ in the first period. Private consumption and global economic activity would also increase respectively by around $2.5 \%$ and $2.7 \%$. This economic growth could be sustained by the large increase in labor demand (see results below). 
Furthermore, according to equations (56) to (58), in a framework of flexible wages and prices, global economic activity could increase until $5.3 \%$ in the first period; private investment would then increase by $6.3 \%$, and private consumption by $5 \%$ (see Figure 4 ). Indeed, inflationary tensions could then contribute to sustain more strongly economic growth. More precisely, equations (45) and (B5) to (B7) in Appendix B imply:

$$
\begin{aligned}
& \frac{\partial y_{T}}{\partial \widehat{\tau_{k, T}}} \\
& =-\frac{\theta\left\{(1+v \varphi) \mu_{2}+(1+\varphi)\left[1+(1-v)\left(\mu_{1}^{w} \mu_{2}^{w}-\mu_{1} \mu_{2}\right)\right]\right\}\left[(1-\beta)+\delta \beta\left(1-\tau_{k, T}\right)\right]}{\left[(1-\beta)+\delta \beta(1-v)\left(1-\tau_{k, T}\right)\right]\left[(1-\delta)+\left(\mu_{1} \mu_{2} \lambda_{\pi, C B}+\lambda_{x, C B}\right) \theta\right](1-v)(1+\theta \varphi)} \\
& \quad-\frac{\delta \beta v\left(1-\tau_{k, T}\right)}{(1+\theta \varphi)\left[(1-\beta)+\delta \beta(1-v)\left(1-\tau_{k, T}\right)\right]} \quad(56) \\
& \\
& \quad \frac{\partial \tau_{T}}{\partial \widehat{\tau_{k, T}}}=\frac{\partial g_{T}}{\partial \widehat{\tau_{k, T}}}=\frac{\partial y_{T}}{\partial \tau_{k, T}}+\frac{\delta \beta\left(1-\tau_{k, T}\right)}{\left[(1-\beta)+\delta \beta(1-v)\left(1-\tau_{k, T}\right)\right]} \\
& \quad \frac{\partial i n v_{T}}{\partial \widehat{\tau_{k, T}}}=\frac{\partial y_{T}}{\partial \tau_{k, T}}-1
\end{aligned}
$$

Besides, in the framework of wages rigidity, according to equations (56) to (58), if the capital taxation rate decreases, global economic activity, private investment and consumption are more improved if monetary policy is passive. Indeed, a higher nominal interest rate (see results below) would slightly reduce the expansionary consequences of the fiscal shock. More obviously, in a framework of wages flexibility, all factors of global demand would decrease with the weight given by the central bank to the stabilization of inflation $\left(\lambda_{\pi, C B}\right)$. Indeed, a higher nominal interest rate would then be necessary in order to reduce the inflationary tensions and the higher potential economic growth. Regarding the robustness of our results to a variation in the calibration of the parameters, global economic activity, private investment and consumption increase in particular with the capital share in the production function $(v)$.

Another consequence of a decrease in the capital taxation rate is to modify the composition of public expenditure [Equations (45), (46) and (47) imply analytical values for $\frac{\partial g_{i n v, T}}{\partial \widetilde{\tau}_{k, T}}$ and $\frac{\partial g_{c, T}}{\partial \widehat{\tau}_{k, T}}$. So, after a $(-1 \%)$ decrease of the capital taxation rate, global public expenditure would strongly increase, and mainly in a framework of wages flexibility. Indeed, public investment would increase by $4 \%$ in the first period (until $15.2 \%$ if wages were fully flexible), whereas public consumption expenditure would increase by $3.4 \%$ in the first period (until $5.5 \%$ if wages were fully flexible). Therefore, the decrease of the capital taxation rate would mainly favor the most productive public investment expenditure. 
Figure 4. Variations in Private and Public Investment and Consumption, after a 1\% Decrease of the Capital Taxation Rate (Persistence: 0.6)

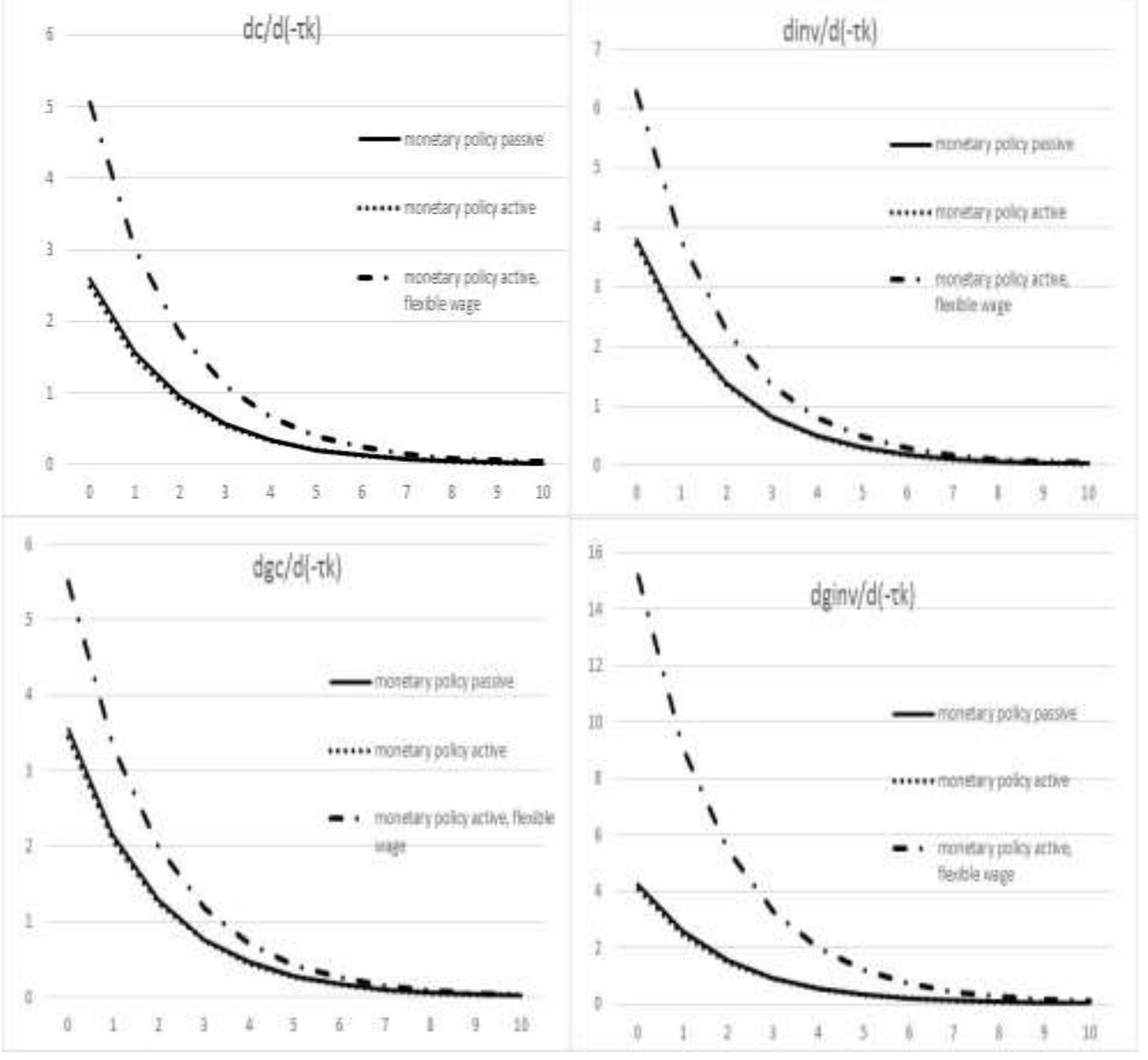

\section{Variation in Interest Rate and in Prices}

A decrease of the capital tax rate would increase economic activity, and would create inflationary tensions. However, in a context of wages rigidity, equation (59) shows that if the capital tax rate decreases by $(-1 \%)$, prices would only increase by $(0.07 \%)$ in the first period, whereas wages would only increase by $(0.18 \%)$ according to equation (60). So, in this context, the variation in nominal wages is a little bit accentuated, but wages and prices rigidities strongly reduce inflationary tensions (see Figure 5).

On the contrary, in a context of wages flexibility, prices could increase by $(4.1 \%)$ and wages by $(9.2 \%)$ in the first period, as economic growth is then much higher (see results above). Indeed, according to equations (45), (A8) and (A9) in Appendix A, we obtain:

$\frac{\partial \pi_{T}}{\partial \tau_{k, T}}=-\frac{\mu_{1} \mu_{2}\left[(1-\beta)+\delta \beta\left(1-\tau_{k, T}\right)\right]}{\left[(1-\delta)+\left(\mu_{1} \mu_{2} \lambda_{\pi, G B}+\lambda_{x, G B}\right) \theta\right]\left[(1-\beta)+\delta \beta(1-v)\left(1-\tau_{k, T}\right)\right]}$ 


$$
\frac{\partial \pi_{T}^{w}}{\partial \tau_{k, T}^{w}}=\frac{\mu_{1}^{w} \mu_{2}^{w}}{\mu_{1} \mu_{2}} \frac{\partial \pi_{T}}{\partial \tau_{k, T}} \quad \text { (60) } \quad \frac{\partial i_{T}}{\partial \tau_{k, T}}=\frac{\left(\mu_{1} \mu_{2} \lambda_{\pi_{C} C B}+\lambda_{x_{i} C B}\right)}{\mu_{1} \mu_{2}} \frac{\partial \pi_{T}}{\partial \tau_{k, T}}
$$

Besides, variations in the nominal interest rate are limited, because of the hypothesis of interest rate smoothing conducted by the central bank. So, according to equation (61), after a $1 \%$ decrease of the capital taxation rate, the nominal interest rate would only slightly increase by $0.05 \%$ in a context of wages rigidity, whereas it would increase by $1.2 \%$ if wages and prices were fully flexible, in order to reduce the inflationary tensions.

Figure 5. Variations in Interest Rate, In Prices and Wages Inflation Rates after a $1 \%$ Decrease of the Capital Taxation Rate (Persistence: 0.6)

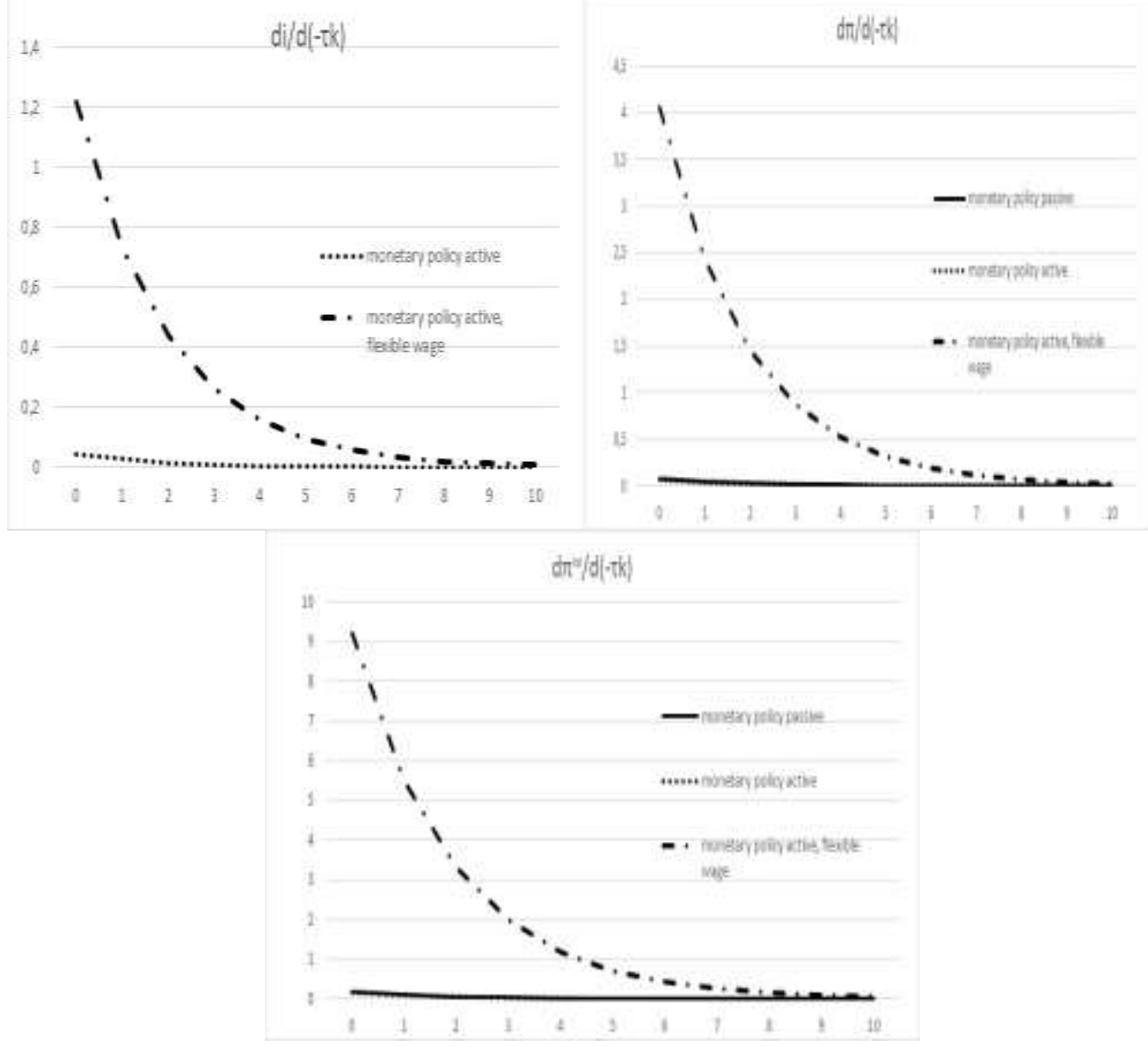

\section{The Labor Market}

The decrease of the capital taxation rate reduces the real capital cost proportionately. So, given the huge reduction in production costs, firms would increase their levels of private investment and production, which necessitates a higher labor demand. Therefore, according to equation (63), labor demand by firms would increase by around (1.4\%) in the first period in a framework of wages rigidity (see Figure 6). Indeed, according to equations (45), (B1), (B3) and (B4) in Appendix B, we obtain: 


$$
\begin{aligned}
& \frac{\partial\left(w_{T}-p_{T}\right)}{\partial \widehat{\tau_{k, T}}}=-\frac{\left(\mu_{1}^{w} \mu_{2}^{w}-\mu_{1} \mu_{2}\right)\left[(1-\beta)+\delta \beta\left(1-\tau_{k, T}\right)\right]}{\left[(1-\delta)+\left(\mu_{1} \mu_{2} \lambda_{\pi, C B}+\lambda_{x, C B}\right) \theta\right]\left[(1-\beta)+\delta \beta(1-v)\left(1-\tau_{k, T}\right)\right]} \\
& \frac{\partial l_{T}^{D}}{\partial \widehat{\tau_{k, T}}}=\frac{\partial y_{T}}{\partial \widehat{\tau_{k, T}}}+\frac{\left(1+\mu_{1}^{w} \mu_{2}^{w}-\mu_{1} \mu_{2}\right)\left[(1-\beta)+\delta \beta\left(1-\tau_{k, T}\right)\right]}{\left[(1-\delta)+\left(\mu_{1} \mu_{2} \lambda_{\pi, C B}+\lambda_{x, C B}\right) \theta\right]\left[(1-\beta)+\delta \beta(1-v)\left(1-\tau_{k, T}\right)\right]} \\
& \frac{\partial l_{T}^{S}}{\partial \widehat{\tau_{k, T}}} \\
& =\frac{\partial y_{T}}{\partial \widehat{\tau_{k, T}}} \\
& +\frac{\left[(1-\beta)+\delta \beta\left(1-\tau_{k, T}\right)\right]\left[(1+v \varphi) \mu_{2}+(1+\varphi)+\varphi(1-v)\left(\mu_{1}^{w} \mu_{2}^{w}-\mu_{1} \mu_{2}\right)\right]}{\varphi\left[(1-\delta)+\left(\mu_{1} \mu_{2} \lambda_{\pi, C B}+\lambda_{x, C B}\right) \theta\right]\left[(1-\beta)+\delta \beta(1-v)\left(1-\tau_{k, T}\right)\right](1-v)}(64)
\end{aligned}
$$

According to equation (62), this higher labor demand would imply a moderate increase of the real wage, by about $(0.1 \%)$ in the first period. So, the purchasing power of households would be improved by the higher real wage, and after a ($1 \%$ ) decrease of the capital tax rate, labor supply could decrease by around ($0.9 \%$ ) in the first period, according to equation (64).

On the contrary, if wages and prices were fully flexible, if the capital taxation rate decreases by $(-1 \%)$, the real wage would strongly increase, by around $5.1 \%$ in the first period according to equation (62), in order to sustain labor supply and to meet the stronger economic activity. Labor supply would then increase by around $1.6 \%$ in the first period, in conformity with the higher attractiveness for households of this compensation. Nevertheless, among the production factors, the weaker capital cost and higher labor cost would be harmful to labor demand, despite the growing global economic activity. According to equation (63), labor demand would then very slightly increase by around $0.1 \%$ in the first period, and only if monetary policy is active.

So, a decrease of the capital taxation rate would mainly favor private and public investment expenditure, because of the reduction of the capital cost. It would also strongly increase private and public consumption; finally, it would be slightly more efficient than a decrease of the consumption taxation rate (see section 4) in order to sustain economic growth. Besides, this economic growth (private as well as public, investment as well as consumption expenditure) would be all the more accentuated as wages are more flexible. Furthermore, labor demand would increase on the labor market, in order to meet the higher global demand, which would create slight inflationary tensions and a small increase of the real wage. Nevertheless, wages rigidity would then avoid the excessive increase of the real wage and of labor supply, which could imply a large unemployment rate if wages were fully flexible. Wages and prices rigidities would also avoid excessive inflationary tensions, which would necessitate a strong increase of the nominal interest rate if wages were fully flexible. 
Figure 6. Real Capital Cost, Labor Supply and Demand, and Real Wage after a $1 \%$ Decrease of the Capital Taxation Rate (Persistence: 0.6)
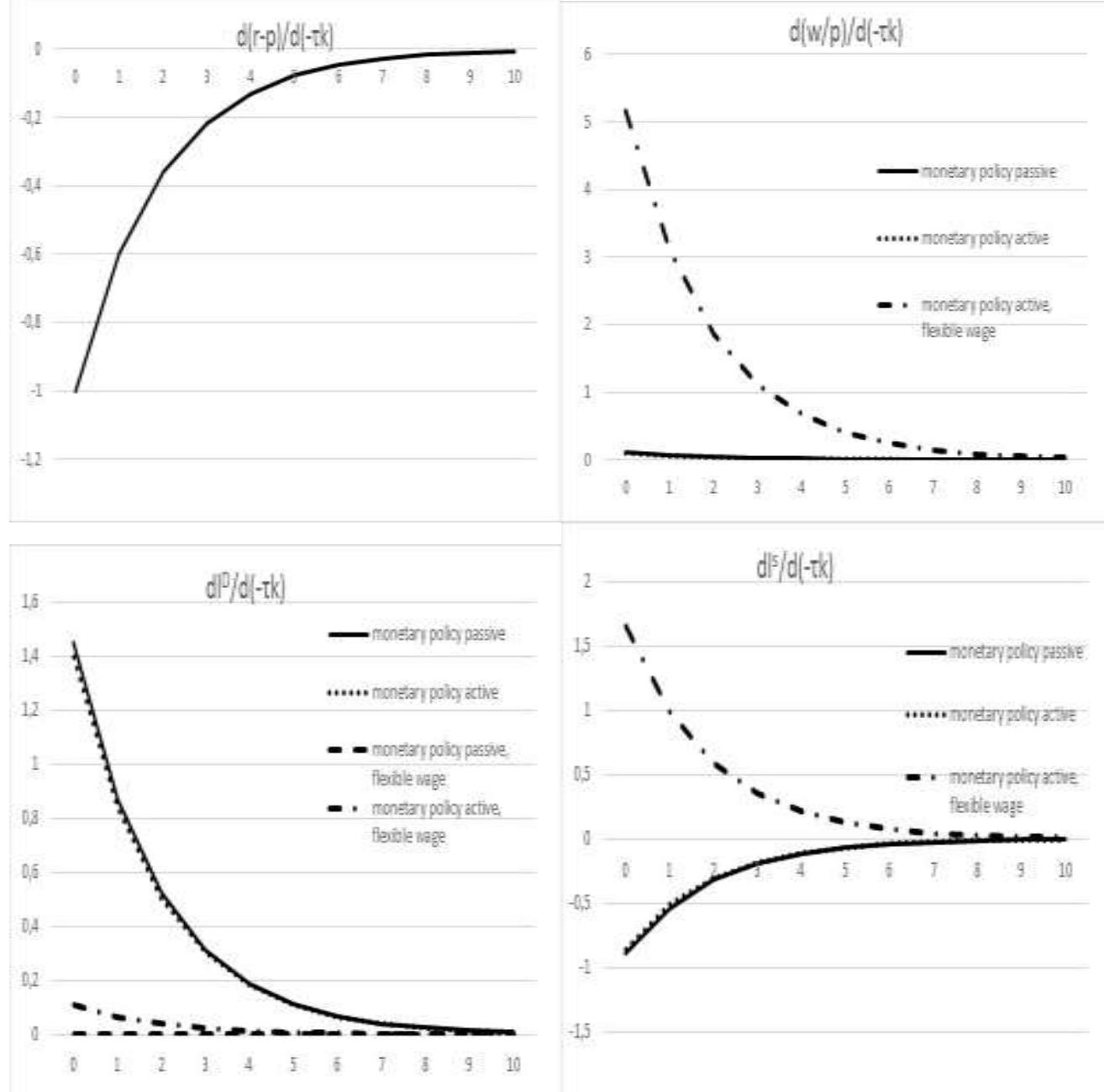

\section{Variation OF the Labor Taxation Rate}

The last fiscal policy to study is a variation of the labor taxation rate. According to equations (45), (A8) and (A9) in Appendix A, a variation of the labor taxation rate implies no variation of interest rates, wages or prices inflation rates. However, it has non negligible consequences on other economic variables, which are independent from wages flexibility on the labor market and from monetary policy activism.

\section{Consequences on Economic Activity}

If the labor taxation rate decreases by $(-1 \%)$, according to equation (65), the expansionary effect on economic activity would be moderate: all demand factors would increase by around $0.5 \%$ in the first period. Indeed, the higher purchasing power of households (less taxes) would increase private consumption and global 
demand (see Figure 7). This economic growth could be sustained by the large increase of labor demand on the labor market (see results below). More precisely, equations (45), (B5) to (B7) in Appendix B imply:

$\frac{\partial y_{T}}{\partial \widetilde{\tau}_{l, T}}=\frac{\partial i n v_{T}}{\partial \widehat{\tau_{l, T}}}=\frac{\partial c_{T}}{\partial \widetilde{\tau}_{l, T}}=\frac{\partial g_{T}}{\partial \widehat{\tau_{l, T}}}=-\frac{\theta}{(1+\theta \varphi)}$

Figure 7. Variations in Private and Public Investment and Consumption, after a $1 \%$ Decrease of the Labor Taxation Rate (Persistence: 0.6)
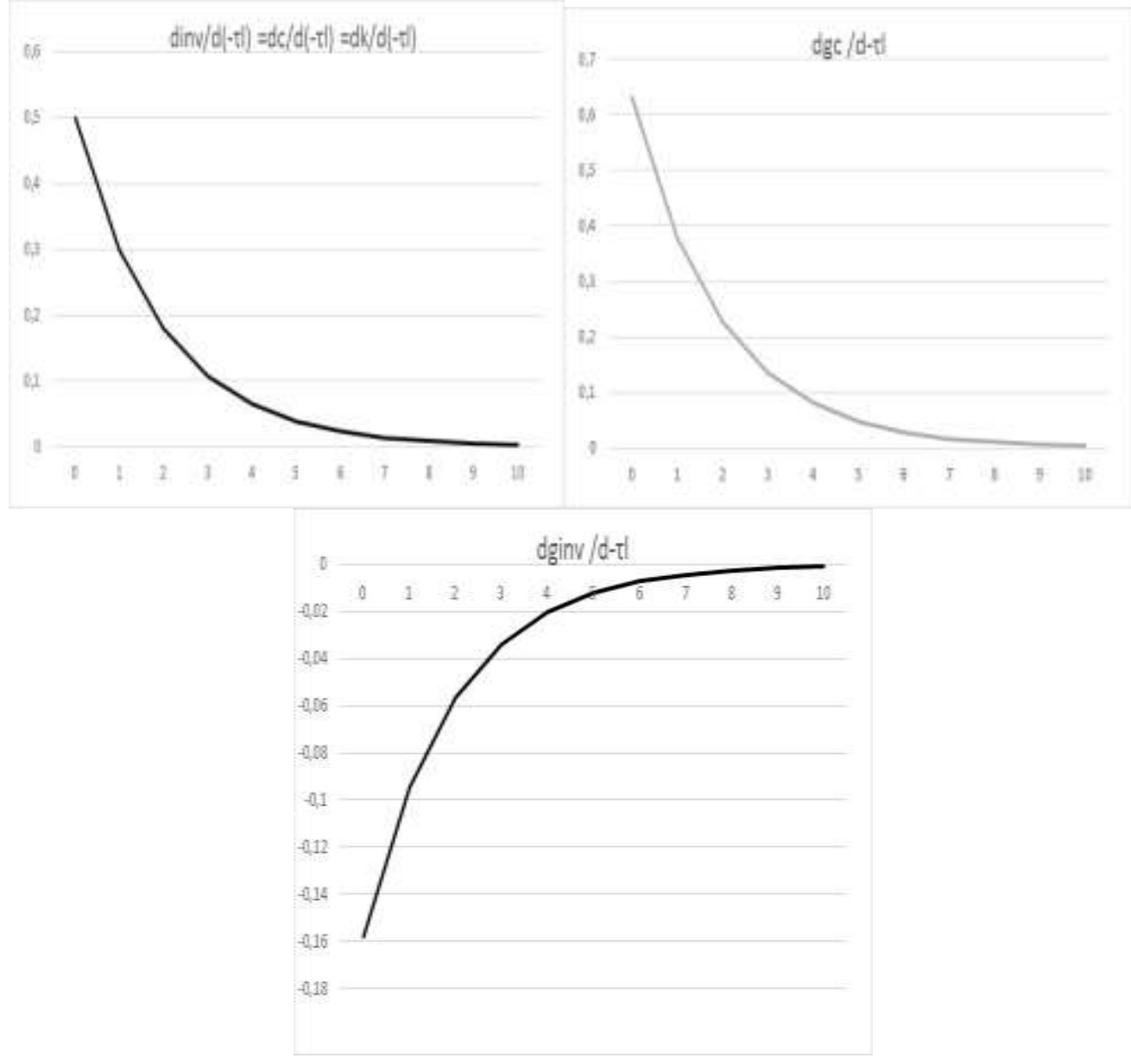

Regarding the robustness of our results to a variation in the calibration of the parameters, economic activity would increase with the inter-temporal elasticity of substitution of households' expenditure $(\theta)$, and with the elasticity of labor supply $(1 / \varphi)$.

A decrease of the labor taxation rate also modifies the composition of public expenditure. Indeed, equations (45), (46) and (47) imply: 


$$
\begin{array}{r}
\frac{\partial g_{i n v, T}}{\partial \widehat{\tau}_{l, T}}=\frac{\theta z_{2} G_{T}}{\left(z_{1} G_{c, T}-z_{2} G_{i n v, T}\right)(1+\theta \varphi)}(66) \quad \frac{\partial g_{c, T}}{\partial \widehat{\tau}_{l, T}} \\
=-\frac{\theta z_{1} G_{T}}{\left(z_{1} G_{c, T}-z_{2} G_{i n v, T}\right)(1+\theta \varphi)}(67)
\end{array}
$$

So, after a $(-1 \%)$ decrease of the labor taxation rate, global public expenditure would slightly increase, but public investment expenditure would decrease by $(-0.16 \%)$ whereas public consumption expenditure would increase by $0.63 \%$ in the first period. Therefore, the decrease of the labor taxation rate would mainly favor the less productive public consumption expenditure.

\section{The Labor Market}

The decrease of the labor taxation rate implies no variation in the real wage. So, it would increase labor supply, as labor would become relatively more attractive for households. Besides, as the purchasing power of households is increased, global demand also increases, which necessitates a higher production level and a higher labor demand by firms. This higher labor demand can be satisfied without increasing wages; indeed, with weaker labor taxation rates, workers reduce their wage claims. So, according to equation (68), if the labor taxation rate decreases by $(-1 \%)$, labor supply and demand would moderately increase by around $(0.5 \%)$ in the first period, in the same proportions as global economic activity (see results above). According to equations (45), (B3) and (B4) in Appendix B, we obtain:

$$
\frac{\partial l_{T}^{s}}{\partial \widehat{\tau_{l, T}}}=\frac{\partial l_{T}^{D}}{\partial \widehat{\tau}_{l, T}}=-\frac{\theta}{(1+\theta \varphi)}
$$

So, a decrease of the labor taxation rate would increase private investment and consumption and public expenditure in the same proportions. The similar increase in labor supply and demand would then always allow to reach the first best equilibrium on the labor market without wage inflation. However, it would be much less efficient than a decrease in the consumption or capital taxation rates in order to sustain economic growth. Besides, such a fiscal policy would favor the less productive public consumption expenditure to the detriment of public investment expenditure.

\section{Conclusion}

We have used a simple DSGE model with prices and wages rigidities in order to evaluate the efficiency of various fiscal policies in order to sustain economic activity and growth. Our modeling shows that a fiscal policy aiming at reducing the tax burden and taxation rates would be all the more efficient in sustaining economic growth as wages are more flexible. 
Besides, a decrease of the capital taxation rate appears as the most efficient fiscal policy. Indeed, it would decrease the capital cost, and it would foster private and public investment, but also private and public consumption. Wages rigidities would then reduce the inflationary tensions due to this economic growth, even if wages inflation would then be slightly higher than prices inflation. Furthermore, if wages were fully flexible, such rigidities would also be necessary in order to avoid an out-bidding of labor supply, real wages, and of the unemployment rate on the labor market. In comparison, a decrease of the consumption taxation rate is less efficient in sustaining economic growth. As goods are less expansive, it increases private consumption, and all other components of global demand; however, economic growth is then more limited than in the context of a decrease of the capital taxation rate. Nevertheless, we can mention that the decrease of the consumption taxation rate would avoid any disequilibrium on the labor market in a framework of a very high wage flexibility. Finally, a decrease of the labor taxation rate would increase private investment and consumption and public expenditure in the same proportions, and it would allow to reach the first best on the labor market without wage inflation. However, it would be much less efficient than a decrease of the consumption or capital taxation rates in order to sustain economic growth. Besides, regarding the composition of public expenditure, such a fiscal policy would favor public consumption expenditure, whereas the decrease of consumption or capital taxation rates would mainly promote the most productive public investment expenditure.

So, this paper gives interesting indications regarding the efficiency of reductions in various taxation rates in order to sustain economic activity. Nevertheless, future researches could include the following directions. We would like to study the consequences of the introduction of rule of thumb consumers who cannot optimize their consumption level but who simply consume their disposable income, as well as transfers from the government to these agents. We could also study more specifically the monetary-fiscal policy mix effect (which authority is active or passive, which coordination is put in place). Finally, we would like to study the consequences of the introduction of an open-economy framework, where households consume both domestically produced and foreign goods, allowing a differential between producer and consumer prices.

\section{References}

Alesina A, Ardagna S (2010) Large Changes in Fiscal Policy: Taxes versus Spending. in J R Brown (ed), Tax Policy and the Economy, 24: 35-68.

Ardagna S (2004) Fiscal Stabilizations: When do they Work and why? European Economic Review, 48(5): 1047-1074.

Baum A, Poplawski-Ribeiro M, Weber A (2012 December) Fiscal Multipliers and the State of the Economy. IMF Working Paper, WP/12/286.

Bhattarai K, Trzeciakiewicz D (2017 February) Macroeconomic Impacts of Fiscal Policy Shocks in the UK: A DSGE Analysis. Economic Modelling 61(C): 331-338.

Bianchi F, Ilut C (2017 October) Monetary/Fiscal Policy Mix and Agents' Beliefs. Review of Economic Dynamics 26: 113-139. 
Blanchard O, Perotti R (2002) An Empirical Characterization of the Dynamic Effects of Changes in Government Spending and Taxes on Output. The Quarterly Journal of Economics, 117(4): 1329-68.

Burnside C, Eichenbaum M, Fisher J (2004 March) Fiscal Shocks and their Consequences. Journal of Economic Theory 115(1): 89-117.

Carvalho VM, Martins MMF (2011) Macroeconomic Effects of Fiscal Consolidations in a DSGE Model for the Euro Area: Does Composition Matter? FEP Working Papers, $\mathrm{n}^{\circ}$ 421, Universidade do Porto, Facultade de Economia do Porto.

Christiano LJ, Eichenbaum M, Evans CL (2005 February) Nominal Rigidities and the Dynamic Effects of a Shock to Monetary Policy. Journal of Political Economy, 113(1): 1-45.

Coenen G, Straub R (2005) Does Government Spending Crowd in Private Consumption? Theory and Empirical Evidence for the Euro Area. International Finance 8(3): 435470.

Coenen G, Mohr M, Straub R (2008) Fiscal consolidation in the Euro Area: Long-run benefits and short-run costs. Economic Modelling, vol.25, n5: 912-932.

Davig T, Leeper EM (2011) Monetary-fiscal policy interactions and fiscal stimulus. European Economic Review 55(2), 211-227.

Drautzberg T, Uhlig H (2011) Fiscal Stimulus and Distortionary Taxation. The Milton Friedman Institute for Research in Economics, Discussion Paper 2011-005.

Edelberg W, Eichenbaum M, Fisher J (1999 January) Understanding the Effects of a Shock to Government Purchases. Review of Economics Dynamics 2(1): 166-206.

Fatas A, Mihov I (2001) The Effects of Fiscal Policy on Consumption and Employment: Theory and Evidence. CEPR Discussion Papers 2760.

Finn MG (1998 August) Cyclical Effects of Government's Employment and Goods Purchases. International Economic Review 39(3): 635-657.

Forni L, Monteforte L, Sessa L (2009) The General Equilibrium Effects of Fiscal Policy: Estimates for the Euro Area. Journal of Public Economics 93(3-4): 559-585.

Furlanetto F (2007) Fiscal Shocks and the Consumption Response when Wages are Sticky. Cahiers de Recherches Economiques du Département d'Econométrie et d'Economie Politique (DEEP) 07.11, Université de Lausanne, Faculté des HEC.

Galí J (2008) Monetary Policy, Inflation, and the Business Cycle: An Introduction to the New Keynesian Framework. Princeton: Princeton University Press.

Galí J, López-Salido JD, Vallés J (2007) Understanding the Effects of Government spending on Consumption. Journal of the European Economic Association 5(1): 227270.

Leeper EM, Traum N, Walker TB (2011 September) Clearing up the Fiscal Multiplier Morass. NBER Working paper 17444.

Ludvigson S (1996 August) The Macroeconomic Effects of Government Debt in a Stochastic Growth Model. Journal of Monetary Economics 38(1): 25-45.

Mertens K, Ravn MO (2011) Understanding the Aggregate Effects of Anticipated and Unanticipated Tax Policy Shocks. Review of Economic Dynamics 14(1): 27-54.

Pappa E (2004) New Keynesian or RBC Transmission? The Effects of Fiscal Policy in Labor Markets. Working Papers 293, IGIER (Innocenzo Gasparini Institute for Economic Research), Bocconi University.

Pappa E (2009 February) The Effects of Fiscal Shocks on Employment and the Real Wage. International Economic Review 50(1): 217-244.

Sims E, Wolff J (2013 December) The Output and Welfare Effects of Government Spending Shocks over the Business Cycle. NBER Working Papers 19749. 
Smets F, Wouters R (2003) An Estimated Stochastic Dynamic General Equilibrium Model of the Euro Area. Journal of the European Economic Association 1(5): 11231175.

Stähler N, Thomas C (2012) FiMod-A DSGE Model for Fiscal Policy Simulations. Economic Modelling 29(2): 239-261.

Straub R, Tchakarov I (2007). Assessing the Impact of Change in the Composition of Public Spending: A DSGE Approach. ECB Working Paper Series, n795, European Central Bank, August.

Thomas C (2008 July) Search and Matching Frictions and Optimal Monetary Policy. Journal of Monetary Economics 55(5): 936-956.

Zubairy S (2014 February) On Fiscal Multipliers: Estimates from a Medium Scale DSGE Model. International Economic Review 55(1): 169-195. 


\section{Appendix A: Optimal Output-Gap, Prices and Wages Inflation Rates}

Equations (5) and (38) imply: $k_{T+1}=k_{T}+\delta x_{T}$

Equations (35), (36), (A1) and ( $\left.y_{T}^{p}=k_{T}+\widehat{\tau_{k, T}}\right)$ imply:

$$
\begin{gathered}
x_{T}=\frac{1}{(1-\delta)} E_{T}\left(x_{T+1}\right)+\frac{\theta}{(1-\delta)} E_{T}\left(\pi_{T+1}\right)+\frac{1}{(1-\delta)} \lambda_{T} \quad(A 2) \\
\lambda_{T}=-\theta i_{T}-\theta\left\{1-\frac{\left[(1-\beta)+\delta \beta\left(1-\tau_{k, T}\right)\right]}{\left[(1-\beta)+\delta \beta(1-v)\left(1-\tau_{k, T}\right)\right]}\left(\frac{G_{T}}{Y_{T}}\right)\right\} \widehat{\tau_{c, T}} \\
+\theta\left\{1-\frac{\left[(1-\beta)+\delta \beta\left(1-\tau_{k, T+1}\right)\right]}{\left[(1-\beta)+\delta \beta(1-v)\left(1-\tau_{k, T+1}\right)\right]} E_{T}\left(\frac{G_{T+1}}{Y_{T+1}}\right)\right\} E_{T}\left(\widehat{\tau_{c, T+1}}\right) \\
-\frac{\left[(1-\beta)+\delta \beta\left(1-\tau_{k, T}\right)\right]}{\left[(1-\beta)+\delta \beta(1-v)\left(1-\tau_{k, T}\right)\right]} \widehat{\tau_{k, T}} \\
+\frac{\left[(1-\beta)+\delta \beta\left(1-\tau_{k, T+1}\right)\right]}{\left[(1-\beta)+\delta \beta(1-v)\left(1-\tau_{k, T+1}\right)\right]} E_{T}\left(\widehat{\tau_{k, T+1}}\right)
\end{gathered}
$$

Equations (42), (43) and (A2) imply:

$$
\begin{gathered}
\pi_{T}=\left[\beta+\frac{\theta \mu_{1} \mu_{2}}{(1-\delta)}\right] E_{T}\left(\pi_{T+1}\right)+\frac{\mu_{1} \mu_{2}}{(1-\delta)} E_{T}\left(x_{T+1}\right)+\frac{\mu_{1} \mu_{2}}{(1-\delta)} \lambda_{T} \\
\pi_{T}^{w}=\beta(1-\varepsilon) E_{T}\left(\pi_{T+1}^{w}\right)+\frac{\theta \mu_{1}^{w} \mu_{2}^{w}}{(1-\delta)} E_{T}\left(\pi_{T+1}\right)+\frac{\mu_{1}^{w} \mu_{2}^{w}}{(1-\delta)} E_{T}\left(x_{T+1}\right) \\
\quad+\frac{\mu_{1}^{w} \mu_{2}^{w}}{(1-\delta)} \lambda_{T}(A 4)
\end{gathered}
$$

So, this implies to solve the following system:

$$
\left(\begin{array}{c}
x_{T} \\
\pi_{T} \\
\pi_{T}^{w}
\end{array}\right)=A\left(\begin{array}{c}
E_{T}\left(x_{T+1}\right) \\
E_{T}\left(\pi_{T+1}\right) \\
E_{\mathrm{T}}\left(\pi_{T+1}^{w}\right)
\end{array}\right)+\frac{1}{(1-\delta)}\left(\begin{array}{c}
\lambda_{T} \\
\mu_{1} \mu_{2} \lambda_{T} \\
\mu_{1}^{w} \mu_{2}^{w} \lambda_{T}
\end{array}\right)
$$

With: $\lim _{n \rightarrow \infty} x_{n}=\lim _{n \rightarrow \infty} \pi_{n}=\lim _{n \rightarrow \infty} \pi_{n}^{w}=0$, this implies:

$$
\left(\begin{array}{c}
x_{T} \\
\pi_{T} \\
\pi_{T}^{w}
\end{array}\right)=\frac{1}{(1-\delta)} \sum_{n=T}^{\infty} A^{n-T}\left(\begin{array}{c}
1 \\
\mu_{1} \mu_{2} \\
\mu_{1}^{w} \mu_{2}^{w}
\end{array}\right) \lambda_{n}
$$




$$
\begin{aligned}
A^{n}=\frac{1}{(1-\delta)^{n}} & \left(\begin{array}{ccc}
1 & \theta & 0 \\
\mu_{1} \mu_{2} & \left(\beta-\beta \delta+\theta \mu_{1} \mu_{2}\right) & 0 \\
\mu_{1}^{w} \mu_{2}^{w} & \theta \mu_{1}^{w} \mu_{2}^{w} & \beta(1-\varepsilon)(1-\delta)
\end{array}\right)^{n} \\
& =\left(\begin{array}{lll}
a_{n} & b_{n} & c_{n} \\
d_{n} & e_{n} & f_{n} \\
g_{n} & h_{n} & j_{n}
\end{array}\right)(A 6)
\end{aligned}
$$

We can notice that: $\quad(\forall n) c_{n}=f_{n}=0 \quad j_{n}=\beta^{n}(1-\varepsilon)^{n}$

Besides, using also equation (A2), we obtain the following economic variables:

$$
\begin{aligned}
& x_{T}=-\frac{\theta}{(1-\delta)} i_{T} \\
& -\frac{\theta}{(1-\delta)}\left\{1-\frac{\left[(1-\beta)+\delta \beta\left(1-\tau_{k, T}\right)\right]}{\left[(1-\beta)+\delta \beta(1-v)\left(1-\tau_{k, T}\right)\right]}\left(\frac{G_{T}}{Y_{T}}\right)\right\} \widehat{\tau_{c, T}} \\
& -\frac{\left[(1-\beta)+\delta \beta\left(1-\tau_{k, T}\right)\right]}{(1-\delta)\left[(1-\beta)+\delta \beta(1-v)\left(1-\tau_{k, T}\right)\right]} \widehat{\tau_{k, T}} \\
& +f\left(\sum_{n=T+1}^{\infty} i_{n}, \sum_{n=T+1}^{\infty} \widehat{\epsilon_{c, n}}, \sum_{n=T+1}^{\infty} \widehat{t_{k, n}}\right)(A 7) \\
& \pi_{T}=\mu_{1} \mu_{2} x_{T} \quad \text { (A8) } \\
& \pi_{T}^{w}=\mu_{1}^{w} \mu_{2}^{w} x_{T} \text { (A9) }
\end{aligned}
$$

\section{Appendix B: Expression of All Other Economic Variables}

According to equations (A8) and (A9), the variation in the real wage is as follows:

$$
\left(w_{T}-p_{T}\right)=f\left(\left(w_{T-1}-p_{T-1}\right), \sum_{n=T}^{\infty} i_{n}, \sum_{n=T}^{\infty} \widehat{\tau_{c, n}}, \sum_{n=T}^{\infty} \widehat{\tau_{k, n}}\right)
$$

Equations (15), (17), (37), (46), (47), the values of $\left(\varepsilon_{T}^{\text {g,inv }}\right)$ and $\left(y_{T}^{p}=k_{T}+\widehat{t_{k, T}}\right.$ ), equations (A7), (A8) and (A9) imply:

$$
\begin{aligned}
& k_{T}=-\frac{\theta}{(1+\theta \varphi)} \widehat{\tau_{l, T}}+f(.) \\
& l_{T}^{D}=-\frac{\theta}{(1+\theta \varphi)} \widehat{\tau_{l, T}}+f(.)
\end{aligned}
$$


Using equations (12), (39), (B1), $\left(y_{T}^{p}=k_{T}+\widehat{\tau_{k, T}}\right),(\mathrm{A} 7),(\mathrm{A} 8),(\mathrm{A} 9)$ and (B2), labor supply is:

$$
l_{T}^{S}=-\frac{\theta}{(1+\theta \varphi)} \widehat{\tau_{l, T}}+f(.)(B 4)
$$

Equations (37), (38), (39), (B2), ( $y_{T}^{p}=k_{T}+\widehat{\tau_{k, T}}$ ), (A7), (A8) and (A9) imply:

$$
\begin{aligned}
& y_{T}=-\frac{\theta}{(1+\theta \varphi)} \widehat{\tau_{l, T}}+f(.) \\
& \operatorname{inv}_{T}=-\frac{\theta}{(1+\theta \varphi)} \widehat{\tau_{l, T}}+f(.) \\
& c_{T}=-\frac{\theta}{(1+\theta \varphi)} \widehat{\tau_{l, T}}+f(.)
\end{aligned}
$$

Detailed analytical values of all variables are available upon request from the author. 


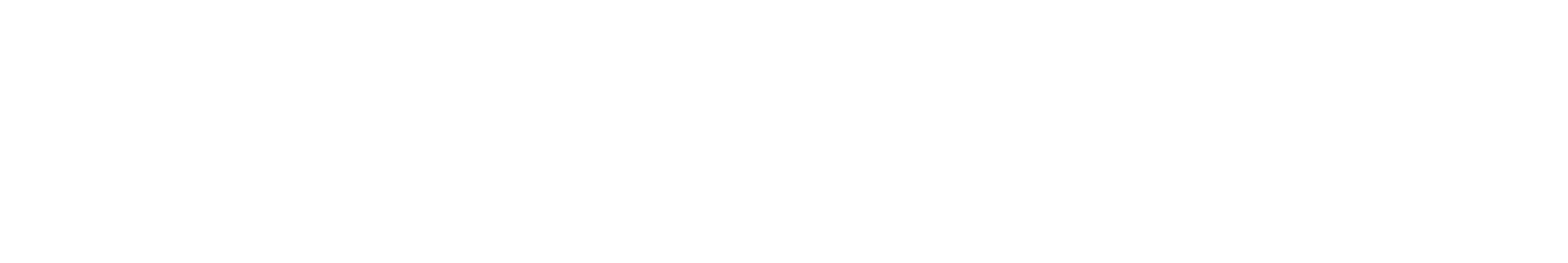




\title{
Optimal Pricing of Deposit Insurance: Aiming at Fairness and Stability
}

\author{
By Jean Roy*
}

Deposit insurance has two main objectives: at the micro-level, it should protect small depositors against the failure of their bank and at the macro-level, it should contribute to the stability of the financial system and of the economy as a whole. To have the appropriate resources to achieve their mission, deposit insurers collect premiums from insured banks to build a so-called ex-ante fund. Setting an optimal pricing scheme is a challenge. On one hand, it should be fair, that is correctly adjusting for the risk of each bank and on the other hand it should be consistent with the stability objective, which implies avoiding pro-cyclicality. Up to now, two main pricing schemes have been used: fixed rate pricing and risk adjusted rate pricing. Our analysis shows that none achieves both goals satisfactorily. Fixed rate pricing is not pro-cyclical but it is somewhat unfair as it does not adjust for risk. Risk adjusted rates are fair but are pro-cyclical. This paper proposes a new approach based on relative risk that reconciles both objectives. Relative risk is defined as the difference between the risk measure of a bank and the weighted risk measure of the banking sector. A numerical example illustrates the working of the new approach and shows that it adjusts for risk and avoids pro-cyclicality while allowing the deposit insurer to accumulate the same revenues over the cycle. Finally, the materiality of the problem of pro-cyclicality and the performance in terms of effectiveness and efficiency of the proposed model are discussed.

Keywords: Banks, Deposit Insurance, Financial Institutions, Pro-cyclicality, Regulation.

\section{Introduction}

Deposit insurance is generally put in place with two main objectives. At the micro-level, it should protect small depositors against the failure of their bank and at the macro-level, it should contribute to the stability of the banking system and more broadly to the stability of the economy as a whole. To fulfill this mission, deposit insurers need to have access to financial resources in case of bank failures. It is generally viewed as a good practice that part of the potential financial resources be in the form of ex-ante funding, which leads naturally to a premium being charged to the insured banks to build such a fund. Setting up an optimal pricing scheme raises several challenges. How to design a fair pricing system, where fairness may be considered from various viewpoints, i.e. between insured banks, between insured banks and non-insured financial institutions, and fairness with regards to depositors? How to design a pricing system which would be consistent with the objective of financial stability? Although this paper will not try to address all the challenges involved in designing an optimal pricing system, it will focus on two important issues:

"Professor, HEC-Montreal, Canada. 
achieving fairness among insured banks and contributing to the stability of the banking sector.

Thus, the objective of this paper is to examine the concept of optimal pricing of deposit insurance assuming that the deposit insurer aims both at being fair across insured banks and at contributing to the stability of the banking sector and the economy. Fairness across insured banks will be understood as using a pricing system which adjusts adequately the premium rate to the risk of the bank. Contributing to the stability of the banking sector will imply that at least the pricing system will not behave through time in such a way as to amplify the business cycle, i.e. it will not be pro-cyclical.

The paper will proceed as follows. Part one will present various pricing schemes, both historical and potential and discuss the properties of these in terms of fairness and stability. It will argue that none of the systems used to date are good at achieving both goals. Part two will propose a new approach to pricing deposit insurance that should better reconcile fairness and stability. The new approach will be illustrated with a clear numerical example. Part three will discuss a few issues relative to the approach proposed. The conclusion will summarize the paper and identify the likely steps to move towards the adoption of the approach.

\section{An Analysis of Pricing Schemes for Deposit Insurance}

This section will analyse various pricing schemes, namely fixed rate schemes and variable or risk-adjusted rates schemes, with the purpose of characterizing their likely performance in terms of fairness and stability.

\section{Fixed Rate Schemes}

Typically, when a deposit insurance system is set up it begins by using a fixed rate approach whereby all banks are charged the same rate. This simple approach has the great advantage of being very easy to implement. It could be argued that it has at least some appearance of fairness as all insured banks are treated alike. It could also be justified using the assumption that regulators maintain all banks in a narrow interval of riskiness such that differences in riskiness are negligible, at least at a first level of approximation. This approach has been generally in use until the nineteen eighties. At that time, critics began arguing that this approach was not fair as banks presented significantly different levels of risk, such that the safe banks were charged too much and the risky banks too little. The safe banks were in effect subsidizing the risky banks creating as a matter of fact a moral hazard. Banks had an incentive to take on more risk, increasing revenues without increasing the cost of deposits, as deposits were kept safe at a constant cost. The argument appeared convincing and many deposit insurers embarked on the journey of setting up pricing schemes which would adjust the premium rate to the risk of the insured bank. 


\section{Risk Adjusted Rate Schemes}

Obviously, the great challenge with the risk adjusted rate approach is the design of an adequate instrument to measure risk. This is no small task given the great complexity of current large banking organizations dealing worldwide in a great number of financial contracts on and off-balance sheet. Although current risk management methodology has identified the core banking risks such as credit risk, market risk and interest rate risk and developed measures of these risks, there remain many other risks that are still difficult to address such as liquidity and funding risk and business risk. Thus given the current state of the art, one needs to remain prudent relative to the performance of any risk measurement methodology trying to assess the overall riskiness of a bank.

For the purpose of our discussion, we will contrast two cases. In the first case, we will assume that the deposit insurer would have a «perfect» risk measurement instrument. More specifically, the risk measure would be unbiased and precise, i.e. it would have the power to distinguish small differences in risk. To illustrate, we assume that the deposit insurer would measure risk with a score of one to one hundred and that each point validly differentiates risk. In the second case, we will assume that the deposit insurer has an unbiased measure of risk but that it can distinguish between only a few risk categories. So, we will call this approach categorical. We will analyse the likely properties of these two approaches, assuming that the deposit insurer measures risk on a yearly basis and also adjusts the rate of the insured bank yearly based on the current risk measurement. How would these two systems likely behave in terms of fairness and stability?

\section{The Case of Precise Risk Measurement}

It can reasonably be argued that the precise risk measurement system would perform highly in term of fairness as any small difference in risk could be reflected in the premium. The problem with this approach is that it would likely perform poorly in terms of stability. Indeed, as the cycle moves to a difficult period the borrowers of the banks would experience problems and become more vulnerable leading their lender to be itself more vulnerable and riskier. The precise risk measurement scheme would catch the increase in risk and the deposit insurer would logically increase the premium rate. Clearly, charging a higher premium when the bank is vulnerable will only increase its vulnerability. Alternatively, the bank may try to maintain its solvency by restricting credit to its riskier borrowers. In both cases, the risk adjusted premium rate will contribute to exacerbate the business cycle and will not achieve its goal of contributing to stability; in short, it would be pro-cyclical. We conclude that the precise risk measurement scheme would be quite good relative to fairness but would be bad with respect to stability.

In retrospect, we can make exactly the opposite conclusion with regard to the fixed rate scheme. It seems to perform badly in terms of fairness as it does not adjust for risk. On the other hand, as the rate would remain constant throughout the business cycle, at least it would not contribute to amplify it and in this sense would 
be better in terms of stability. Clearly, the two objectives of fairness and stability seem to conflict and pose a challenge to any system trying to pursue both.

\section{The Case of Categorical Risk Measurement}

In this light, we can try to characterize the categorical approach to risk measurement and pricing, by which insured banks are classified into a small number of risk classes. We will argue that this approach represents some kind of trade-off between the two objectives. With regard to fairness, we will claim that this approach is fair to banks between categories as banks in a riskier category would be charged a higher premium, but it could be said to be unfair to banks within a risk category as all banks within the category would most likely not have exactly the same level of risk and the system would charge them as if they had, which is somewhat unfair. Thus, we conclude that fairness would be achieved only partially. With respect to stability, we can assume that a deterioration of economic conditions will increase the riskiness of banks. For some banks, the deterioration will be such that they will remain in the same risk category while others will migrate to a riskier category, such that some banks will be able to maintain the same rate while others will experience a higher rate. Stability would be achieved for banks within a risk category but would not be achieved for banks moving from a category to another. Thus, we conclude that a categorical risk measurement system achieves each goal of fairness and stability only partially.

In our opinion, none of the three pricing schemes analysed up to now are satisfactory in terms of their potential to achieve simultaneously fairness and stability. As risk adjusted pricing is now widely used, several authors have acknowledged the issue of pro-cyclicality and some have tried to address it. The next section will present a review of this literature.

\section{Review of the Literature on Pro-Cyclicality}

The analysis of pro-cyclicality induced by regulation has been focused on capital regulation. Borio et al. (2001), Goodhart (2010), Gordy and Howells (2006) and Repullo et al. (2010) have all studied the pro-cyclical effects of the Basel II accord and proposed some remedies. The pro-cyclical effect of riskadjusted deposit insurance premia has received much less attention. However, the similarity between the two regulatory interventions is obvious. In both cases, risk is measured on a yearly basis and a proportional cost is imposed on the regulated bank, be it in the form of a capital cost or an insurance premium. We review below the very few proposals made to address the pro-cyclicality of risk adjusted deposit insurance premia.

The FDIC paper by Pennacchi (2004) provides a broad analysis of procyclicality as caused by risk-based capital standards and deposit insurance. His analysis is interesting because it takes into account the interaction between the two types of regulation. The main recommendation of the paper with regard to deposit insurance is to lengthen the contracts over which the premium rate of a bank would be constant. In so doing, changes in rates would be smoothed over time. It 
is obviously an interesting proposal but would reduce the reactivity of the deposit insurer to changes in the risk position of an insured bank.

The IMF paper by Andritzky et al. (2009) also examines the issue of procyclicality very broadly and makes several recommendations both to the private and the public sector. A mere two pages are devoted to deposit insurance. The two policy recommendations for deposit insurance are to «establish an ex-ante deposit insurance fund that has mandatory membership» and «deposit insurance funds should have a target range (instead of point target) for the optimal level of their reserves» (p. 18). Although these two recommendations would help reduce procyclicality, they do not guarantee however that the pro-cyclicality of deposit insurance rates would be completely avoided.

The FDIC paper by Jarrow et al. (2008) is the most focused and the most elaborate of the three papers. We believe interesting to cite the complete abstract:

«The paper proposes a counter cyclical and risk based aggregate deposit insurance premium design where the system attains a given survival probability over a fixed horizon. The fixed horizon is determined by economic and political considerations. Such a premium system necessarily exceeds actuarial fair value and results in the insurance fund growing over time. To mitigate this growth, the proposed system includes a swap contract that reduces the premia when the fund size exceeds a threshold. The system is made countercyclical by including another swap contract that exchanges premia in good times for relief in bad times. The costs for obtaining such a countercyclical deposit insurance premium system are documented. » (p.1)

Clearly, this proposal is theoretically interesting; however its high level of complexity represents a significant hurdle with regard to its implementation. Although each of these proposals provides some potential for reducing the procyclicality problem, none claims to eliminate it entirely and thus the challenge to engineer a better solution remains. The next section will present a novel approach based on the concept of relative risk.

\section{A Relative Risk Scoring Scheme}

This section will first present the concept of relative scoring in general terms and will then provide a numerical example to show its workings and illustrate its behaviour.

\section{The Concept of Relative Risk Scoring}

The scheme we are proposing is based on the view that to achieve fairness and stability, insured banks should be charged for the risk that is under their control. According to this view, the total or absolute risk of a bank depends both on macroeconomic conditions on which it has no control and on specific decisions taken by the bank which eventually position it as more or less risky as its 
competitors; this we will call relative risk. Following this line of reasoning, banks should be charged their deposit insurance premium based on their relative risk and not on their total risk, which depends on economic conditions not under their control.

To operationalize a model, we will assume that the deposit insurer has a precise measurement method. Specifically, let us make the hypothesis that the deposit insurer scores the insured banks using a score between 0 and 100, with 100 corresponding to the least risky situation possible. Under an absolute risk scoring scheme, we will assume that the premium would be a decreasing linear function of the score.

Under the relative risk scoring scheme we suggest, the deposit insurer would each year compute the weighted risk score for the entire banking sector. Thus, the score of each bank would be weighted by its share of insured deposits, i.e. its insured deposits divided by the total of all insured deposits in the banking sector. These weighted scores would be totalled to get the average score of the sector. The relative score of a bank would be the difference between its score and the average score of the sector. It is expected that economic conditions will impact the average score of the sector, but because the average score is subtracted from the absolute score of a bank to get its relative score the effect of macroeconomic conditions would thus be taken out of the risk measurement of the bank. The relative score would measure how much a bank is more or less risky than the average of the sector at one point in time. Finally, the premium rate of a bank would be based on its relative score.

What would be the likely properties of such an approach? We believe it would be fair because banks with a higher relative risk would be charged a higher premium rate. Cross-sectional fairness would be achieved. As for stability, as long as a bank would maintain its relative risk along the business cycle its premium rate would remain constant even though the average score of the sector could suffer fluctuations. Thus, stability would be enhanced. To further the understanding of the working and properties of such an approach, the next section presents and discusses a numerical example.

\section{A Numerical Example of Relative Risk Scoring}

In this section, we will construct a numerical example to show the behaviour of conventional risk scoring, which we will call absolute risk scoring, and the approach we call relative risk scoring. The purpose will be to examine the ability of the two approaches to achieve fairness and stability. The complete example is shown in Table 1.

We consider a banking sector made of three banks: bank 1 has 200.000 millions \$ of insured deposits, bank 2 has 100.000 millions $\$$ and Bank 3 has 400.000. Thus there is a total of 700.000 million $\$$ of insured deposits in the system and the share of each bank is respectively, 28.6\%, $14.3 \%$ and $57.1 \%$.

We assume that each bank has its own risk profile. We model the risk profile by assuming that each bank is characterized by a base score (BS) and an economic cycle sensitivity (CS). The economic cycle is measured by a cycle index (CI), 
where a value of one is neutral, a value below one indicate worse than normal conditions and above one better than normal conditions.

\section{The Absolute Risk Scoring Approach}

In the context described above, the absolute risk score (ARS) for a bank is then computed according to:

$$
\mathrm{ARS}=\mathrm{BS}+\mathrm{CS} *(\mathrm{CI}-1)
$$

The absolute risk score is the base score plus the cycle sensitivity times the value of the cycle index minus one. Note that the ARS is equal to the base score when the cycle index equals 1 . The three banks have different base scores, respectively 85,75 and 90 . They also have different economic cycle sensitivities, respectively 10, 20 and 15 . We will examine three types of economic conditions: normal, bad and good, which are characterized respectively by the values: $1,0.75$ and 1.4. The numerical example shows that under the good scenario, the three banks get scores of 89,83 and 96 respectively.

Now, we assume that the deposit insurer applies a linear function to translate a score into a rate. The premium rate function computes the rate $(\mathrm{R})$ as:

$\mathrm{R}=\mathrm{RCA}+\mathrm{RSA} * \mathrm{ARS}$

Where RCA is the rate constant, i.e. the rate for a bank with a score of 0 and RSA is the rate slope, the slope is negative as a higher score should get a lower rate. In our example, RCA is set at 0.0021 i.e. 21 basis points at a score of 0 and the rate slope is -0.00001814 , such that a bank with a score of 100 would get a rate of 2.86 basis points.

Applying this formula, the premium rate for Bank 3 would be $4.674 \mathrm{bp}$ under the normal scenario, $5.3543 \mathrm{bp}$ under the bad scenario and $3.5856 \mathrm{bp}$ under the good scenario. Note that for all three banks, the premium rate increases in the bad scenario and decreases in the good scenario.

It is then possible to compute aggregate indicators under the three scenarios. The weighted score evolves from 86.34 to 82.86 to 92.14 . Accordingly, total premium collected move from 372.53 million $\$$ to $417.88 \mathrm{M} \$$ to $299.97 \mathrm{M} \$$. Finally, we can compute the average premium rate for the banking sector as total premiums divided by total insured deposits. This average premium rate evolves from $5.322 \mathrm{bp}$ to $5.97 \mathrm{bp}$ to $4.285 \mathrm{bp}$. Overall, the average premium rate increases when economic conditions are bad and decreases when they are good.

Under this conventional risk adjustment approach, we could say that premium rates are fair as they exactly adjust to the risk score; however this approach is clearly pro-cyclical because higher rates are charged in bad times. 
Table 1. Absolute Versus Relative Risk Scoring: a Numerical Example

\begin{tabular}{|c|c|c|c|c|c|c|c|}
\hline Banking sector & & & Bank 1 & Bank 2 & Bank 3 & Total & Average \\
\hline Insured deposits & ID & & 200000 & 100000 & 400000 & 700000 & \\
\hline Insured deposits -weight & $\mathrm{W}$ & $=\mathrm{ID} / \sum \mathrm{ID}$ & $28.6 \%$ & $14.3 \%$ & $57.1 \%$ & $100.0 \%$ & \\
\hline Base score & $\mathrm{BS}$ & & 85 & 75 & 90 & & \\
\hline Cycle sensitivity & $\mathrm{CS}$ & & 10 & 20 & 15 & & \\
\hline \multicolumn{8}{|l|}{ Economic cycle } \\
\hline Economic conditions & $\mathrm{EC}$ & & Normal & $\mathrm{Bad}$ & Good & & \\
\hline Cycle index & $\mathrm{CI}$ & & 1 & 0.75 & 1.4 & & \\
\hline \multicolumn{8}{|l|}{ Absolute Risk Scoring } \\
\hline \multicolumn{8}{|l|}{ Risk pricing } \\
\hline Rate constant & RCA & 0.0021000 & & & & & \\
\hline Rate slope & RSA & -0.00001814 & & & & & \\
\hline \multicolumn{8}{|l|}{ Bank 1 } \\
\hline Absolute Risk Score & ARS & $=\mathrm{BS}+\mathrm{CS} *(\mathrm{CI}-1)$ & 85 & 82.5 & 89 & & 85.5 \\
\hline Rate & $\mathrm{R}$ & $=\mathrm{RCA}+\mathrm{RSA}^{*} \mathrm{ARS}$ & 0.00056 & 0.00060 & 0.00049 & & 0.00055 \\
\hline Premium & $\mathrm{P}$ & $=\mathrm{ID} * \mathrm{R}$ & 112 & 121 & 97 & 329 & \\
\hline \multicolumn{8}{|l|}{ Bank 2} \\
\hline Absolute Risk Score & ARS & $=\mathrm{BS}+\mathrm{CS} *(\mathrm{CI}-1)$ & 75 & 70 & 83 & & 76.0 \\
\hline Rate & $\mathrm{R}$ & $=\mathrm{RCA}+\mathrm{RSA} * \mathrm{ARS}$ & 0.0007395 & 0.0008302 & 0.00059438 & & 0.00072 \\
\hline Premium & $\mathrm{P}$ & $=\mathrm{ID} * \mathrm{R}$ & 73.95 & 83.02 & 59.438 & 216 & \\
\hline \multicolumn{8}{|l|}{ Bank 3} \\
\hline Absolute Risk Score & ARS & $=\mathrm{BS}+\mathrm{CS} *(\mathrm{CI}-1)$ & 90 & 86 & 96 & & 90.8 \\
\hline Rate & $\mathrm{R}$ & $=\mathrm{RCA}+\mathrm{RSA}^{*} \mathrm{ARS}$ & 0.0004674 & 0.000535425 & 0.00035856 & & 0.00045 \\
\hline Premium & $\mathrm{P}$ & $=\mathrm{ID} * \mathrm{R}$ & 186.96 & 214.17 & 143.424 & 545 & \\
\hline \multicolumn{8}{|l|}{ Banking sector } \\
\hline Mean Absolute Risk Score & MARS & $=\sum \mathrm{Wi}^{*} \mathrm{ARSi}$ & 86.43 & 82.86 & 92.14 & & 87.1 \\
\hline Total premium & $\mathrm{TP}$ & $=\mathrm{P} 1+\mathrm{P} 2+\mathrm{P} 3$ & 372.53 & 417.88 & 299.97 & 1090 & 363.5 \\
\hline Weighted average rate & WARA & $=\mathrm{TP} / \mathrm{IDT}$ & 0.0005322 & 0.0005970 & 0.0004285 & & 0.0005192 \\
\hline \multicolumn{8}{|l|}{ Relative Risk Scoring } \\
\hline \multicolumn{8}{|l|}{ Risk pricing } \\
\hline Rate constant & RCR & 0.00051923 & & & & & \\
\hline Rate slope & RSR & -0.00001814 & & & & & \\
\hline Bank 1 & & & & & & & \\
\hline
\end{tabular}




\begin{tabular}{|c|c|c|c|c|c|c|c|}
\hline Relative Risk Score & RRS & $=\mathrm{ARS}-\mathrm{WAS}$ & -1.43 & -0.36 & -3.14 & & -1.6 \\
\hline Rate & $\mathrm{R}$ & $=\mathrm{RCR}+\mathrm{RSR} * \mathrm{RRS}$ & 0.0005451 & 0.0005257 & 0.0005762 & & 0.00055 \\
\hline Premium & $\mathrm{P}$ & $=\mathrm{ID} * \mathrm{R}$ & 109.0 & 105.1 & 115.2 & 329 & \\
\hline \multicolumn{8}{|l|}{ Bank 2} \\
\hline Relative Risk Score & RRS & $=\mathrm{ARS}-\mathrm{WAS}$ & -11.43 & -12.86 & -9.14 & & -11.1 \\
\hline Rate & $\mathrm{R}$ & $=\mathrm{RCR}+\mathrm{RSR} * \mathrm{RRS}$ & 0.0007265 & 0.0007525 & 0.0006851 & & 0.00072 \\
\hline Premium & $\mathrm{P}$ & $=\mathrm{ID} * \mathrm{R}$ & 72.7 & 75.2 & 68.5 & 216 & \\
\hline \multicolumn{8}{|l|}{ Bank 3} \\
\hline Relative Risk Score & RRS & $=\mathrm{ARS}-\mathrm{WAS}$ & 3.57 & 3.39 & 3.86 & & 3.6 \\
\hline Rate & $\mathrm{R}$ & $=\mathrm{RCR}+\mathrm{RSR} * \mathrm{RRS}$ & 0.0004544 & 0.0004577 & 0.0004493 & & 0.00045 \\
\hline Premium & $\mathrm{P}$ & $=\mathrm{ID} * \mathrm{R}$ & 181.8 & 183.1 & 179.7 & 545 & \\
\hline \multicolumn{8}{|l|}{ Banking sector } \\
\hline Mean Relative Risk Score & MRRS & $=\sum \mathrm{Wi} * \mathrm{RSCi}$ & 0.00 & 0.00 & 0.00 & & 0.0 \\
\hline Total premium & TP & $=\mathrm{P} 1+\mathrm{P} 2+\mathrm{P} 3$ & 363.46 & 363.46 & 363.46 & 1090 & 363.5 \\
\hline Weighted average rate & WARR & $=\mathrm{TP} / \mathrm{IDT}$ & 0.0005192 & 0.0005192 & 0.0005192 & & 0.0005192 \\
\hline Rate differential & $\mathrm{RD}$ & =WARR-WARA & -0.0000130 & -0.0000777 & 0.0000907 & 0.000000 & 0.0000000 \\
\hline
\end{tabular}

Source: Author 


\section{The Relative Risk Scoring Approach}

Now, let us examine how the relative risk scoring approach would work and behave. The relative risk score (RRS) would be computed as the absolute risk score (ARS) minus the Mean Absolute Risk Score (MARS), the mean being computed as a weighted average. The formula is:

$\mathrm{RRS}=\mathrm{ARS}-\mathrm{MARS}$

For example, the relative risk score of Bank 1 in the normal scenario would be 85 minus the mean of 86.43 for the sector which gives -1.43 , i.e. Bank 1 is a bit more risky than the sector.

The pricing parameters have to be rescaled. The rate constant has to be set as the rate for a relative score of 0 , but the rate slope may remain the same. In our case, the rate constant becomes $5.1923 \mathrm{bp}$, which would be the rate for a relative score of 0 , i.e. a risk level equal to that of the sector.

The premium rates are computed in Table 1 for the three banks under the three scenarios. First, we can easily observe that although each would experience some rate fluctuations over the cycle these fluctuations would be much smaller than under the absolute scoring approach. Secondly, we see that the average rate for the sector would remain absolutely constant at $5.192 \mathrm{bp}$ under the three scenarios.

To help understand the behaviour of the relative risk scoring approach, it is interesting to look at several graphs. Figure 1 presents graphs of the absolute and relative scores of the three banks versus the ordered values of the cycle index. It is clear in the graph of absolute scores that all three banks and the sector have scores that increase with better economic conditions. In the graph of relative scores, though banks 1 and 2 still have positive slopes, bank 3 , the biggest bank has a negative slope such that the average slope for the sector is totally flat.

Figure 2 shows graphs of the premium rates versus the cycle index under absolute and relative scoring. As expected, premium rates decrease for the three banks and the sector as economic conditions improve under absolute scoring. Banks are affected differently under relative scoring. Banks 2 and 3 experience slightly decreasing rates whereas Bank 1 sees its rate increase with the cycle index. Overall, the average premium rate remains perfectly constant over the different values of the cycle index.

Figure 3 displays graphs of the premium rates versus absolute and relative scores. Note because the origin is moved from the lowest score to the average score, the constant or intersect with the y axis is changed. However, the slope remains the same in the two graphs. 
Figure 1. Absolute and Relative Scores versus the Cycle Index


Source: Author 
Vol. 5, No. 1

Roy: Optimal Pricing of Deposit Insurance: Aiming at Fairness...

Figure 2. Premium Rates versus Cycle Index under Absolute and Relative Scoring

Premium rates under Absolute scoring
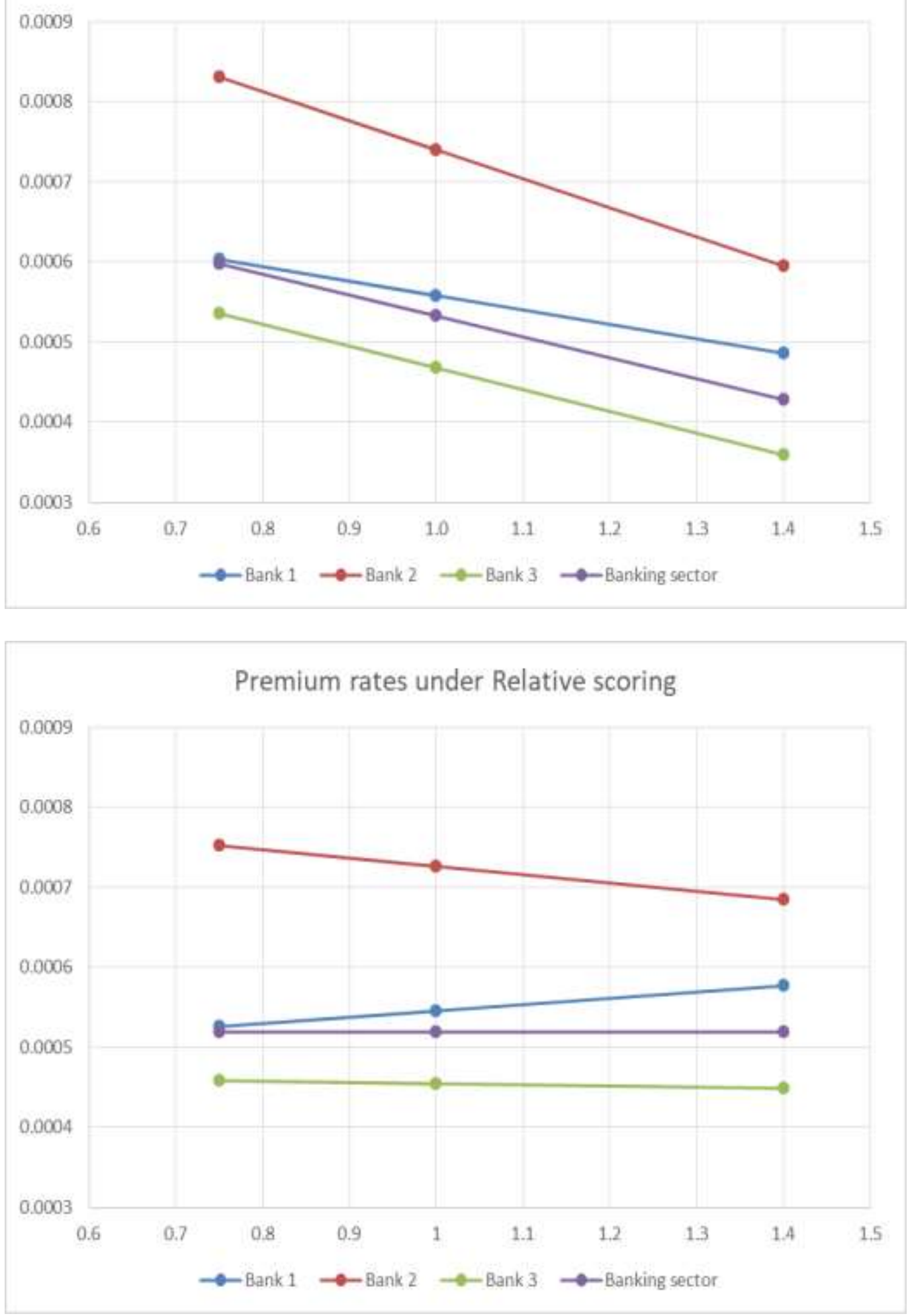

Source: Author 
Figure 3. Premium Rates versus Absolute and Relative Scores
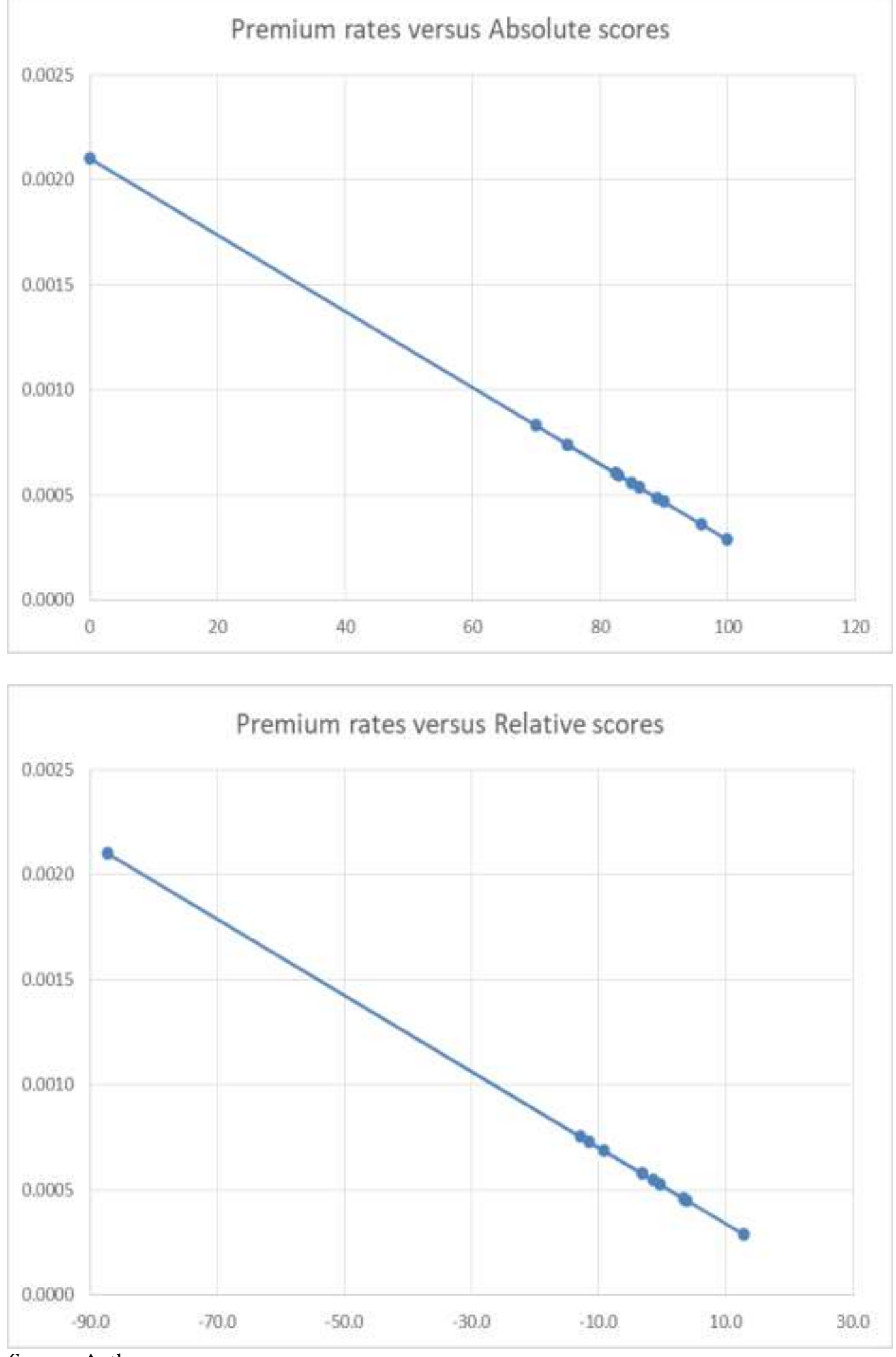

Source: Author 
What then, are the properties of this relative risk approach? We claim that it achieves an interesting form of fairness, because its rate will reflect the risk position relative to the average of the sector. Thus, the general principle that riskier banks should pay a higher rate is respected. The system also performs well in terms of stability because the average premium rate remains constant throughout the economic cycle. In particular, the approach avoids increasing the average rate in bad times. So, at the very least it is not pro-cyclical. Also, we find that with proper adjustments to the pricing formula, the total amount of premium generated over the cycle by the relative risk approach can be the same as the amount which would be generated by the absolute risk approach, while maintaining the average rate constant through the cycle. We conclude that using the two criteria of fairness and stability, the relative risk approach seem to perform better than the approaches that have historically been used. We summarize our analysis of the various approaches in the following, admittedly simple, Table 2.

Table 2. Performance of Various Risk Adjustment Approaches

\begin{tabular}{|l|c|c|}
\hline Approaches to risk adjustment & Fairness & Stability \\
\hline Fixed rate - no risk adjustment & No & Yes \\
\hline Precise risk adjustment & Yes & No \\
\hline Categorical risk adjustment & Partial & Partial \\
\hline Relative risk adjustment & Yes & Yes \\
\hline
\end{tabular}

Source: Author

\section{Discussion}

This section proposes a discussion of two issues: the materiality of the problem that relative scoring tries to address and eventually the performance of relative scoring as a potential solution.

\section{The Materiality of the Problem of Pro-cyclicality}

The similarity between risk-adjusted deposit insurance pricing and the riskadjusted capital requirement as implemented in the recent Basel accords has already been pointed out. In the latter case, the effect was deemed material enough such that the Basel Committee on Bank Supervision agreed that action needed to be taken to somewhat offset this negative effect. Eventually, the Basel III accord introduced the concept of a counter cyclical buffer. Reasoning with this analogy, it would seem appropriate that deposit insurers also try to mitigate the potential negative effect of their risk adjusted premium rates. Nonetheless, the issue of materiality remains an empirical issue which should be researched empirically. It could well be the case that different jurisdictions experience pro-cyclicality with different intensities. Thus, we believe that data should be gathered on scores, premium rates and one or several indicators of economic conditions. Then, the following question should be asked. To what extent are the risk scores correlated with economic conditions? To what extent are the premium rates correlated with economic conditions? These questions could be studied both at the aggregate level 
and at the bank level. Only a rigorous analysis of this type of data can provide a solid answer to the question of the materiality of pro-cyclicality in a given jurisdiction.

\section{The Performance of Relative Risk Scoring as a Potential Solution}

Should the problem of pro-cyclicality prove material, one would need to examine the performance of relative risk scoring as a potential solution. First, we believe that the previous section provides strong arguments to think that relative risk scoring would be quite effective at stabilizing premium rates. Second, it should also be quite efficient because the cost of implementing it should be rather low as the approach is quite simple. On the other hand, it may be difficult to evaluate the economic value of the benefits generated by the improvement in stability. Again, an empirical approach could help shed light on the issue. We think that a jurisdiction could easily develop a simulator to examine what would have been the behaviour of a relative risk scoring approach on its historical data. It could then evaluate the improvement achieved with regard to stability and try to put a value on these gains.

\section{Conclusion}

The purpose of this paper was to examine the notion of optimal deposit insurance pricing assuming that the two goals of fairness and stability were aimed at. Fairness was interpreted as charging higher rates to riskier borrowers. Stability, in turn, was characterized minimally as avoiding pro-cyclicality. In this context, it was argued that none of the known schemes to establish premium rates are totally satisfactory. Fixed rate schemes provide stability but are deemed unfair, as they do not adjust for risk. Precise risk adjusted schemes would be fair but are naturally pro-cyclical. Categorical risk adjustment represents some kind of trade off achieving both goals partially.

The relative risk scoring approach was proposed to try to better achieve both goals. The rationale behind it is twofold. First, banks should be charged only for the risk which they can control, so they should not be penalized for macroeconomic risks beyond their control. Second, by defining the relative risk of a bank as the difference between its absolute score and the mean score of the banking sector, the effect of macroeconomic conditions is removed. A numerical example was provided to illustrate the workings and the behaviour of this relative scoring approach. It showed, we believe, that a premium rate proportionate to risk can be achieved, while at the same time avoiding pro-cyclicality.

Finally, the issues of the materiality of the problem of pro-cyclicality and the performance of relative risk scoring as a potential solution were discussed. In both cases, empirical analyses using econometrics and simulation would provide valuable information that should help deposit insurers and their insured banks converge to an agreement. 


\section{References}

Andritzky J, Kodres L, Madrid P, Maechler A, Narain A, Sacasa N, Scarlata J (2009) Policies to Mitigate Procyclicality. IMF Staff Position Note, SPN 09/09.

Borio C, Furfine C, Lowe P (2001) Procyclicality of the Financial System and Financial Stability: Issues and Policy Options, in Marrying the Macro- and Micro-prudential Dimensions of Financial Stability. BIS Papers 1.

Goodhart C (2010 February) Is a Less Pro-cyclical Financial System an achievable Goal? National Institute Economic Review 211(1): 81-90.

Gordy M, Howells B (2006) Procyclicality in Basel II: Can We Treat the Disease without Killing the Patient? Journal of Financial Intermediation 15(3): 395-417.

Jarrow R, Madan D, Unal H (2008) Designing Counter-cyclical and Risk Based Aggregate Deposit Insurance Premia. Kamakura Corporation.

Pennacchi GG (2004) Risk-Based Capital Standards, Deposit Insurance and Procyclicality. FDIC Center for Financial Research, Working Paper 2004-05.

Repullo R, Saurina J, Trucharte C (2010) Mitigating the Procyclicality of Basel II. Economic Policy 25(64): 659-702. 


\title{
Spillover Effects from the ECB's Unconventional Monetary Policies: The Case of Denmark, Norway and Sweden
}

\author{
By Arthur Korus*
}

\begin{abstract}
Using event-study techniques we investigate the impact of ECB's announcements of nonstandard policy measures on a broad range of financial assets from Denmark, Norway and Sweden. We find evidence that unconventional monetary policy announcements by the ECB resulted in pronounced spillovers to Denmark, Norway and Sweden. In particular, our results suggest that medium- and long-term government bond yields, corporate bond yields and CDS spreads were affected by ECB's announcements of non-standard policy measures. Our empirical results indicate that the portfolio rebalancing channel played an important role in the transmission of ECB's non-standard policy measures on mediumand long-term government bonds and corporate bond yields. However, it also seems that declining government bond yields transmitted to decreasing corporate bond yields. Moreover, our results suggest that benchmark stock market indices and exchange rates vis-à-vis the euro were mainly unaffected by ECB's announcements of unconventional monetary policies. Furthermore, we find pronounced spillover effects from Forward Guidance statements, Securities Markets Programme announcements, and Corporate Sector Purchase Programme announcements on financial assets from Denmark, Norway and Sweden. Though, our results highly depend on the monetary policy surprise measure used in our regressions and the degree of policy anticipation.
\end{abstract}

Keywords: ECB, Event-Study, Monetary Policy Spillovers, Nordic countries

\section{Introduction}

In recent years the European Central Bank (ECB) has announced and implemented unconventional monetary policies (UMPs) in response to both the financial crisis and the euro area sovereign debt crisis. The ECB has announced and adopted a broad range of non-standard monetary policy measures, including the purchase of euro area government bonds and corporate bonds. Moreover, the ECB has implemented a series of key policy rate changes. Due to these changes, key policy rates have even reached negative territory. Empirical evidence suggests that the ECB's unconventional monetary policies, adopted since 2008, have influenced macroeconomic variables and financial assets in euro area countries (Abbassi and Linzert 2012, Peersman 2012, Ghysels et al. 2013, Andrade et al. 2016, Gambetti and Musso 2017). Moreover, several studies document spillover effects of euro area non-standard monetary policy measures on advanced economies and emerging markets (Fratzscher et al. 2014, Falagiarda et al. 2015, Georgiadis and Gräb 2015, Potjagailo 2016). This strand of literature shows that

*Research Assistant, Chair for Macroeconomic Theory and Policy, Schumpeter School of Business and Economics, University of Wuppertal, Germany. 
the ECB's unconventional monetary policies have had price effects and output effects on non-euro area countries. However, evidence regarding the spillover effects resulting from the ECB's unconventional monetary policies to small advanced open economies outside the euro area remains scarce (Bernhard and Ebner 2016, Bluwstein and Canova 2016). To fill this gap, we empirically investigate the impact of the ECB's announcements of non-standard policy measures on a broad range of financial assets from Denmark, Norway and Sweden.

In general, Denmark, Norway and Sweden are small, advanced and highly open economies for which the euro area countries are important trading partners and providers of capital. Moreover, these countries share a common model, namely the Nordic model (IMF 2013b). The Nordic model is marked by growthenhancing trade, financial openness, stable public finances, cooperative labour markets and an equitable income distribution. The Nordic model resulted in macroeconomic stability and a history of fiscal prudence in Denmark, Norway and Sweden. These features established the aforementioned countries as safe havens in the eyes of financial markets during the financial and the euro area sovereign debt crises. Moreover, the banking sector is relative large and highly-concentrated in the Nordic countries. However, important differences between the three countries exist (IMF 2013b). For instance, Norway and Sweden follow inflation targeting with freely floating exchange rates. Whereas Denmark follows a fixed-exchange rate policy vis-à-vis the euro area and participates in the European Exchange Rate Mechanism, ERM2. Thus, the common approach on the one hand and differences between our selected countries on the other hand makes it interesting to study the effects of the ECB's unconventional monetary policies on financial variables from Denmark, Norway and Sweden.

We find evidence that UMP announcements by the ECB resulted in pronounced spillovers to Denmark, Norway and Sweden. In particular, our results suggest that medium- and long-term government bond yields, corporate bond yields and Credit Default Swaps (CDS) spreads were affected by the ECB's announcements of non-standard policy measures. Although our estimation strategy does not allow to identify the underlying transmission channels, through which the ECB's UMP measures may affect financial assets from our countries of interest, our results do indicate that the portfolio rebalancing channel played an important role in the transmission of the ECB's non-standard policy measures on mediumand long-term government bonds and corporate bond yields. However, it also seems that declining government bond yields transmitted to decreasing corporate bond yields. Moreover, our results suggest that benchmark stock market indices and exchange rates vis-à-vis the euro were largely unaffected by the ECB's announcements of unconventional monetary policies.

Furthermore, we find pronounced spillover effects from Forward Guidance (FWG) statements, Securities Markets Programme (SMP) announcements and Corporate Sector Purchase Programme (CSPP) announcements on financial assets from Denmark, Norway and Sweden. While spillover effects from the Outright Monetary Transactions (OMT) and Public Sector Purchase Programme (PSPP) announcements on financial variables from our countries of interest were limited. Our results suggest that SMP operated perhaps via the portfolio rebalancing 
channel, the confidence and the exchange rate channel. The OMT mainly operated via the confidence channel. Furthermore, we argue that FWG statements spilled over to all countries mainly via the signalling channel. Regarding PSPP announcements, we argue that PSPP mainly operated via the portfolio rebalancing channel. Whereas our results indicate that CSPP announcements possibly spilled over via both the confidence and exchange rate channel.

The remainder of the paper is organized as follows. First, we take a brief look at the literature on monetary spillovers. Section 3 gives an overview of the unconventional monetary policies adopted by the ECB since 2008. In Section 4 we discuss several transmission channels through which unconventional monetary policy in advanced economies spills over internationally. In Section 5 we formulate specific expectations regarding the impact of the ECB's unconventional monetary policies on financial assets from Denmark, Norway and Sweden. Section 6 presents our empirical methodology and estimation results, while Section 7 concludes.

\section{Literature Review}

So far, many studies have focused on the impact of unconventional monetary policy measures on domestic variables (see Angelini et al. 2011, Gagnon et al. 2011, Krishnamurthy and Vissing-Jorgensen 2011, Abbassi and Linzert 2012, Baumeister and Benati 2013, Krishnamurthy et al. 2014, Andrade et al. 2016). For the euro area, the literature suggests that the ECB's unconventional monetary policies positively affected regional output (Lewis and Roth 2015). However, it seems that conventional monetary policy measures had a stronger influence on regional output than non-standard monetary policy measures (Peersman 2012). Moreover, Lewis and Roth (2015) show that the ECB's non-standard policy measures only slightly influenced inflation in the euro area. Moreover, the ECB's UMP measures led to declining market spreads (Abbassi and Linzert 2012) and a reduction in the term premia (Ghysels et al. 2013). Furthermore, there is evidence that the ECB's UMP measures reduced the yields of euro area long-term sovereign bonds (Ghysels et al. 2013, Andrade et al. 2016). Andrade et al. (2016) also show that the ECB's non-standard policy measures led to increasing share prices of banks holding a high share of government bonds in their portfolio.

In recent years, the analysis of spillover effects of such policies has received more attention. Many studies focus on the analysis of spillover effects of the Federal Reserve's (FED) non-standard monetary policies on advanced and emerging economies. Empirical evidence shows that the FED's UMP measures led to a depreciation of the US dollar, lower global short-term interest rates, falling global long-term government bond yields and declining corporate bond yields (Chen et al. 2012, Glick and Leduc 2012, Diez and Presno 2014, Fratzscher et al. 2013, IMF 2013a, Berge and Cao 2014, Glick and Leduc 2015, Neely 2015). Moreover, this literature shows that the effects of the FED's non-standard policy measures on global equity prices and capital flows were more ambiguous. 
Chen et al. (2012) analyse the international spillover effects of unconventional policy actions taken by central banks with a focus on the US asset purchase program. They find that the US asset purchase programs increased asset prices globally. The IMF (2013a) finds that early FED's announcements of UMP measures had stronger effects on global asset prices than later announcements. Fratzscher et al. (2013) elaborate on the international spillover effects of US quantitative easing (QE). They show that the FED's QE policies influenced portfolio flows and asset prices both in the US and globally. Moreover, they conclude that QE 1 led to a substantial rebalancing in global portfolios whereby investors turned to US markets. Hence, QE 1 led to an appreciation of the US dollar, lower US bond yields and higher equity prices on the US stock markets. In contrast to QE 1, QE 2 led to portfolio rebalancing in the opposite direction. Fratzscher et al. (2013) also show that the spillover effects of FED operations, such as government bond purchases, were larger than the effects of the FED's announcements of UMP measures. Furthermore, their findings suggest that a fixed exchange rate regime did not insulate from the FED's non-standard monetary policies.

While a large number of studies which elaborate on the impact of FED's nonstandard policy measures on economic and financial variables in other countries exist, only a few studies focus on spillovers from the ECB's unconventional monetary policies to non-euro area countries. Fratzscher et al. (2014) and Georgiadis and Gräb (2015) investigate spillover effects from the ECB's nonstandard policy measures on global financial markets. Both studies find that ECB UMP measures boosted equity prices globally, caused the euro to depreciate vis-àvis advanced and emerging market economy currencies and hardly influenced global bond yields. Georgiadis and Gräb (2015) show that scope and size of spillover effects across economies depended on differences in economies' financial openness, the exchange rate regime, the degree of financial and trade integration with the euro area and a countries attractiveness for carry trades. Additionally, Fratzscher et al. (2014) report that ECB non-standard policy measures reduced risk aversion and lowered credit risk globally. Moreover, they conclude that the ECB's non-standard policy measures exerted limited international effects because ECB policies resulted in modest effects on international portfolio flows. Chen et al. (2012) argue that the international spillover effects of the FED's unconventional monetary policy measures were stronger than those of ECB policies.

Falagiarda et al. (2015) study the effects of the ECB's non-standard policy measures on financial variables from non-euro area EU countries in Central and Eastern Europe (CEE). Using an event-study analysis they find that ECB UMP measures spilled over to CEE countries. In particular, sovereign bond yields were affected by ECB announcements of UMP measures. They find no impact on exchange rates vis-à-vis the euro, equity prices and CDS spreads. Furthermore, their results suggest that spillovers from SMP announcements were the most pronounced. The spillover effects of both OMT and PSPP on financial assets from CEE countries was limited. Potjagailo (2016) elaborates on the spillover effects 
from euro area monetary policy shocks to thirteen EU countries outside the euro area and finds that these shocks decreased interest rates and reduced uncertainty.

So far, evidence regarding the spillover effects from non-standard monetary policies of the ECB on small, open advanced economies remains scarce (Bernhard and Ebner 2016, Bluwstein and Canova 2016). By using a Bayesian mixedfrequency structural vector autoregressive technique, Bluwstein and Canova (2016) document international spillovers but they find that there was considerable cross-country heterogeneity. They document that a flexible exchange rate will not insulate non-euro area countries from importing non-standard ECB policy measures. Bernhard and Ebner (2016) investigate cross-border spillover effects of unconventional monetary policies on Swiss asset prices. By using an event-study setting and the change in 10-year government bond futures as a proxy for market anticipation, they find that non-standard monetary policies conducted by the FED, the ECB, the BoE and the BoJ exerted spillover effects on Swiss asset prices whereby ECB announcements had the strongest impact on financial variables from Switzerland. Furthermore, they show evidence that the effects of foreign UMP surprises on Swiss asset prices were less pronounced after the introduction of the Swiss franc/euro exchange rate floor of 1.20 francs per euro.

We contribute to the existing literature by assessing the effects of the ECB's non-standard policy measure announcements on small, open advanced economies. Our paper focuses on the impact of ECB announcements of UMP measures on a broad set of financial variables from three Nordic countries, namely Denmark, Norway and Sweden. Moreover, to the best of our knowledge, we are the first to analyse the impact of the ECB's announcements of unconventional monetary policies on a broad range of financial assets from Denmark, Norway and Sweden.

\section{The ECB's Unconventional Monetary Policy Measures}

During the global financial crisis and sovereign debt crisis, the ECB decreased its key interest rates significantly. The main refinancing rate was set at zero and the deposit facility rate has even been negative for some time. At the same time, the ECB has used, besides conventional monetary policy tools, unconventional monetary policy tools. Early on in the financial crisis, the ECB adopted several non-standard monetary policy measures in order to rekindle the functioning of the interbank money market. In order to ensure a smooth functioning of the interbank money market, the ECB introduced an unlimited provision of liquidity through a fixed-rate full allotment tender procedure (FRTPFA). This policy tool allows banks to lend an unlimited amount of euros at the main refinancing rate, subject to appropriate collateral. This measure ensured that the high demand for liquidity could be satisfied. Further, the list of eligible collateral (COLL) was extended. The extension of the list of eligible collateral accepted in Eurosystem refinancing operations allowed banks to refinance a larger part of their balance sheet with the Eurosystem. The aforementioned unconventional monetary policy measures ensured that euro area banks, with access to the auctions of the $\mathrm{ECB}$, have received an almost unlimited refinancing. 
The ECB also introduced longer-term refinancing operations (LTRO) with maturities from three months up to three years. Thus, the ECB provided long-term liquidity to euro area banks. Objectives of the longer-term refinancing operations were to improve liquidity conditions to banks and to reduce tensions within the interbank money market. Furthermore, the ECB established foreign currency lines (FOR) with several central banks. The ECB temporarily provided liquidity in foreign currencies, at various maturities, and against euro-denominated collateral. For this, the ECB used currency arrangements, notably with the FED. Thereby it was possible to avoid a massive shortfall in the US dollar. Hence, the aim of this non-standard monetary policy measure was to improve banks foreign currency funding.

In May 2009, the ECB introduced the Enhanced Credit Support (ECS). The ECS included the fixed-rate full allotment, the expansion of the list of eligible collateral, longer-term liquidity provision, liquidity provision in foreign currency, and purchases of covered bonds. The aim of the Covered Bond Purchasing Programme (CBPP1) was to stabilize the covered bond market, which is a primary source of funding for banks in large parts of the euro area, and to eliminate banks refinancing problems. Within the first Covered Bond Purchasing Programme, the ECB purchased covered bonds in the amount of 60 billion euro. In November 2011, the Eurosystem launched a second Covered Bond Purchasing Programme (CBPP2). CBPP2 encompassed an aggregated volume of 40 billion euro. The program ended, as planned, in October 2012, when it reached a nominal value of 16.4 billion Euros. In October 2014, the third CBPP (CBPP3) was introduced with duration of two years. The objective of the third CBPP was to improve monetary transmission and to bring inflation rates closer to the inflation target of the ECB.

In May 2010, the Securities Market Programme (SMP) was announced by the ECB. SMP involved purchases of euro area government bonds on the secondary markets. Liquidity injected through the SMP was sterilized through specific operations. Objectives of the SMP were to address the malfunctioning of securities markets and to restore the monetary policy transmission mechanism. At the peak, the volume of sovereign bonds held by the ECB amounted to 210 billion. The ECB announced an Outright Monetary Transactions (OMT) program in August 2012. OMT included transactions in secondary sovereign bond markets with no quantitative limits conditional on certain domestic conditions. With the introduction of the OMT, the SMP program was terminated. The overall aim of OMT was to remove monetary and financial fragmentation of the euro area. So far, OMT has never been activated. Nevertheless, its announcement reassured financial markets and especially sovereign bond markets (Altavilla et al. 2014).

Furthermore, during the sovereign debt crisis the ECB changed its monetary policy communication strategy. Namely in July 2013, the ECB introduced forward guidance (FWG) as an additional non-standard monetary policy tool. Forward guidance corresponds to a commitment on future interest rate decisions, so as to influence not only short-term rates, but also long-term rates which are largely determined by expectations on future short-term rates (Chinn 2013). Hence, since July 2013 the ECB has been providing explicit statements on the future path of the ECB's policy interest rates conditional on the outlook for price stability. The aim 
of forward guidance is to clarify the Governing Council's assessment of the inflation outlook in the euro area and its monetary policy strategy. In June 2014, the ECB started to conduct a series of targeted longer-term refinancing operations (TLTRO1) and also began to purchase asset-backed securities (ABSPP). The aim of TLTRO is to improve bank lending to households and non-financial corporations. In June 2016, a second series of targeted longer-term refinancing operations (TLTRO2) was launched by the ECB. The Asset-backed Securities Purchase Programme is limited to asset-backed securities that are eligible as collateral for Eurosystem refinancing operations, and secured by claims against non-financial sector entities. The ABSPP should help banks to diversify funding sources and to stimulate the issuance of new securities.

In January 2015, the ECB announced an expanded Asset Purchase Programme (APP), which initially consisted of the third Covered Purchase Programme, the Asset-Backed Securities Purchase Programme (ABSPP), and the Public Sector Asset Purchase Programme (PSPP). PSPP was introduced in March 2015 and consists of purchases of bonds issued by euro-area governments, agencies and European institutions. Under APP, the Eurosystem's monthly purchase has amounted to 60 billion euro since March 2015. APP should contribute to an increase of the inflation rate within the euro area. On March 2016, the ECB extended the Asset Purchase Programme. Since March 2016 the ECB has purchased 80 billion euro worth of securities every month. Furthermore, the Corporate Sector Purchase Programme (CSPP) was announced by the ECB as a fourth pillar of the APP. CSPP contains purchases of corporate bonds in the primary and secondary markets. Since June 2016 the monthly purchasing volume of investment grade euro-denominated bonds issued by non-bank corporations has totalled 10 billion euro.

\section{Transmission Channels}

In this section we discuss possible transmission channels through which nonstandard monetary policies conducted by the ECB influence prices of the selected financial assets in our countries of interest. The financial assets used in our event analysis are the following variables: a bilateral nominal exchange rate vis-à-vis the euro, yields of government bonds issued in local currencies, sovereign creditdefault swaps, an interbank interest rate, a benchmark stock market index and a corporate bond index. This selection of financial assets is broadly similar to the selection of variables employed by Takatas and Vela (2014) and Falagiarda et al. (2015). Takatas and Vela (2014) investigate the impact of the FED's policy on financial conditions in emerging markets economies. Falagiarda et al. (2015) examine whether the ECB's non-standard policy measures spilled over to noneuro area EU countries in Central and Eastern Europe. From a theoretical point of view, there are several possible transmission channels through which the ECB's non-standard monetary policies may spillover to non-euro small open advanced economies. In this section, we present the major transmission channels of international monetary policy spillovers. We suspect that both asset purchases 
(quantitative easing or credit easing) and forward guidance statements made by the ECB could exert spillover effects on financial variables through at least five channels: an exchange rate channel, the portfolio rebalancing channel, the signalling channel, the confidence channel and an international bank lending channel.

First, we elaborate on the exchange rate channel, through which conventional monetary policies and non-standard monetary policy announcements may affect our financial variables of interest. Standard monetary models imply that a decrease of the policy rate or, equivalently, an increase in the money supply in one country under a flexible exchange rate regime leads to a depreciation of the nominal spot exchange rate of its currency. This result is a consequence of Mundell's "Trilemma". Foreign monetary policy shocks will lead to an adjustment of the exchange rate in an economy with an open capital account if the domestic monetary authority doesn't response to the foreign monetary policy innovation. Unconventional monetary policies, like quantitative easing, are designed to influence long-term rates more directly. In principle, quantitative easing in a foreign country is associated with lower foreign long-term interest rates. Hence, it becomes more attractive for investors to invest in the domestic country. This adjustment of capital flows will result in an appreciation of the domestic currency. But the narrative is potentially more complex because a reduction of foreign longterm interest rates could also result in lower domestic long-term rates even if the domestic monetary authority does not adjust (Bernhard and Ebner 2016).

A second channel through which monetary policy spillovers may affect our countries of interest is the so-called portfolio rebalancing channel (Krishnamurthy and Vissing-Jorgensen 2011). At least two explanations of how this channel may affect foreign assets exist. First, the ECB's purchases of euro area government bonds would reduce the amount of these securities available to private investors. Thus, private investors are crowded out from this market segment by the ECB's asset purchases. In search of assets with a similar risk-return profile as the assets purchased by the ECB, private investors would move to close substitute assets. Substitute assets could include comparable domestic assets or assets in other countries. Hence, ECB purchases of government bonds may induce investors to rebalance their portfolio and this would lead to price changes of other financial assets. Second, in the standard portfolio balance model, the ECB's purchases of euro area government bonds would reduce their yields relative to comparable noneuro area bonds. Thus, foreign assets would get more attractive. Optimizing investors could turn to non-euro area assets for higher risk-adjusted returns. Higher demand for non-euro area bonds induces higher bond prices and thus lower bond yields. This channel could be a prominent channel of transmission of ECB announcements of SMP, PSPP and CSPP because these programs are characterized by the direct purchases of assets. These non-standard policies are designed to influence the prices and yields of domestic bonds directly.

Third, non-standard monetary policies may induce international spillover effects through the signalling channel (Krishnamurthy and Vissing-Jorgensen 2011, Falagiarda et al. 2015). The signalling channel is closely related to the portfolio rebalancing channel because it also operates via changes in the prices and 
yields of domestic financial assets. The signalling channel may work in the following way: if a central bank announces its intention to maintain lower shortterm interest rates for a longer period, market expectations for future interest rates may change. This could, through the expectations hypothesis of the term structure (Chinn 2013), lead to declining long-term interest rates. This results in changes in the interest rate differentials between economies across all maturities of bonds. Hence, this could influence financial variables in our selected economies. We expect that forward guidance may mainly operate via the signalling channel because the ECB sends signals about the future path of the main refinancing rate by using forward guidance.

The confidence channel could be a potential channel of transmission through which announcements of unconventional monetary policies may affect financial assets from small open advanced economies. Announcements of the ECB's nonstandard monetary policy measures could lead to both improved confidence and economic sentiment in the euro area. This could lead to a reprising of risks and capital outflows from Denmark, Norway and Sweden. Safe havens in particular could be affected by the confidence channel. Denmark, Norway and Sweden could be categorised as safe havens during the financial crisis (IMF 2013b). ECB announcements of unconventional monetary policy measures could lead to improved confidence in the euro area. This may lead to a higher demand for assets from the euro area and thus to capital outflows from our countries of interest. Capital outflows from our countries of interest should lead to lower asset prices and thus higher yields. The OMT announcements in particular might operate via the confidence channel because OMT reduced the perceived risk of euro area government bonds and has never been applied, yet.

The ECB's non-standard policy measures may also spillover via the international bank lending channel to other countries. Global financial integration potentially leads to a disruption of the transmission mechanism of conventional monetary policy (Hume and Sentence 2009). For instance, the rise in cross border financial flows could affect financial conditions in the domestic country. This also means that policy action taken by the ECB could have an impact on domestic credit conditions. An increase in liquidity in the euro area may have an impact on credit conditions in our countries of interest because of the presence of foreignowned banks in their local banking systems, which are controlled by parent banks located in the euro area. Hence, a decrease in the interbank rate available to the parent bank is associated with lower costs of funding for the subsidiary. However, it should be noted, that the costs of funding for the parent banks and subsidiaries are not perfectly correlated.

\section{Hypotheses}

In this section we discuss possible effects of the ECB's announcements of unconventional monetary policies on our selected financial assets. Based on the above mentioned international transmission channels, we can formulate specific expectations regarding the impact of ECB's unconventional monetary policies on 
selected financial assets from Denmark, Norway and Sweden. The formation of expected spillovers may facilitate the discussion of the empirical results, particularly with respect to the analysis of the systematic measures of ECB policies. However, our empirical set-up does not allow for an identification of individual international transmission channels of the ECB's non-standard monetary policy. So, we formulate hypotheses about how the announcements of the ECB's non-standard monetary policy measures affect financial assets from our countries of interest. Hence, we try to answer from a theoretical point of view what the overall effect of the ECB's UMP measures on financial assets from Denmark, Norway and Sweden could be.

Hypothesis 1: The net effect of the ECB's unconventional monetary policies on exchanges rates vis-à-vis the euro is ambiguous. Exchange rates vis-à-vis the euro could be affected by the ECB's non-standard policy measures via the exchange rate channel and the confidence channel. The exchange rate channel is especially important in the case of Sweden and Norway, given their flexible exchange rate regime and the high degree of financial and real integration of both economies with the euro area. As mentioned before, the impact of the exchange rate channel on exchange rates vis-à-vis the euro is negative and thus associated with an appreciation of the domestic currency. Hence, ECB announcements of unconventional monetary policies are associated with an appreciation of the Swedish krona and Norwegian krone and an upward pressure of the Danish krone. At the same time, the confidence channel should dampen the decrease of exchange rates vis-à-vis the euro because of raising confidence levels in the euro area.

Hypothesis 2: The net effect of the ECB's unconventional monetary policy measures on yields of Danish, Norwegian and Swedish government bonds is unclear. Given that government bonds from Denmark, Norway and Sweden are close substitutes for euro area sovereign bonds, announcements of non-standard policy measures by the ECB may affect government bond yields in our countries of interest via the portfolio rebalancing channel. We expect that the effect of the portfolio rebalancing channel on government bond yields in our selected countries is negative. The signalling channel also implies a decrease of yields of government bonds from our countries of interest. As discussed earlier, ECB announcements of non-standard monetary policy measures could boost both confidence levels and economic sentiment in the euro area. This could lead to capital outflows from safe haven countries. Denmark, Norway and Sweden can be classified as safe haven countries (IMF 2013b). Capital outflows from these countries induced by the ECB's UMP measures are associated with increasing yields of government bonds from our countries of interest. Furthermore, the exchange rate channel implies an appreciation of the respective currency against the euro. This effect will make Danish, Norwegian and Swedish bonds more expensive for foreign investors. Thus, demand for these bonds will decrease. Hence, an appreciation of the respective currency is associated with increasing yields of government bonds.

Hypothesis 3: Ex ante, the net effect of the ECB's unconventional monetary policies on the prices of non-euro area corporate bonds is ambiguous. In principle, corporate bonds from Denmark, Norway and Sweden could be affected by the ECB's non-standard policy measures via the portfolio rebalancing channel. Yields 
of corporate bonds from Denmark, Norway and Sweden will be affected modestly by ECB UMP measures via the portfolio rebalancing channel if non-standard monetary policy measures only contain purchases of euro area government bonds. Only ECB purchases of euro area corporate bonds would have a visible impact on corporate bond yields in our countries of interest. If the ECB buys only euro area sovereign bonds, yields of corporate bonds from our countries of interest will be mostly unaffected because only a few corporate bond segments from our countries of interest could be considered as close substitutes for euro area government bonds. In principle, the portfolio rebalancing channel implies that the yields of corporate bonds from our countries of interest will decline. Whether the signalling channel could be considered as an important channel in explaining price reactions of foreign corporate bonds depends on whether the prices of euro area corporate bonds react to ECB announcements to keep short-term interest rates down for a longer period. If euro area corporate bonds react to the ECB's commitment to maintain lower interest rates in the future, this will lead to spillovers similar to that mentioned before in the case of the portfolio rebalancing channel. The confidence channel implies that the yields of corporate bonds from our countries of interest may increase. The exchange rate channel also implies increasing corporate bond yields in Denmark, Norway and Sweden due to the related appreciation of the respective domestic currency against the euro.

Hypothesis 4: The net effect of the ECB's non-standard monetary policy measures on CDS spreads in our countries of interest is ambiguous. CDS spreads in our countries of interest could be indirectly affected by the ECB's UMP measures. As mentioned before, the ECB's purchases of euro area government bonds may result in lower yields of sovereign bonds from non-euro area countries if the portfolio rebalancing channel or the signalling channel is at play. Lower yields of government bonds from Denmark, Norway and Sweden may imply an improved debt liability of the respective country. This could result in an improved debt sustainability of these countries. Hence, the probability of default of government bonds from our countries of interest may fall. This process could result in declining CDS spreads in non-euro area countries. If yields of non-euro area government bonds increase due to non-standard monetary policy measures of the ECB, CDS spreads in non-euro area countries will increase. This could be the case if both the confidence channel and the exchange rate channel are the main driver of spillover effects.

Hypothesis 5: The ECB's unconventional monetary policy measures will induce decreasing interbank rates in our countries of interest. The ECB's unconventional monetary policies may affect interbank rates in our countries of interest via the international bank lending channel. A reduction of the interbank rate in the euro area induced by an increase in liquidity may result in a lower demand at the local money market if the presence of foreign-owned banks in the local banking is large enough (Falagiarda et al. 2015). Lower demand at the domestic money markets will lead to declining interbank rates in Denmark, Norway and Sweden.

Hypothesis 6: The net effect of the ECB's non-standard monetary policy measures on equity prices in our countries of interest is ambiguous. Equity prices 
in our countries should be negatively affected by non-standard policy measures conducted by the ECB via the confidence channel and the exchange rate channel, respectively. First, the confidence channel implies a negative impact on equity prices in Denmark, Norway and Sweden. The ECB's non-standard monetary policy measures could lead to both improved confidence and economic outlook in the euro area and thus, ceteris paribus, risky assets from the euro area get more attractive relative to risky assets from our countries of interest. Moreover, improved confidence and economic sentiment in the euro area may be associated with higher expected dividends of euro area equities. Hence, ceteris paribus, euro area equities get more attractive relative to equities from our selected countries. Second, the exchange rate channel induces lower equity prices in our countries of interest. An appreciation of the domestic currency against the euro induced by the ECB's unconventional monetary policies leads to higher equity prices for foreign investors. This results in a lower demand for Danish, Norwegian and Swedish equities and hence lower equity prices. Furthermore, an appreciation of the respective domestic currency against the euro is associated with a reduction of competitiveness of internationally exposed firms. Hence, an appreciation of the respective currency against the euro should weigh on the equity prices of these firms. Though, more available liquidity and lower discount rate expectations due to the ECB's expansionary unconventional monetary policy measures should lead to higher equity prices in non-euro area countries (Bernhard and Ebner 2016).

\section{Event Study Methodology and Empirical Results}

\section{Event Study Methodology}

Our event study analysis, through which we try to detect the spillovers from the ECB's unconventional monetary policies, uses the ordinary least squares estimation. We use Newey-West adjusted standard errors because we have detected autocorrelation by conducting Breusch Pagan LM tests. The Newey-West standard errors are computed by using a non-pre-whitened Bartlett Kernell with a specified bandwidth of eleven. Note, that the bandwidth is equal to one plus the truncation parameter $m=0.75 T^{1 / 3}$, where $T$ represents the included observations. In our regression without controlling for the extent of monetary policy surprise, we estimate the following country specific equation using daily data from 01.01.2008 to 20.05.2016:

$$
\begin{aligned}
& \Delta X_{t}=\alpha+\beta_{1} \Delta I R_{t}^{D o m}+\beta_{2} \Delta I R_{t}^{E C B}+\beta_{3} N S M P_{t}^{D o m}+\delta N S M P_{t}^{E C B}+\gamma N S M P_{t}^{U S}+\beta_{4} \Delta V I X_{t}+ \\
& \beta_{5} \Delta T E D_{t}+\beta_{6} \Delta E U D S_{t}+\varepsilon_{t}
\end{aligned}
$$

where $X_{t}$ is our dependent variable of interest and it represents the change in the following asset prices: the main equity price index, the exchange rate vis-à-vis the euro, medium- and long-term government bond yields, the 3-month interbank rate, 5- and 10-year CDS spreads and the S\&P corporate bond index. The variable 
$I R_{t}^{\text {Dom }}$ reflects the domestic central bank policy rate and $I R_{t}^{E C B}$ stands for the ECB policy rate. The vector $N S M P_{t}^{\text {Dom }}$ is a country specific dummy and contains the announcements of unconventional monetary policies released by the domestic monetary policy authority. $N S M P_{t}^{E C B}$ is our independent variable of interest. This vector is an event-dummy associated with the ECB's announcements of nonstandard monetary policy measures. The event list used in our empirical analysis is based on the list of Falagiarda et al. (2015) and a thorough investigation of statements issued by the ECB. Here we use press conferences and press releases published by the ECB. By including $N S M P_{t}^{U S}$ we control for spillover effects from the FED's announcements of non-standard monetary policies on financial assets from Denmark, Norway and Sweden. The variable VIX is the volatility index for the euro area. With this variable we control for financial turmoil in euro area financial markets. The variable $T E D_{t}$ reflects the ted spread. The ted spread is calculated as the three-month LIBOR rate less the US Treasury bill rate. We control for perceived credit risk in the global economy by including the ted spread in our baseline regressions. The variable $E U D S_{t}$ is the total stock market index for the EU and it controls for market-wide business climate changes in the EU. Furthermore, we introduce two interaction terms in our regression as control variables (Falagiarda et al. 2015). With the first interaction term we control for occasions when the ECB and domestic central banks implemented changes of the policy rates on the same day. Through the inclusion of the second interaction term we control for events when the ECB and domestic central banks adopted nonstandard monetary policy measures on the same day. With the inclusion of these interaction terms, we address the problem of policy endogeneity (Falagiarda et al. 2015).

Furthermore, we estimate our baseline specification relying on a market-based measure of monetary policy surprise. In order to measure the surprise component of the ECB's policy announcements, we interact to our event-dummy associated with ECB announcements of non-standard monetary policy measures with a quantitative measure of monetary policy surprise. Hence, we also estimate the following country specific equation using daily data from 01.01.2008 to 20.05.2016:

$$
\begin{aligned}
& \Delta X_{t}=\alpha+\beta_{1} \Delta I R_{t}^{D o m}+\beta_{2} \Delta I R_{t}^{E C B}+\beta_{3} N S M P_{t}^{D o m}+\delta N S M P_{t}^{E C B} \Delta s_{t}+\gamma N S M P_{t}^{U S}+\beta_{4} \Delta V I X_{t}+ \\
& \beta_{5} \Delta T E D_{t}+\beta_{6} \Delta E U D S_{t}+\varepsilon_{t}
\end{aligned}
$$

where $\Delta s_{t}$ reflects different quantitative measures of monetary policy surprise. In our baseline specification we use the change in longer-term government bond futures (Bernhard and Ebner 2016). Following Bernhard and Ebner (2016), we use the change in 10-year German Bund futures as a market-based measure of monetary policy surprise. An increase in the price of the 10-year German Bund future could be interpreted as a more expansionary monetary policy of the ECB than expected by financial markets. The financial variables used in our regressions 
are defined as follows: the bilateral exchange rate vis-à-vis the euro, the CDS spreads, the stock market indices and the VIX volatility index are expressed as daily percentage changes. The monetary policy rate, the interbank interest rate, government bond yields are expressed as daily percentage point changes. The $\mathrm{S} \& \mathrm{P}$ corporate bond index is defined as daily basis point changes. For the event dummies we use one-day event windows. It seems that international spillovers are likely to have a longer transmission lag compared to the transmission lag of domestically implemented monetary policy to domestic variables (Bernhard and Ebner 2016). Hence, it is justified that we use daily data in order to investigate the impact of the ECB's unconventional monetary policies on financial variables from Denmark, Norway and Sweden.

\section{Spillovers of ECB's Unconventional Monetary Policies}

At first, we discuss the results of our regressions without controlling for monetary policy surprise. Hence, we use the binary dummy variable without interacting it with a market surprise measure. We find spillover effects on financial variables from Denmark, Norway and Sweden. However, our results in Table 1 suggest that only few financial assets were affected by ECB's announcements of non-standard policy measures.

Table 1. Impact of ECB's Announcements of Unconventional Monetary Policy Measures (Regression without Surprise, All Events)

\begin{tabular}{|l|c|c|c|}
\hline \multirow{2}{*}{ Benchmark bond yield (10 y) } & \multicolumn{3}{|c|}{ ECB's Non-standard Monetary Policies } \\
\cline { 2 - 4 } & Sweden & Denmark & Norway \\
\cline { 2 - 4 } & 0.0058 & 0.0020 & $0.0149^{* *}$ \\
\hline \multirow{2}{*}{ Benchmark bond yield (5 y) } & -0.0027 & $-0.0068)$ & $(0.0066)$ \\
\cline { 2 - 4 } & $(0.0062)$ & $(0.0072)$ & 0.0133 \\
\hline \multirow{2}{*}{ Benchmark bond yield (2/3 y) } & -0.0069 & -0.0028 & $(0.0083)$ \\
\cline { 2 - 4 } & $(0.0060)$ & $(0.0081)$ & 0.0062 \\
\hline \multirow{2}{*}{ CDS 10-year (USD) } & 0.0042 & $-0.0203^{* *}$ & $(0.0074)$ \\
\cline { 2 - 4 } & $(0.0107)$ & $(0.0087)$ & -0.0028 \\
\hline \multirow{2}{*}{ CDS 5-year (USD) } & 0.0011 & $-0.0211^{* * *}$ & $(0.0027)$ \\
\cline { 2 - 4 } & $(-0.0097)$ & $(0.0776)$ & -0.0015 \\
\hline \multirow{2}{*}{ Interbank rate (3 M) } & -0.0063 & -0.0004 & $(0.0038)$ \\
\cline { 2 - 4 } & $(0.0075)$ & $(0.0035)$ & 0.0033 \\
\hline \multirow{2}{*}{ Exchange Rate } & -0.0002 & 0.0000 & $(0.0151)$ \\
\cline { 2 - 4 } & $(0.0006)$ & $(0.0000)$ & 0.0004 \\
\hline \multirow{2}{*}{ Stock market index } & $-0.0018^{*}$ & -0.0014 & $(0.0008)$ \\
\cline { 2 - 4 } & $(0.0010)$ & $(0.0011)$ & -0.0021 \\
\hline \multirow{2}{*}{ S\&P Corporate bond index } & 0.0051 & -0.0612 & $-0.0019)$ \\
\cline { 2 - 4 } & $(0.0191)$ & $(0.0459)$ & $(0.0277)$ \\
\hline
\end{tabular}

Note: Newey-West standard errors in parentheses. $* * *, * *$ and $*$ display significance at the $1 \%, 5 \%$ and $10 \%$ level, respectively. 
Announcements of the ECB's unconventional monetary policies were associated with increasing long-term government bond yields in Norway. Thus, the confidence channel could be a prominent channel in explaining the impact of ECB announcements of non-standard measures on 10-year government bond yields from Norway. As mentioned before, the ECB's announcements of UMP measures could operate via the confidence channel. The announcement of ECB programs could lead to improved confidence in the euro area. The return of confidence should be associated with capital outflows from Denmark, Norway and Sweden and hence with increasing government bond yields. It seems that this was the case in Norway because Norwegian 10-year sovereign bond yields increased due to the ECB's announcements of non-standard policy measures.

Moreover, announcements of the ECB's UMP measures were associated with declining CDS spreads in Denmark. Both the Danish 5- and 10-year CDS spreads were affected by the ECB's announcements of non-standard policy measures. Furthermore, the Swedish benchmark stock market index was negatively affected by ECB announcements. In addition, the Norwegian S\&P corporate bond index was negatively influenced by announcements of the ECB's UMP measures. Thus, it seems that both the Swedish stock market index and the Norwegian S\&P corporate bond index were mainly affected by the confidence channel.

We find that the exchange rates of Nordic currencies vis-à-vis the euro were not affected by ECB announcements. Furthermore, we find no impact of ECB announcements of UMP measures on interbank rates in Denmark, Norway and Sweden. Similarly, medium-term government bonds in our countries of interest were not influenced by announcements of the ECB's non-standard policy measures.

Next, we discuss the empirical results of our estimations when controlling for monetary policy surprise. Here, we rely on the daily change in 10-year German Bund futures as a measure for monetary policy surprise. Our results in Table 2 show that significantly more financial variables were affected by the ECB announcements than in our regressions without controlling for monetary policy surprise. Hence, we confirm the result of Bernhard and Ebner (2016), who find that only unexpected changes of monetary policy had a systematic impact on Swiss asset prices. Moreover, our results change considerably when we interact our dummy with the daily change in 10-year German bund futures.

We find that medium- and long-term government bond yields were significantly influenced by surprising ECB announcements of non-standard policy measures. Furthermore, our results suggest that expansionary surprises led to decreasing sovereign bond yields in Denmark, Norway and Sweden. Hence, it seems that surprising ECB announcements of UMP measures could mainly operate via the portfolio rebalancing channel and the signalling channel. Thus, Danish, Norwegian and Swedish government bonds tend to be adequate substitutes for euro area sovereign bonds. 
Table 2. Impact of ECB's Announcements of Unconventional Monetary Policy Measures (Regression with Surprise, All Events)

\begin{tabular}{|l|c|c|c|}
\hline \multirow{2}{*}{ Benchmark bond yield (10 y) } & \multicolumn{3}{|c|}{ ECB's Non-standard Monetary Policies } \\
\cline { 2 - 4 } & Sweden & Denmark & Norway \\
\cline { 2 - 4 } & $-0.0244 * * *$ & $-0.0347 * * *$ & $-0.0196 * * *$ \\
\hline \multirow{2}{*}{ Benchmark bond yield (5 y) } & $-0.0227 * * *$ & $-0.0213 * * *$ & $-0.0222^{* * *}$ \\
\cline { 2 - 4 } & $(0.0041)$ & $(0.0053)$ & $(0.0048)$ \\
\hline \multirow{2}{*}{ Benchmark bond yield (2/3 y) } & $-0.0160 * * *$ & $-0.0279 * * *$ & $-0.0167 * * *$ \\
\cline { 2 - 4 } & $(0.0034)$ & $(0.0059)$ & $(0.0042)$ \\
\hline \multirow{2}{*}{ CDS 10-year (USD) } & 0.0054 & $0.0209 * *$ & 0.0008 \\
\cline { 2 - 4 } & $(0.0068)$ & $(0.0081)$ & $(0.0017)$ \\
\hline \multirow{2}{*}{ CDS 5-year (USD) } & 0.0047 & $0.0154 * *$ & 0.0005 \\
\cline { 2 - 4 } & $(0.0061)$ & $(0.0070)$ & $(0.0021)$ \\
\hline \multirow{2}{*}{ Interbank rate (3 M) } & 0.0035 & 0.0008 & $0.0148 * *$ \\
\cline { 2 - 4 } & $(0.0052)$ & $(0.0025)$ & $(0.0067)$ \\
\hline \multirow{2}{*}{ Exchange Rate } & -0.0004 & 0.0000 & -0.0007 \\
\cline { 2 - 4 } & $(0.0005)$ & $(0.0000)$ & $(0.0005)$ \\
\hline \multirow{2}{*}{ Stock market index } & 0.0011 & 0.0001 & -0.0003 \\
\hline \multirow{2}{*}{ S\&P Corporate bond index } & $(0.0009)$ & $(0.0012)$ & $(0.0013)$ \\
\cline { 2 - 4 } & $0.0568 * * *$ & $0.2038 * * *$ & $0.1150 * * *$ \\
\hline
\end{tabular}

Note: Newey-West standard errors in parentheses. $* * *, * *$ and $*$ display significance at the $1 \%, 5 \%$ and $10 \%$ level, respectively.

Moreover, we show that a positive surprise stemming from ECB announcements was associated with increasing corporate bond indices in our countries of interest. Hence, declining medium- and long-term government bond yields transmitted to corporate bond yields. However, our results may also suggest that corporate bonds from Denmark, Norway and Sweden were affected by surprising ECB UMP measures via the portfolio rebalancing channel. Furthermore, we find that CDS spreads in Denmark were significantly influenced by our monetary surprise variable. Our results show that ECB announcements led to increasing CDS spreads in Denmark, which is at odds with our theoretical considerations. As mentioned before, the ECB's announcements should affect CDS spreads indirectly via their impact on government bond yields. We have argued that declining sovereign bond yields due to the ECB's announcements of non-standard policy measures may lead to decreasing CDS spreads because lower yields of government bonds could imply an improved debt liability of a country. Our results also show that CDS spreads in Norway and Sweden were not affected by surprising ECB announcements of unconventional monetary policies.

In addition, we find that the ECB's announcements of non-standard policy measures had a positive statistically significant impact on the 3-month money market rate in Norway. Hence, this result stands in contradiction to the impact of 
the international bank lending channel on the 3-month interest rate. We have argued before, that the ECB's announcements should lead to increasing 3-month interbank rates in Denmark, Norway and Sweden via the international bank lending channel. Furthermore, we find no impact of ECB announcements on the 3month money market rates in Denmark and Sweden, respectively. We find that the exchange rates of Nordic currencies vis-à-vis the euro were not affected by the ECB announcements. All coefficients are not statistically significant. Moreover, benchmark stock indices in Denmark, Norway and Sweden were not influenced by the ECB's non-standard policy measures.

\section{Spillovers of Systematic Unconventional Monetary Policies}

In this section we study the impact of systematic measures of the ECB's unconventional monetary policies on our selected financial variables. During the last number of years, the ECB announced and implemented various unconventional monetary policy measures. Each non-standard measure had different objectives and thus could result in qualitatively and quantitatively different monetary spillover effects to our selected countries (Falagiarda et al. 2015). In particular, we investigate the impact of the ECB's announcements related to SMP, OMT, FWG, PSPP and CSPP on financial variables from Denmark, Norway and Sweden. Hence, we estimate our baseline specification over the whole sample with systemized $N S M P_{t}^{E C B}$ variables.

The results in Table 3 show that SMP announcements exert the strongest impact on financial variables from Norway. Almost all selected Norwegian financial assets were statistically significantly affected by announcements related to SMP. In contrast, SMP announcements had only modest effects on financial assets from Sweden. Moreover, our results indicate that cross-country heterogeneity exists. For instance, we find that SMP announcements were associated with declining government bond yields in Denmark, whereas Norwegian government bond yields increased due to SMP announcements.

Our results in Table 3 show that events related to SMP announcements influenced sovereign bond yields in Denmark and Norway, respectively. Whereas Swedish government bonds were not affected by SMP announcements. Our results suggest that in the case of Danish 5- and 10-year government bonds, the portfolio rebalancing channel outweighed the impact of the confidence channel and the exchange rate channel. Hence, SMP announcements led to declining 5- and 10year government bond yields in Denmark. In contrast to that, SMP announcements were associated with increasing 5- and 10-year government bond yields in Norway. Hence, the impact of the portfolio rebalancing channel was offset by the effects of the confidence channel and exchange rate channel on Norwegian sovereign bond yields. 
Table 3. Impact of ECB's Announcements of Unconventional Monetary Policy Measures (Regression without Surprise, SMP)

\begin{tabular}{|l|c|c|c|}
\hline \multirow{2}{*}{ Benchmark bond yield (10 y) } & \multicolumn{3}{|c|}{ SMP } \\
\cline { 2 - 4 } & Sweden & Denmark & Norway \\
\cline { 2 - 4 } & 0.0501 & $-0.0451^{* * *}$ & $0.1104^{* * *}$ \\
\hline \multirow{2}{*}{ Benchmark bond yield (5 y) } & $0.0338)$ & $(0.0059)$ & $(0.0198)$ \\
\cline { 2 - 4 } & $(0.0380)$ & $-0.0339^{* * *}$ & $0.0853^{* * *}$ \\
\hline \multirow{2}{*}{ Benchmark bond yield (2/3 y) } & -0.0233 & -0.0140 & $(0.0093)$ \\
\cline { 2 - 4 } & $(0.0437)$ & $(0.0184)$ & 0.0148 \\
\hline \multirow{2}{*}{ CDS 10-year (USD) } & 0.0064 & $-0.0312^{*}$ & $-0.0173)$ \\
\cline { 2 - 4 } & $(0.0529)$ & $(0.0166)$ & $(0.0063)$ \\
\hline \multirow{2}{*}{ CDS 5-year (USD) } & 0.0040 & $-0.0417^{* *}$ & -0.0133 \\
\cline { 2 - 4 } & $(0.0649)$ & $(0.0162)$ & $(0.0100)$ \\
\hline \multirow{2}{*}{ Interbank rate (3 M) } & 0.0220 & -0.0013 & $0.0777^{* * *}$ \\
\cline { 2 - 4 } & $(0.0136)$ & $(0.0039)$ & $(0.0210)$ \\
\cline { 2 - 4 } Exchange Rate & -0.0057 & 0.0000 & $-0.0049^{* * *}$ \\
\cline { 2 - 4 } & $(0.0041)$ & $(0.0001)$ & $(0.0010)$ \\
\cline { 2 - 4 } Stock market index & $-0.0089^{* * * *}$ & 0.0045 & $-0.0137 * * *$ \\
\hline \multirow{2}{*}{ S\&P Corporate bond index } & $(0.0012)$ & $(0.0037)$ & $(0.0007)$ \\
\cline { 2 - 4 } & $0.1226^{*}$ & $0.2983^{* *}$ & $-0.1526^{* * *}$ \\
\hline \multirow{2}{*}{ Note: Newey-West standard errors } & $(0.0733)$ & $(0.1470)$ & $(0.0581)$ \\
\hline
\end{tabular}

Note: Newey-West standard errors in parentheses. $* * *, * *$ and $*$ display significance at the $1 \%, 5 \%$ and $10 \%$ level, respectively.

Furthermore, SMP announcements had a significant impact on CDS spreads in Denmark and Norway. SMP announcements led to decreasing CDS spreads in Denmark and Norway. Hence, declining government bond yields transmitted to decreasing CDS spreads in the case of Denmark but not in the case of Norway. SMP related announcements increased the Danish S\&P corporate bond index whereas the Norwegian S\&P corporate bond index decreased due to SMP announcements. Hence, declining government bond yields transmitted to decreasing corporate bond yields in Denmark. In the case of Norway, increasing sovereign bond yields resulted in rising corporate bond yields. Moreover, our results suggest that the Swedish S\&P corporate bond index was not affected by SMP announcements. Furthermore, we find that SMP announcements appreciated the Norwegian krone against the euro. This result confirms our notion that the ECB's unconventional monetary policy measures were associated with appreciations of local currencies vis-à-vis the euro. However, we find no impact of SMP announcements on exchange rates vis-à-vis the euro in Denmark and Sweden.

Benchmark stock market indices were negatively affected by SMP announcements in Sweden and Norway. Hence, the negative response of Norwegian and Swedish equity prices suggest that in both countries the confidence channel and the exchange rate channel outweighed the positive impact of the portfolio rebalancing channel. We find no statistically significant effect of SMP-related announcements on the Danish benchmark stock market index. 
Moreover, we find that SMP announcements led to an increase of the 3-month interest rate in Norway. Our results also suggest that the 3-month interbank rate was not affected by SMP announcements in Denmark and Sweden, respectively.

Table 4. Impact of ECB's Announcements of Unconventional Monetary Policy Measures (Regression without Surprise, OMT)

\begin{tabular}{|l|c|c|c|}
\hline \multirow{2}{*}{ Benchmark bond yield (10 y) } & \multicolumn{2}{|c|}{ OMT } \\
\cline { 2 - 4 } & Sweden & Denmark & Norway \\
\cline { 2 - 4 } & -0.0186 & -0.0064 & -0.0136 \\
\hline \multirow{2}{*}{ Benchmark bond yield (5 y) } & -0.0152 & 0.0084 & $(0.0088)$ \\
\cline { 2 - 4 } & $(0.0257)$ & $(0.0144)$ & $-0.0316^{*}$ \\
\hline \multirow{2}{*}{ Benchmark bond yield (2/3 y) } & -0.0155 & 0.0015 & $(0.0183)$ \\
\cline { 2 - 4 } & $(0.0178)$ & $(0.0212)$ & $-0.0224^{* *}$ \\
\hline \multirow{2}{*}{ CDS 10-year (USD) } & 0.0004 & -0.0079 & $(0.0092)$ \\
\cline { 2 - 4 } & $(0.0056)$ & $(0.0093)$ & -0.0114 \\
\hline \multirow{2}{*}{ CDS 5-year (USD) } & -0.0014 & -0.0102 & $(0.0070)$ \\
\cline { 2 - 4 } & $(0.0079)$ & $(0.0122)$ & 0.0018 \\
\hline \multirow{2}{*}{ Interbank rate (3 M) } & $0.0556^{* * *}$ & 0.0030 & $(0.0116)$ \\
\cline { 2 - 4 } & $(0.0142)$ & $(0.0026)$ & -0.0024 \\
\hline \multirow{2}{*}{ Exchange Rate } & 0.0004 & 0.0001 & $(0.0134)$ \\
\cline { 2 - 4 } & $(0.0020)$ & $(0.0001)$ & $0.0076^{* * *}$ \\
\hline \multirow{2}{*}{ Stock market index } & -0.0067 & $-0.0052^{*}$ & $(0.0022)$ \\
\cline { 2 - 4 } & $(0.0042)$ & $(0.0032)$ & $-0.0077^{* *}$ \\
\hline \multirow{2}{*}{ S\&P Corporate bond index } & $0.0773^{* *}$ & 0.0393 & $(0.0038)$ \\
\cline { 2 - 4 } & $(0.0349)$ & $(0.0665)$ & 0.0506 \\
\hline
\end{tabular}

Note: Newey-West standard errors in parentheses. $* * *, * *$ and $*$ display significance at the $1 \%, 5 \%$ and $10 \%$ level, respectively.

The empirical results reported in Table 4 indicate that announcements related to OMT exerted weak spillover effects on financial assets from Denmark, Norway and Sweden. Few financial variables were statistically significantly influenced by OMT announcements. In particular, we find that medium-term government bond yields were negatively affected by OMT announcements in Norway. It was expected that OMT announcements should lead to rising sovereign bond yields in Denmark, Norway and Sweden. However, our results indicate the opposite, namely that OMT announcements led to declining medium-term sovereign yields in Norway. Thus, it could be that the portfolio channel and signalling channel outweighed the negative impact of the confidence channel on government bond yields. Nevertheless, our results indicate that the confidence channel was not a prominent channel in explaining how OMT announcements spilled over to Norwegian medium-term government bonds.

As expected, OMT announcements led to a depreciation of local currencies vis-à-vis the euro. However, only the Norwegian krone was statistically 
significantly affected by OMT announcements. Moreover, we find that OMT announcements led to decreasing equity prices in Denmark and Norway. Hence, we conclude that the Danish and Norwegian benchmark stock market indices were influenced by OMT announcements mainly via the confidence channel. Furthermore, we conclude that in the case of Norwegian equities, the confidence channel outweighed the positive impact of the depreciation of the Norwegian krone. We also find that OMT-related announcements affected the Swedish S\&P corporate bond index positively. Moreover, OMT announcements increased the 3month interbank rate in Sweden

Table 5. Impact of ECB's Announcements of Unconventional Monetary Policy Measures (Regression without Surprise, PSPP)

\begin{tabular}{|l|c|c|c|}
\hline \multirow{2}{*}{ Benchmark bond yield (10 y) } & \multicolumn{3}{|c|}{ PSPP } \\
\cline { 2 - 4 } & Sweden & Denmark & Norway \\
\cline { 2 - 4 } & -0.0142 & $-0.0337 * *$ & -0.0226 \\
\hline \multirow{2}{*}{ Benchmark bond yield (5 y) } & $-0.0120)$ & $(-0.0159)$ & $(0.0185)$ \\
\cline { 2 - 4 } & $(0.0075)$ & -0.0160 & -0.0077 \\
\hline \multirow{2}{*}{ Benchmark bond yield (2/3 y) } & 0.0023 & $-0.0117)$ & $(0.0155)$ \\
\cline { 2 - 4 } & $(0.0040)$ & $(0.0159)$ & -0.0053 \\
\hline \multirow{2}{*}{ CDS 10-year (USD) } & 0.0004 & 0.0278 & $(0.0116)$ \\
\cline { 2 - 4 } & $(0.0023)$ & $(0.0230)$ & -0.0005 \\
\hline \multirow{2}{*}{ CDS 5-year (USD) } & 0.0015 & 0.0149 & $(0.0017)$ \\
\cline { 2 - 4 } & $(0.0025)$ & $(0.0213)$ & -0.0016 \\
\hline \multirow{2}{*}{ Interbank rate (3 M) } & 0.0027 & $0.0113 * * *$ & $0.0030)$ \\
\cline { 2 - 4 } & $(0.0121)$ & $(0.0030)$ & $(0.0016$ \\
\hline \multirow{2}{*}{ Exchange Rate } & -0.0013 & 0.0001 & 0.0021 \\
\cline { 2 - 4 } & $(0.0015)$ & $(0.0002)$ & $(0.0015)$ \\
\hline \multirow{2}{*}{ Stock market index } & -0.0012 & -0.0006 & -0.0003 \\
\cline { 2 - 4 } & $(0.0036)$ & $(0.0027)$ & $(0.0056)$ \\
\hline \multirow{2}{*}{ S\&P Corporate bond index } & 0.0078 & $-0.0509 *$ & 0.0514 \\
\cline { 2 - 4 } & $(0.0230)$ & $(0.0281)$ & $(0.0600)$ \\
\hline
\end{tabular}

Note: Newey-West standard errors in parentheses. $* * *, * *$ and $*$ display significance at the $1 \%, 5 \%$ and $10 \%$ level, respectively.

PSPP announcements resulted in limited spillover effects on financial assets from Denmark, Norway and Sweden (see Table 5). In the case of Norway and Sweden, no statistically significant coefficient has been found. Events related to the announcements regarding PSPP resulted in limited spillover effects on financial variables from Denmark. We find that PSPP announcements decreased long-term government bond yields in Denmark. Hence, Danish long-term government bond yields were mainly affected by PSPP announcements via the portfolio rebalancing channel. Moreover, our results in Table 5 suggest that PSPP announcements decreased the Danish S\&P corporate bond index. We also show 
that PSPP announcements were associated with an increase of the 3-month interest rate in Denmark.

Table 6. Impact of ECB's Announcements of Unconventional Monetary Policy Measures (Regression without Surprise, CSPP)

\begin{tabular}{|l|c|c|c|}
\hline \multirow{2}{*}{ Benchmark bond yield (10 y) } & \multicolumn{3}{|c|}{ CSPP } \\
\cline { 2 - 4 } & Sweden & Denmark & Norway \\
\cline { 2 - 4 } & $0.0518^{*}$ & $0.0703^{* * *}$ & 0.0270 \\
\hline \multirow{2}{*}{ Benchmark bond yield (5 y) } & $0.0360^{* * *}$ & $(0.0148)$ & $(0.0269)$ \\
\cline { 2 - 4 } & $(0.0112)$ & $(0.0172)$ & $(-0.01250)$ \\
\hline \multirow{2}{*}{ Benchmark bond yield (2/3 y) } & $0.0294^{* *}$ & $0.0634^{* * *}$ & $0.0106^{*}$ \\
\cline { 2 - 4 } & $(0.0123)$ & $(0.0196)$ & $(0.0055)$ \\
\hline \multirow{2}{*}{ CDS 10-year (USD) } & -0.1571 & -0.1160 & $-0.0022^{* *}$ \\
\cline { 2 - 4 } & $(0.1124)$ & $(0.0855)$ & $(0.0010)$ \\
\hline \multirow{2}{*}{ CDS 5-year (USD) } & -0.1130 & -0.0823 & -0.0022 \\
\cline { 2 - 4 } & $(0.0807)$ & $(0.0620)$ & $(0.0014)$ \\
\hline \multirow{2}{*}{ Interbank rate (3 M) } & 0.0200 & -0.0063 & $0.0158^{* * *}$ \\
\cline { 2 - 4 } & $(0.0176)$ & $(0.0067)$ & $(0.0034)$ \\
\hline \multirow{2}{*}{ Exchange Rate } & 0.0006 & $-0.0003 * * *$ & $-0.0077 * * *$ \\
\hline \multirow{2}{*}{ Stock market index } & $(0.0021)$ & $(0.0000)$ & $(0.0025)$ \\
\hline \multirow{2}{*}{ S\&P Corporate bond index } & $-0.0048^{* *}$ & 0.0029 & 0.0057 \\
\cline { 2 - 4 } & $(0.0021)$ & $(0.0069)$ & $(0.0040)$ \\
\cline { 2 - 4 } & -0.0779 & $-0.6789 * * *$ & $-0.2061^{* *}$ \\
\hline
\end{tabular}

Note: Newey-West standard errors in parentheses. ${ }^{* * *}, * *$ and $*$ display significance at the $1 \%, 5 \%$ and $10 \%$ level, respectively.

CSPP announcements affected sovereign bond yields in Denmark, Norway and Sweden. Our results in Table 6 suggest however that long-term government bond yields in Norway were not influenced by CSPP announcements. In contrast to PSPP announcements, announcements related to CSPP led to rising mediumand long-term government bond yields. Hence, the response of government bond yields to CSPP announcements suggest that the exchange rate channel and confidence channel outweighed the impact on sovereign bond yields through the portfolio rebalancing channel and signalling channel. Moreover, we find that increasing government bond yields transmitted to declining S\&P corporate bond indices in Denmark and Norway. Hence, this transmission channel outweighed the effect on corporate bond yields via the portfolio rebalancing channel.

Furthermore, CSPP announcements were associated with declining benchmark stock market indices in Denmark and Norway. Thus, it seems that CSPP announcements spilled over to Danish and Norwegian equities mainly via the confidence channel and exchange rate channel. It seems that CSPP announcements led to improved confidence and economic sentiment in the euro area and hence to 
declining equity prices in Denmark and Norway. Furthermore, it seems that the exchange rate channel induced lower equity prices in Denmark and Norway as in our findings CSPP announcements were associated with decreasing exchange rates in Denmark and Norway. As mentioned before, appreciation of the local currencies vis-à-vis the euro is associated with declining domestic equity prices. We also find that CSPP announcements influenced CDS spreads in Norway and affected the three-month interbank rate in Norway.

So far, we have analysed the international spillover effects of the ECB's unconventional monetary policy measures associated with asset purchases. Now, we turn to the effects of the ECB's forward guidance on financial assets from Denmark, Norway and Sweden. Forward guidance is not associated with the purchases of assets. With forward guidance, the ECB specifies the future path of short-term interest rates. Hence, we expect that FWG announcements mainly operated via the signalling channel.

Table 7. Impact of ECB's Announcements of Unconventional Monetary Policy Measures (Regression without Surprise, FWG Statements)

\begin{tabular}{|l|c|c|c|}
\hline \multirow{2}{*}{ Benchmark bond yield (10 y) } & \multicolumn{3}{|c|}{ FWG } \\
\cline { 2 - 4 } & Sweden & Denmark & Norway \\
\cline { 2 - 4 } & $-0.0462^{* * *}$ & -0.0201 & $-0.0134 * * *$ \\
\hline \multirow{2}{*}{ Benchmark bond yield (5 y) } & $-0.0485^{* * *}$ & $-0.0362^{* * *}$ & $-0.0200^{* * *}$ \\
\cline { 2 - 4 } & $(0.0032)$ & $(-0.0130)$ & $(0.0023)$ \\
\hline \multirow{2}{*}{ Benchmark bond yield (2/3 y) } & $-0.0359 * * *$ & $-0.0324 * * *$ & $-0.0223^{* *}$ \\
\cline { 2 - 4 } & $(0.0036)$ & $(0.0055)$ & $(0.0104)$ \\
\hline \multirow{2}{*}{ CDS 10-year (USD) } & $0.0099^{* * *}$ & -0.0671 & $0.0556^{*}$ \\
\cline { 2 - 4 } & $(0.0028)$ & $(0.0633)$ & $(0.0284)$ \\
\hline \multirow{3}{*}{ CDS 5-year (USD) } & $0.0115^{* * *}$ & -0.0376 & $0.0914 *$ \\
\cline { 2 - 4 } & $(0.0033)$ & $(0.0552)$ & $(0.0480)$ \\
\hline \multirow{2}{*}{ Interbank rate (3 M) } & $-0.0339^{* *}$ & $0.0055^{* * *}$ & -0.0036 \\
\cline { 2 - 4 } & $(0.0148)$ & $(0.0013)$ & $(0.0070)$ \\
\hline \multirow{2}{*}{ Exchange Rate } & $-0.0016^{*}$ & $-0.0001 * * *$ & $0.0034 * *$ \\
\cline { 2 - 4 } & $(0.0009)$ & $(0.0000)$ & $(0.0014)$ \\
\hline \multirow{2}{*}{ Stock market index } & $0.0031^{* * *}$ & $0.0120^{* * *}$ & $0.0056^{*}$ \\
\cline { 2 - 4 } & $(0.0004)$ & $(0.0042)$ & $(0.0030)$ \\
\hline \multirow{2}{*}{ S\&P Corporate bond index } & $0.1418^{* * *}$ & 0.2627 & $0.2816^{* * *}$ \\
\cline { 2 - 4 } & $(0.0500)$ & $(0.1742)$ & $(0.1028)$ \\
\hline
\end{tabular}

Note: Newey-West standard errors in parentheses. $* * *, * *$ and $*$ display significance at the $1 \%, 5 \%$ and $10 \%$ level, respectively.

Announcements related to FWG resulted in pronounced spillover effects to financial assets from our countries of interest (see Table 7). FWG announcements affected long-term government bond yields in Norway and Sweden. Moreover, FWG announcements influenced medium-term sovereign bond yields in our 
countries of interest. As expected, medium- and long-term government bond yields were mainly affected by the signalling channel because FWG announcements were associated with decreasing government bond yields. In addition, declining government bond yields transmitted to increasing S\&P corporate bond indices in Norway and Sweden. As expected, FWG announcements led to increasing benchmark stock market indices in our countries of interest.

Furthermore, we find that FWG announcements coincided with a declining 3month interest rate in Sweden, while the FWG announcements led to an increasing 3-month interbank rate in Denmark. Hence, our results suggest that the 3-month interbank rate in Sweden was influenced by FWG announcements via the international bank lending channel. As argued before, FWG announcements were associated with an appreciation of local currencies vis-à-vis the euro in Sweden and Denmark, while FWG announcements depreciated the Norwegian krone against the euro. Finally, we find that FWG announcements affected CDS spreads in Norway and Sweden.

\section{Conclusion}

This study investigates the spillover effects of the ECB's unconventional monetary policies on small, open advanced economies. In particular, we study whether ECB announcements of non-standard monetary policies spilled over to Denmark, Norway and Sweden. We find that the ECB's announcement of unconventional monetary policies exerted substantial spillover effects on financial assets in Denmark, Norway and Sweden. In particular, the unexpected part of the ECB's non-standard policies influenced asset prices in our countries of interest.

Using a broad event set and the daily change in 10-year German Bund futures as a measure for monetary policy surprise, we show that the ECB's announcements of UMP measures resulted in substantial spillover effects of asset prices in Denmark, Norway and Sweden. The ECB's announcement of UMP measures spilled over to our countries of interest irrespective of the respective exchange rate regime. Specifically, the ECB's announcements led to declining government bond yields and increasing corporate bond indices. Hence, our results indicate that ECB announcements affected sovereign bond yields and corporate bond yields via the portfolio rebalancing channel. Hence, it seems that long- and medium-term government bonds from Denmark, Norway and Sweden are close substitutes for medium- and long-term euro area government bonds. Additionally, declining sovereign bond yields transmitted to decreasing corporate bond yields. Moreover, we find that CDS spreads in Denmark and the interbank rate in Norway were influenced by the ECB's announcement of non-standard policy measures, respectively. Our results also indicate that bilateral exchange rates and benchmark stock market indices were not affected by the ECB's announcements.

Turning to specific non-standard monetary policies of the ECB, we show that SMP announcements, CSPP announcements and forward guidance resulted in pronounced spillover effects on financial assets in Denmark, Norway and Sweden. SMP announcements in particular affected government bond yields and corporate 
bond indices. Moreover, our results indicate that asset prices in Norway were strongly influenced by SMP announcements. CSPP announcements resulted in pronounced spillover effects on government bonds, corporate bond indices and bilateral exchange rates vis-à-vis the euro. We argue that SMP announcements operated via both the portfolio rebalancing channel and the confidence channel, while CSPP influenced asset prices mainly via the confidence channel and the exchange rate channel. Statements regarding forward guidance had the most pronounced effects on asset prices in Denmark, Norway and Sweden. In particular, long- and medium-term government bond yields, stock prices and bilateral exchange rates vis-à-vis the euro were affected by FWG statements. Our results also indicate that FWG statements mainly operated via the signalling channel.

Furthermore, we find that OMT and PSPP announcements had limited spillover effects on financial assets in Denmark, Norway and Sweden. OMT announcements mainly influenced benchmark stock indices and operated via both the confidence channel and signalling channel. PSPP announcements only affected asset prices in Denmark. PSPP announcements led to declining government bond yields, decreasing corporate bond yields and increasing interbank rate in Denmark.

Our study could be extended by conducting a formal analysis of the spillover channels. With our empirical approach we could only tentatively identify the international transmission channels of the ECB's non-standard policy measures. Furthermore, the size of the spillover effects induced by the ECB's announcements of UMP measures could be compared with the effects of domestic non-standard monetary policies. An additional extension of the study could be to quantify spillover effects on macroeconomic variables in Denmark, Norway and Sweden.

\section{References}

Abbassi P, Linzert T (2012) The Effectiveness of Monetary Policy in steering Money Market Rates during the Financial Crisis. Journal of Macroeconomics 34(4): 945-954.

Altavilla C, Giannone D (2014) The Effectiveness of Non-standard Monetary Policy Measures: Evidence from Survey Data. ECARES Working Papers (2014-30).

Andrade P, Breckenfelder J, De Fiore F, Karadi P, Tristani O (2016) The ECB's Asset Purchase Programme: An Early Assessment. ECB Working Paper Series (1956).

Angelini P, Nobili A, Picillo C (2011) The Interbank Market after August 2007: What has changed, and why? Journal of Money, Credit and Banking 43(5): 923-958.

Baumeister C, Benati L (2013) Unconventional Monetary Policy and the Great Recession: Estimating the Impact of a Compression in the Yield Spread at the Zero Lower Bound. ECB Working Paper Series (1258).

Berge T, Cao G (2014) Global Effects of U.S. Monetary Policy: Is Unconventional Policy Different? Economic Review (Q I): 1-10.

Bernhard S, Ebner T (2016) Cross-border Spillover Effects of Unconventional Monetary Policies on Swiss Asset Prices. SNB Working Papers (9/2016).

Bluwstein K, Canova F (2016) Beggar-Thy-Neighbor? The International Effects of ECB Unconventional Monetary Policy Measures. International Journal of Central Banking 12(3): 69-120.

Chen H, Cúrdia V, Ferrero A (2012) The Macroeconomic Effects of Large-scale Asset Purchase Programmes. The Economic Journal 122(564): 289-315. 
Chinn MD (2013) Global Spillovers and Domestic Monetary Policy. BIS Working Papers (436).

Diez FJ, Presno I (2014) Domestic and Foreign Announcements on Unconventional Monetary Policy and Exchange Rates. Public Policy Briefs (13-7). Federal Reserve Bank of Boston.

Falagiarda M, McQuade P, Tirpák M (2015) Spillovers from the ECB's Non-standard Monetary Policies on Non-euro area EU Countries: Evidence from an Event-study Analysis. ECB Working Paper Series (1869).

Fratzscher M, Lo Duca M, Straub R (2013) On the International Spillovers of US Quantitative Easing. ECB Working Paper Series (1557).

Fratzscher M, Lo Duca M, Straub R (2014) ECB Unconventional Monetary Policy Actions: Market Impact, International Spillovers and Transmission Channels. Paper presented at the $15^{\text {th }}$ Jacques Polak Annual Research Conference hosted by the International Monetary Fund.

Gagnon J, Raskin M, Remache J, Sack B (2011) The Financial Market Effects of the Federal Reserve's Large-scale Asset Purchases. International Journal of Central Banking 7(1): 3-43.

Gambetti L, Musso A (2017) The Macroeconomic Impact of the ECB's Expanded Asset Purchase Programme (APP). ECB Working Paper Series (2075).

Georgiadis G, Gräb J (2015) Global Financial Market Impact of the Announcement of the ECB's Extended Asset Purchase Programme, Globalization and Monetary Policy Institute Working Paper (232). Federal Reserve Bank of Dallas.

Ghysels E, Idier J, Manganelli S, Vergote O (2013) A High Frequency Assessment of the ECB Securities Markets Programme. SSRN Scholarly Paper ID 2365833, Social Science Research Network, Rochester, NY.

Glick R, Leduc S (2012) Central Bank Announcements of Asset Purchases and the Impact on Global Financial and Commodity Markets. Journal of International Money and Finance 31(8): 2078-2101.

Glick R, Leduc S (2015) Unconventional Monetary Policy and the Dollar: Conventional Signs, Unconventional Magnitudes. Working Paper Series (2015-18), Federal Reserve Bank of San Francisco.

Hume M, Sentance A (2009) The Global Credit Boom: Challenges for Macroeconomics and Policy. Journal of International Money and Finance 28(8): 1426-1461.

International Monetary Fund (IMF) (2013a) Global Impact and Challenges of Unconventional Monetary Policies. IMF Policy Paper.

International Monetary Fund (IMF) (2013b) Nordic Regional Report - Staff Report for the 2013 Cluster Consultation. IMF Country Report (13/274).

Krishnamurthy A, Vissing-Jorgensen A (2011) The Effects of Quantitative Easing on Interest Rates: Channels and Implications for Policy. NBER Working Papers (17555).

Krishnamurthy A, Nagel S, Vissing-Jorgensen A (2014) ECB Policies involving Government Bond Purchases: Impact and Channels. Unpublished Manuscript.

Lewis V, Roth M (2015) Financial Market Effects of ECB's Balance Sheet Policies. Technical report, Bundesbank.

Neely CJ (2015) Unconventional Monetary Policy had Large International Effects. Journal of Banking \& Finance 52(C): 101-111.

Peersman G (2012) Effectiveness of Unconventional Monetary Policy at the Zero Lower Bound. Meeting Paper (400), Society for Economic Dynamics.

Potjagailo G (2016) Spillover Effects from Euro Area Monetary Policy across the EU: A Factor-Augmented VAR Approach. Kiel Working Paper (2033).

Takátas E, Vela A (2014) International Monetary Policy Transmission. BIS Papers (78). 


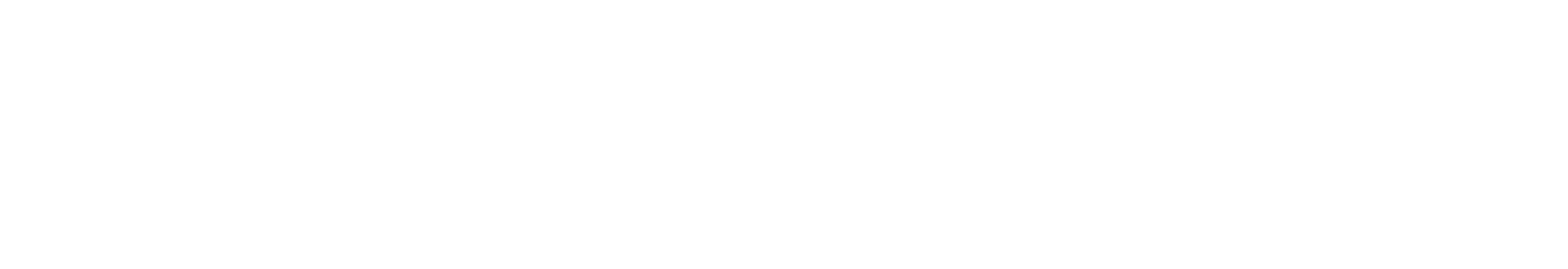




\title{
Monetary Policy Transmission in the Euro Zone
}

\author{
By Ayla Ŏguş Binatli \\ Niloufer Sohrabji ${ }^{\dagger}$
}

\begin{abstract}
This paper focuses on monetary policy transmission through the bank lending channel in the euro zone. We analyze the relationship between output, inflation, short-term and longterm interest rates, and bank loans. In addition, based on recent concerns of rising deficits and debt we include three variables that capture fiscal vulnerability. Using quarterly data from 2002 to 2016 for the original twelve members of the euro zone (Austria, Belgium, Finland, France, Germany, Greece, Ireland, Italy, Luxembourg, Netherlands, Portugal, and Spain) we estimate a panel vector autoregression and examine impulse responses and variance decompositions. Our results show that tight monetary policy leads to an expected decline in output, but surprisingly, raises prices. We also find that the high deficits and debt burdens affect monetary policy transmission for the euro zone-12 countries. Overall, our results suggest that the euro zone is at best, only partially functioning as a cohesive unit.
\end{abstract}

Keywords: Bank Lending, Eurozone, Monetary Policy Transmission, Panel VAR.

\section{Introduction}

A significant concern for central banks is the transmission effect of monetary policy on the macro-economy such as output or unemployment. This paper analyzes monetary policy transmission for the original twelve euro zone members (Austria, Belgium, Finland, France, Germany, Greece, Ireland, Italy, Luxembourg, Netherlands, Portugal and Spain) referred to as euro zone-12. We address two main questions: How has monetary policy impacted output and inflation in the euro zone since the introduction of the euro? Do high deficits and debt burdens affect monetary policy transmission in the euro zone? Through addressing these questions we shed light on the effectiveness in monetary policy transmission since the introduction of the euro.

Monetary policy transmission has been studied for euro zone countries but our work differs from the literature in a few ways. First, we focus on the banklending channel of monetary policy transmission which has been studied significantly in the literature, but not in the context of the euro zone. Secondly, we use a panel approach to study the euro zone as a group. Finally, we add fiscal indicators to the empirical analysis to capture if, and how, monetary policy transmission is affected by countries breaching the established thresholds outlined in the Maastricht Treaty.

Using quarterly data from 2002 to 2016 for the euro zone-12 countries we estimate a panel VAR and analyze the impulse response function and the variance

${ }^{*}$ Professor, Department of Economics, Izmir University of Economics, Turkey.

${ }^{\dagger}$ Associate Professor, Department of Economics, Simmons University, USA. 
decomposition results. Our panel result shows that positive shocks to short-term interest rate lead to falling output and unexpectedly, rising prices. We also find that a "large" deficits and debt affect monetary policy transmission for the euro zone-12 countries. A comparative analysis of our results with earlier work leads us to conclude that euro zone is at best, only partially functioning as a cohesive unit

The paper is organized as follows: the next section provides a background on monetary policy transmission in the euro zone which is followed by a discussion of the relevant literature. The section after that provides the framework for examining monetary policy transmission which is followed by an analysis the results. The last section concludes.

\section{Monetary Policy Transmission in the Euro zone}

The monetary policy transmission mechanism seeks to identify the impact of monetary policy on output and unemployment. There are different channels of monetary policy transmission including the interest rate channel and the bank lending channel. ${ }^{2}$ In the case of the interest rate channel, monetary policy impacts the short-term interest rate which affects the long-term interest rate and finally leading to higher costs for firms and thus a decline in output (Ireland 2005). According to Angeloni et al. (2002), the interest channel is significant for European countries. Another channel is bank lending which has been emphasized by Bernanke and Blinder (1992) and Kashyap and Stein (1995) in the U.S. and Hülsewig et al. (2004) for Germany. In this view tight monetary policy which reduces bank deposits, leads to cuts in bank lending and ultimately hurts output (Ireland 2005). We do not address the debate of the relative importance of different channels in monetary policy transmission. Rather we focus on the bank lending channel which is widely studied in the literature, although, not in the context of the euro zone.

Analyzing monetary policy transmission in the euro zone is especially challenging because the European Central Bank (ECB) must coordinate policy for a heterogeneous group of countries. Even once the policy is formulated, diverse conditions in member countries can lead to differential impacts of monetary policy. In addition to economic differences, Cecchetti (1999) argues that variations in financial structures due to legal differences are another reason why euro zone countries may be affected differently by monetary policy.

The creation of a monetary union was expected to reduce this asymmetry. Angeloni and Ehrmann (2003) examine monetary policy transmission since the European Monetary Union was established by which they mean the "entire process of preparation and introduction of the single currency" (p. 6). By examining banking systems, "cross-border banking penetration" and "effect of monetary impulses on lending and deposit interest rates" (p. 7) and financial

\footnotetext{
${ }^{1}$ Large is defined using the Maastricht Treaty threshold of 3\% and 60\% for deficits and debt respectively.

${ }^{2} \mathrm{We}$ discuss two most common channels here, but there are others as well including exchange rates, asset prices, and balance sheet discussed more carefully by Ireland (2005).
} 
markets (real interest rates and equity prices) they conclude that there is some convergence in responses to monetary policy in euro zone countries since the creation of the union. We analyze the asymmetry question by estimating the monetary policy transmission since the euro was introduced in 2001.

In addition, our paper incorporates another challenge in monetary policy transmission, high deficits and debt burdens. As set up by the Maastricht Treaty, countries had to meet two fiscal standards to qualify to become members of the euro zone namely, budget deficit must not exceed 3\% of GDP and government debt must not exceed $60 \%$ of GDP. On average, debt for the euro zone-12 was approximately $60 \%$ of GDP until 2008 but rose to approximately $93 \%$ by before coming down slightly to $89 \%$ in 2017 (Table 1). Among the sample only Luxembourg did not breach the $60 \%$ threshold at any time in our sample period and Finland and Netherlands breached the threshold for brief periods (Table 1). The countries known as the PIIGS (Portugal, Ireland, Italy, Greece and Spain) have struggled with high debt levels. Greece and Italy had levels of debt to GDP over $100 \%$ for most of the period and Portugal breached the $60 \%$ threshold for most of the period with debt levels rising dramatically after the global financial crisis of 2008 (Table 1). Ireland and Spain started off strong with debt to GDP below the Maastricht threshold until 2009 and 2010 respectively, but suffered high debt for the rest of the period (Table 1). The rest of the countries, Austria, Belgium, France, and Germany breached the $60 \%$ threshold for most of the period, with the highest levels experienced by Belgium in this group (Table 1).

Deficit performance is slightly better with Luxembourg and Finland being the most successful in keeping deficits below 3\% of GDP for most of the period (Table 2). As with debt, the PIIGS struggle with deficits as well with Greece and Portugal being the worst performers (Table 2). Among the rest of the countries, France struggled with deficits for most of the period (Table 2). On average, deficits as a percentage of GDP stayed below the 3\% threshold until 2009 (following the global crisis) when it rose very high, reaching $8 \%$ in 2010 before declining and finally reaching below 3\% in 2015 (Table 2).

The European Commission introduced policies to address the various vulnerabilities and weaknesses experienced by member countries. The European Semester which is an annual cycle of coordination and surveillance of EU policies was implemented in 2010 and was revised since then, most recently in 2015 (Verdun and Zeitlin 2018). In 2011, Six-pack was introduced which included six regulations designed to reduce "macroeconomic imbalances and ensuring the viability of national finances through either preventive or corrective actions" (Delivorias 2014). This was followed by two-pack in 2013 which introduced "common budgetary timeline" and "enhanced surveillance" as a way to improve budgetary coordination (Delivorias 2014). All these measures were designed to improve EU governance and promote fiscal discipline. Overall improvements in fiscal indicators in the euro zone may be linked to these measures, although the debate about their benefit to member countries remains.

The relevant literature for analyzing monetary policy transmission is discussed in the following section. 
Table 1. Debt as a Percentage of GDP for Euro-12 Countries

\begin{tabular}{|c|c|c|c|c|c|c|c|c|c|c|c|c|c|c|c|c|}
\hline Country & 2002 & 2003 & 2004 & 2005 & 2006 & 2007 & 2008 & 2009 & 2010 & 2011 & 2012 & 2013 & 2014 & 2015 & 2016 & 2017 \\
\hline Austria & 59.8 & 59.9 & 59.8 & 64.1 & 64.2 & 62.5 & 66.0 & 78.1 & 80.8 & 80.5 & 80.9 & 80.6 & 83.1 & 83.5 & 82.6 & 77.7 \\
\hline Belgium & 102.7 & 99.8 & 95.7 & 94.1 & 90.6 & 86.8 & 91.3 & 99.4 & 99.7 & 102.6 & 104.3 & 105.3 & 107.0 & 106.1 & 106.0 & 103.4 \\
\hline Finland & 34.8 & 41.7 & 42.0 & 39.3 & 37.4 & 33.3 & 32.1 & 40.9 & 46.3 & 47.8 & 53.1 & 55.7 & 59.1 & 62.4 & 61.9 & 59.6 \\
\hline France & 60.0 & 64.1 & 64.9 & 66.0 & 63.5 & 63.5 & 67.5 & 79.4 & 81.5 & 84.0 & 87.9 & 90.6 & 92.8 & 93.3 & 93.9 & 94.0 \\
\hline Germany & 59.3 & 62.8 & 64.5 & 66.5 & 66.0 & 63.2 & 64.2 & 71.5 & 79.9 & 76.8 & 77.3 & 75.1 & 72.2 & 68.1 & 65.3 & 61.2 \\
\hline Greece & 102.0 & 99.6 & 101.6 & 106.0 & 102.6 & 102.3 & 108.7 & 126.2 & 143.6 & 167.6 & 154.3 & 170.1 & 171.2 & 170.5 & 175.1 & 173.7 \\
\hline Ireland & 29.2 & 28.1 & 27.7 & 25.9 & 23.5 & 23.4 & 38.6 & 58.1 & 85.7 & 105.1 & 111.1 & 109.7 & 96.7 & 73.7 & 70.1 & 66.6 \\
\hline Italy & 99.1 & 98.5 & 98.2 & 100.1 & 101.9 & 99.6 & 102.2 & 112.4 & 115.3 & 116.4 & 123.2 & 128.9 & 131.6 & 131.3 & 131.8 & 131.6 \\
\hline Luxembourg & 6.9 & 6.8 & 7.3 & 7.4 & 7.8 & 7.7 & 14.9 & 15.7 & 19.8 & 18.7 & 22.0 & 23.7 & 22.7 & 22.0 & 20.8 & 23.0 \\
\hline Netherlands & 48.1 & 49.2 & 49.5 & 48.9 & 44.4 & 42.0 & 52.5 & 53.3 & 56.1 & 58.6 & 62.2 & 66.2 & 67.0 & 63.9 & 61.1 & 56.2 \\
\hline Portugal & 54.3 & 57.9 & 61.7 & 67.2 & 69.0 & 68.3 & 71.2 & 82.4 & 94.9 & 102.4 & 112.5 & 114.2 & 112.0 & 114.7 & 118.7 & 120.9 \\
\hline Spain & 50.2 & 46.8 & 44.7 & 41.8 & 38.6 & 35.4 & 39.2 & 52.4 & 59.8 & 69.2 & 85.4 & 95.1 & 100.1 & 99.2 & 98.8 & 98.2 \\
\hline Euro-12 Av. & 58.9 & 59.6 & 59.8 & 60.6 & 59.1 & 57.3 & 62.4 & 72.5 & 80.3 & 85.8 & 89.5 & 92.9 & 93.0 & 90.7 & 90.5 & 88.9 \\
\hline
\end{tabular}

Notes: Data reported is a three-year moving average. Shaded cells indicate that the debt as a percentage of GDP is $60 \%$ or greater (meaning the Maastricht Treaty was breached).

Source: European Central Bank. 
Table 2. Budget Deficit as a Percentage of GDP for Euro-12 Countries

\begin{tabular}{|c|c|c|c|c|c|c|c|c|c|c|c|c|c|c|c|c|}
\hline Country & 2002 & 2003 & 2004 & 2005 & 2006 & 2007 & 2008 & 2009 & 2010 & 2011 & 2012 & 2013 & 2014 & 2015 & 2016 & 2017 \\
\hline Austria & -1.4 & -1.8 & -4.8 & -2.5 & -2.5 & -1.4 & -1.5 & -5.3 & -4.4 & -2.6 & -2.2 & -2.0 & -2.7 & -1.0 & -1.6 & -0.7 \\
\hline Belgium & 0.0 & -1.8 & -0.2 & -2.8 & 0.2 & 0.1 & -1.1 & -5.4 & -4.0 & -4.1 & -4.2 & -3.1 & -3.1 & -2.5 & -2.5 & -1.0 \\
\hline Finland & 4.1 & 2.4 & 2.2 & 2.6 & 3.9 & 5.1 & 4.2 & -2.5 & -2.6 & -1.0 & -2.2 & -2.6 & -3.2 & -2.8 & -1.8 & -0.6 \\
\hline France & -3.2 & -4.0 & -3.6 & -3.4 & -2.4 & -2.6 & -3.3 & -7.2 & -6.9 & -5.2 & -5.0 & -4.1 & -3.9 & -3.6 & -3.4 & -2.6 \\
\hline Germany & -3.9 & -4.2 & -3.7 & -3.4 & -1.7 & 0.2 & -0.2 & -3.2 & -4.2 & -1.0 & 0.0 & -0.1 & 0.5 & 0.8 & 1.0 & 1.3 \\
\hline Greece & -6.0 & -7.8 & -8.8 & -6.2 & -5.9 & -6.7 & -10.2 & -15.1 & -11.2 & -10.3 & -8.9 & -13.2 & -3.6 & -5.7 & 0.6 & 0.8 \\
\hline Ireland & -0.5 & 0.4 & 1.3 & 1.6 & 2.8 & 0.3 & -7.0 & -13.8 & -32.1 & -12.7 & -8.0 & -6.1 & -3.6 & -1.9 & -0.5 & -0.3 \\
\hline Italy & -3.0 & -3.3 & -3.5 & -4.1 & -3.5 & -1.5 & -2.6 & -5.2 & -4.2 & -3.7 & -2.9 & -2.9 & -3.0 & -2.6 & -2.5 & -2.3 \\
\hline Luxembourg & 2.4 & 0.2 & -1.3 & 0.1 & 1.9 & 4.2 & 3.3 & -0.7 & -0.7 & 0.5 & 0.3 & 1.0 & 1.3 & 1.4 & 1.6 & 1.5 \\
\hline Netherlands & -2.1 & -3.0 & -1.7 & -0.3 & 0.2 & 0.2 & 0.2 & -5.4 & -5.0 & -4.3 & -3.9 & -2.4 & -2.3 & -2.1 & 0.4 & 1.1 \\
\hline Portugal & -3.3 & -4.4 & -6.2 & -6.2 & -4.3 & -3.0 & -3.8 & -9.8 & -11.2 & -7.4 & -5.7 & -4.8 & -7.2 & -4.4 & -2.0 & -3.0 \\
\hline Spain & -0.4 & -0.4 & 0.0 & 1.2 & 2.2 & 1.9 & -4.4 & -11.0 & -9.4 & -9.6 & -10.5 & -7.0 & -6.0 & -5.3 & -4.5 & -3.1 \\
\hline Euro-12 Av. & -1.4 & -2.3 & -2.5 & -1.9 & -0.8 & -0.3 & -2.2 & -7.1 & -8.0 & -5.1 & -4.4 & -3.9 & -3.1 & -2.5 & -1.3 & -0.7 \\
\hline
\end{tabular}

Notes: Shaded cells indicate that the deficit as a percentage of GDP is $3 \%$ or greater (meaning the Maastricht Treaty was breached).

Source: European Central Bank. 


\section{Relevant Literature}

There are many studies estimating monetary policy transmission mechanisms including Bernanke and Blinder (1992) and Kashyap and Stein (1995) for the U.S. and Hülsewig et al. (2004) for Germany. Others have conducted comparative analyses monetary policy transmission mechanisms in different countries such as Dedola and Lippi (2005) for France, Germany, Italy, UK, and U.S., and Gerlach and Smets (1995) for Canada, Italy, Germany, France, Japan, UK, and U.S. Monetary transmission in regions or economic and monetary unions has also been investigated such as Haug et al. (2005) on Australia and New Zealand for the possible effects of a currency union between the two countries and Buigut (2009, 2010) on Uganda and Kenya for the proposed East African Community.

One important strand of research compares the "similarity" of monetary transmission within countries of the European Monetary Union. Evidence of this before the introduction of the euro is mixed. Some scholars including Ehrmann (1998), Cecchetti (1999), Mihov (2001), Van Els et al. (2001), Clausen and Hayo (2002) find significant differences in the monetary transmission mechanism across countries. However, Kieler and Saarenheimo (1998), and Guiso et al. (1999) and Mojon and Peersman (2001) do not find significant variation in the transmission mechanism prior to the introduction of a single currency.

There are also monetary transmission studies after the introduction of the euro. Poghosyan and de Haan (2007) combine pre and post-euro data (1980-2006) to analyze monetary transmission in the euro zone. They find evidence that financial integration in the union was not yet complete. Barigozzi et al. (2014) finds that there are differences between more and less developed countries.

However, Anzuini and Levy (2007) find that not only is monetary tranmission similar between newer members of the euro zone, Hungary, Poland, and the Czech Republic, but it is also similar to more developed countries in the euro zone. Boivin et al. (2008) find heterogeneity in the monetary transmission mechanism among countries before the inception of the euro while the launch of the euro has brought greater homogeneity. They also conclude that the launch of the euro has resulted in a dampening of the effects of monetary shocks

The above studies shed light on monetary transmission in individual countries for the euro area. Our focus is on monetary transmission for the euro zone as a group. This is examined by Peersman and Smets (2001) who estimate euro area wide monetary transmission based on 'synthetic' euro area data from 1980 to 1998 (before the introduction of the euro). They find that an increase in the short-term interest rate (tight monetary policy) will lead to a decline in GDP and inflation. Also, they find that significantly more variation in output can be explained by monetary policy compared with inflation. We extend this analysis, by estimating monetary policy transmission in the euro zone since the introduction of the euro. The framework for our analysis is discussed in the following section. 


\section{Methodology}

We estimate monetary policy transmission through the bank lending channel for the euro zone-12 countries. "Kashyap and Stein (1994) trace the origins of thought on the bank lending channel back to Roosa (1951) and also highlight Blinder and Stiglitz's (1983) resurrection of the loanable funds theory and Bernanke and Blinder's (1988) extension of the IS-LM model" (Ireland, 2005, p. 5). As noted earlier, the bank lending channel relates changes in the short-term interest with bank lending and long-term interest which ultimately impacts output (Ireland 2005).

The standard empirical framework to estimate monetary transmission mechanism is through a vector autoregression (VAR). Most of the studies discussed earlier use VAR analysis ${ }^{1}$ which includes a system of variables that are endogenous and interdependent, although there could be exogenous variables as well. We estimate a panel VAR (pVAR) with quarterly data from 2002 to 2016 for the original twelve euro zone countries. A pVAR is similar in structure in that variables in a system are endogenous and interdependent (again, allowing for exogenous variables) but differs from a VAR because it also includes a cross sectional dimension. This allows for cross sectional heterogeneity which in practical terms indicates that it allows for country differences.

The $\mathrm{pVAR}$ is represented by the following equation:

$Y_{i t}=\Gamma_{1} Y_{i t-1}+\Gamma_{2} Y_{i t-2}+\cdots+\Gamma_{p-1} Y_{i t-p+1}+\Gamma_{p} Y_{i t-p}+\mathrm{A} X_{i t}+u_{i}+\varepsilon_{i t}$

where $Y_{i t}$ is a vector of endogenous variables, $X_{i t}$ is a vector of exogenous variables, $u_{i}$ is a vector of panel fixed effects, $\varepsilon_{i t}$ is a vector of idiosyncratic error terms and $\Gamma_{s}$ and $\mathrm{B}$ are matrices of parameters to be estimated.

The variables in our pVAR estimation are based on Hülsewig et al. (2004) for Germany which include output, inflation, short-term interest rate, bank loans, and long-term interest rates, so $Y_{i t}$ is a $(5 \mathrm{x} 1)$ vector of these variables. We contribute three variables that capture the role of fiscal indicators in monetary policy transmission which has, and continues, to be a challenge for the euro zone. To capture the importance of debt, we add a variable which is calculated as the deviation of debt as a percentage of GDP from the $60 \%$ threshold in the Maastricht Treaty. For deficits, we must account for both positive and negative balances as well as negative balances below and above the 3\% Maastricht Treaty threshold. Thus, we construct a variable by multiplying the fiscal balance as a percentage of GDP with a dummy variable that takes a value of 1 if the $3 \%$ threshold is breached and 0 otherwise. Finally, we hypothesize that if a country breaches both the debt and deficit threshold, it may have a bigger impact on economic variables. Thus, we include a dummy variable that takes on a value of 1 if both thresholds are breached and 0 if only one or neither of the thresholds has been breached. These

${ }^{1}$ Poghosyan and de Haan (2007) use vector error correction method (VECM) and Barigozzi et al. (2014) employ a structural dynamic factor model. 
three fiscal variables are exogenous in the VAR system, so $X_{i t}$ is a $(3 \times 1)$ vector including these variables.

After we determine the appropriate lag length using Schwarz criterion we estimate a pVAR. We then analyze the impulse responses and variance decomposition to shed light on monetary policy transmission in the euro zone. The order of the variables matters for these results. We follow Hülsewig et al. (2004) as described earlier (and the three variables related to fiscal vulnerability are exogenous to the system). The impulse response function captures the impact of a one-unit shock to monetary policy (short-term interest rate) on other variables. The variance decomposition shows the percentage of variation in each variable that can be explained by other variables in the system. We are interested in the effect of monetary policy as determined by changes in the short-term interest rate on output and inflation. Data and results are discussed in the following section.

\section{Data and Results}

We use quarterly data from 2002:Q1 to 2016:Q3 for euro zone-12 countries in our panel VAR estimation of monetary policy transmission. As noted earlier, the variables in our system (in this order) are: output, inflation, short-term interest rate, bank loans, and long-term interest rate. The three fiscal variables are exogenous to the system. We use the index of industrial production, IIP, as a proxy for output $(2010=100)$, the percentage change in the three-month average of the harmonized index of consumer prices $(2015=100)$ for inf, and the ECB marginal lending facility interest rate for short-term interest rate $(S T I R)$. If there are multiple interest rates in a quarter, we use an average for that period. Long-term interest rates (LTIR) are represented by monetary financial institutions (MFI) over-5 year maturity rates. For bank loans (loans) we use total outstanding end-of-period loan stocks from the MFI balance sheet. We construct debt as the deviation of debt as a percentage of GDP from the $60 \%$ threshold set by the Maastricht Treaty. For def we calculate the deviation of fiscal balance as a percentage of GDP from the 3\% Maastricht Treaty threshold and multiply it by a dummy variable which takes on a value 1 if the deficit threshold is breached and 0 otherwise. Finally, we calculate a combination variable, debtdef, which is a dummy variable that takes a value of 1 if both thresholds are breached and 0 if either one or neither one of them have been breached. IIP and loans, are expressed in logarithmic form. Data for IIP is available from IMF, International Financial Statistics database and the rest are available from European Central Bank, statistical data warehouse.

Our sample contains macroeconomic variables that could be no stationary. We test for stationary using the Levin, Lin, and Chu test and the results are summarized in Table 3. Most variables are stationary except for loans. Although, the unit root test results show that one of the variables, loans, is no stationary we are still able to estimate a VAR (Sims 1980, Sims et al. 1990). 
Table 3. Unit Root Tests

\begin{tabular}{|l|c|c|}
\hline Variable & Test & P-value \\
\hline IIP & $-2.76^{*}$ & 0.00 \\
\hline Loans & -0.74 & 0.23 \\
\hline$\Delta$ Loans & $-9.01^{*}$ & 0.00 \\
\hline LTIR & $-2.23^{*}$ & 0.01 \\
\hline Inf & $-7.33^{*}$ & 0.00 \\
\hline STIR & $-2.73^{*}$ & 0.00 \\
\hline
\end{tabular}

Notes: Test statistics are reported for the Levin, Lin, and Chu test assuming a constant and using one lag. We report test statistics and p-values. The null hypothesis is that the series is no stationary.

*indicates rejection of the null hypothesis at $5 \%$ level of significance respectively.

The appropriate lag length is determined to be 2 lags based on the Schwarz criterion. Once we estimate the panel VAR, we can analyze impulse response functions and variance decomposition results. We first analyze the impulse responses which are graphed with 95\% confidence intervals in Figure 1.

As noted earlier, the bank lending channel for monetary policy transmission is based on the impact that tight monetary policy reduces bank lending and thus hurts output. Similar to the results for the U.S. (Bernanke and Blinder 1992) and Germany (Hülsewig et al. 2004), we find that higher short-term interest rates lead to a decline in bank loans (Figure 1). However, the small decline suggests that bank lending is a weak channel for monetary policy transmission, at least for the euro zone countries. This is likely related to the sample period which includes the global financial crisis and the PIIGS crisis that led to significant non-traditional monetary policy (quantitative easing) programs. As Ciccarelli et al. (2013) concludes, "the bank-lending channel has been to a large extent neutralized" by ECB's "non-standard monetary policy interventions" (p. 463).

We turn now to analyzing the impact of the monetary policy on output and inflation and compare our results on output and inflation to Peersman and Smets (2001) that shed light on monetary policy transmission for the 'synthetic' euro area. We expect that a positive shock to short term interest rates would reduce both output and inflation. Like Peersman and Smets (2001) we find that after the first quarter, tight monetary policy reduces output (Figure 1). Unexpectedly, we find a positive relation between a shock to short-term interest rates and inflation (Figure 1). For a significant portion of the sample period, countries in the euro zone (and elsewhere) were experiencing economic distress. This helps explain why lowering interest rates did not lead to higher inflation.

We also examine variance decomposition results, reported in Table 4. Similar to Peersman and Smets (2001) we see an increasing amount of variation due to short-term interest rates in output and inflation over the two-year period. In the case of output, the variation attributed to short-term interest rises from about $5 \%$ in the last quarter of the first year to a little over $6 \%$ by the end of the second year (Table 4). For prices, the variation explained by short term interest rates doubles from a little above $5 \%$ at the end of the first year to close to $10 \%$ by the end of the second year (Table 4). The comparable numbers for Peersman and Smets (2001) are $13 \%$ to $28 \%$ for output and $3 \%$ to $9 \%$ for prices (Table 1, p. 13). The much smaller impact on output in our results is not surprising given that standard 
monetary policy tools proved ineffective in the face of the severe global financial crisis. It is also possible that the smaller impact is related to the inclusion of disparate countries that were facing differential challenges.

Figure 1. Impulse Responses of Variables to a One-Unit Shock in STIR (Monetary Policy)
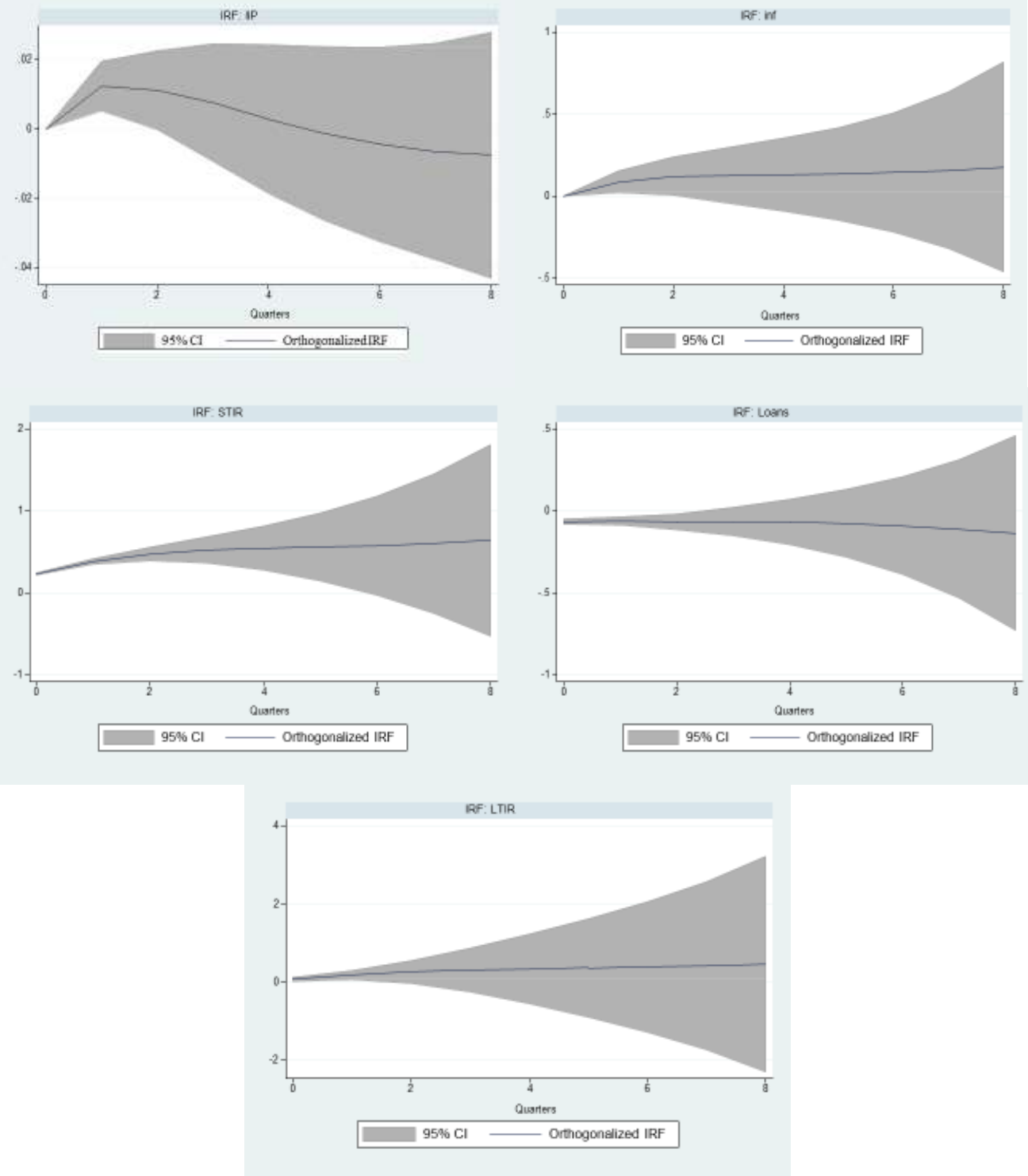
Table 4. Forecast-Error Variance Decomposition of Output and Prices

\begin{tabular}{|c|c|c|c|c|c|}
\hline Period & IIP & Inf & \multicolumn{1}{l|}{ STIR } & Loans & LTIR \\
\hline \multicolumn{5}{|c|}{ Variance Decomposition of IIP } \\
\hline Q 1 & 100 & 0.00 & 0.00 & 0.00 & 0.00 \\
\hline Q 2 & 97.17 & 0.10 & 2.74 & $\sim 0.00$ & $\sim 0.00$ \\
\hline Q 3 & 95.28 & 0.18 & 4.52 & $\sim 0.00$ & 0.02 \\
\hline Q 4 & 94.02 & 0.56 & 5.30 & $\sim 0.00$ & 0.12 \\
\hline Q 5 & 93.40 & 0.84 & 5.39 & $\sim 0.00$ & 0.37 \\
\hline Q 6 & 92.95 & 0.91 & 5.39 & 0.01 & 0.75 \\
\hline Q 7 & 92.23 & 0.91 & 5.66 & 0.01 & 1.20 \\
\hline Q 8 & 91.06 & 1.07 & 6.23 & 0.01 & 1.63 \\
\hline Variance Decomposition of Prices & \multicolumn{5}{|l}{} \\
\hline Q 1 & 1.22 & 98.78 & 0 & 0 & 0 \\
\hline Q 2 & 8.22 & 85.73 & 1.24 & 4.45 & 0.37 \\
\hline Q 3 & 8.06 & 82.66 & 3.27 & 5.29 & 0.73 \\
\hline Q 4 & 7.52 & 77.95 & 5.16 & 8.40 & 0.98 \\
\hline Q 5 & 8.14 & 73.23 & 6.70 & 10.86 & 1.08 \\
\hline Q 6 & 8.71 & 68.09 & 7.92 & 14.20 & 1.08 \\
\hline Q 7 & 9.68 & 62.81 & 8.90 & 17.58 & 1.02 \\
\hline Q 8 & 10.55 & 57.46 & 9.75 & 21.31 & 0.93 \\
\hline
\end{tabular}

Notes: The forecast variance decomposition are based on the same order of the variables in the panel VAR as the impulse reponse functions. We report results eight quarters. In some cases, the sum of the variance decomposition exceeds $100 \%$ due to rounding off numbers.

We turn now to examining the role of debt and deficits in monetary policy transmission. These results are reported in Table 5. None of the fiscal indicators are statistically significant determinants of short-term interest rates and bank loans (Table 5) which suggests that monetary policy and bank lending are unaffected by rising debt and deficit levels. While debt does not have a statistically significant impact on any of the variables in the system, it is "important" for output (Table 5). This indicates that high debt levels hurt economic growth. The deficit variable has a statistically significant negative impact on prices (Table 5). As fiscal balance as a percentage of GDP falls (meaning as the deficit increases), prices rise. Unexpectedly, breaching the fiscal thresholds lowers the long-term interest rate (Table 5). The combination variable has a statistically significant impact on IIP (Table 5) which indicates that vulnerability in both fiscal indicators (meaning that debt and deficit exceed the Maastricht Treaty threshold) hurts output. This is expected as breaching the threshold for debt and deficits puts even more pressure on countries struggling with the global crisis. This was likely exacerbated by various ECB policies to impose greater fiscal discipline discussed earlier.

We conclude with the broader implications of our results in the following section. 
Table 5. Impact of Fiscal Indicators on Endogenous Variables in the Panel VAR

\begin{tabular}{|c|c|c|c|c|c|c|}
\hline & \multicolumn{2}{|c|}{ Debt } & \multicolumn{2}{c|}{ Def } & \multicolumn{2}{c|}{ Debtdef } \\
\hline & Coefficient & p-value & Coefficient & p-value & Coefficient & p-value \\
\hline IIP & $-0.0008^{+}$ & 0.1550 & 0.0005 & 0.3960 & $-0.0318^{*}$ & 0.0000 \\
\hline Inf & 0.0061 & 0.2835 & $-0.0386^{* *}$ & 0.0810 & -0.0061 & 0.4700 \\
\hline STIR & -0.0025 & 0.2375 & -0.0008 & 0.4630 & -0.0168 & 0.2645 \\
\hline Loans & -0.0006 & 0.4170 & -0.0011 & 0.4500 & -0.0052 & 0.415 \\
\hline LTIR & 0.0016 & 0.4550 & -0.0181 & 0.3190 & $-0.1055^{* *}$ & 0.0710 \\
\hline
\end{tabular}

Notes: the coefficients for the three fiscal variables (debt, def, and debtdef) and their p-values are reported for the pVAR.

"and ${ }^{* *}$ indicates the variable is statistically significant at 5\% and $10 \%$ level of significance respectively. ${ }^{+}$indicates that while the variable is not statistically significant at usual levels of significance, the variable is important.

\section{Conclusion}

In this paper we analyze monetary policy transmission via the bank lending channel in euro zone-12 countries. Using quarterly data from 2002 to 2016 we estimate a panel VAR with output, prices, short-term interest rate, bank loans, and long-term interest rate. We also include debt and deficit indicators to capture the role of fiscal vulnerability on output and prices.

We find evidence that bank lending is an appropriate, albeit a weak, mechanism for monetary policy transmission in the euro zone. As noted earlier, this could be linked to the period under study that included a global crisis and excessive use of non-standard monetary policy. Bank lending may become a more effective channel of monetary policy transmission in the future with the expected conclusion of ECB's quantitative easing program at the end of $2018 .{ }^{1}$

Our empirical analysis reveals that a positive shock to in short-term interest rates has a negative impact on output, which suggests that loose monetary policy promotes growth. Unexpectedly, a positive shock in short-term interest rates has a small but positive impact on inflation. This trend is likely related to the breakdown of the link between monetary policy and inflation due to the severe global crisis that impacted the euro zone countries dramatically.

The trajectory of the impact of monetary policy on output is similar to that found by Peersman and Smets (2001) for the 'synthetic' euro area. However, the variation in output due to the monetary policy variable is much smaller in our sample than that observed by Peersman and Smets (2001). The global crisis that weakened the effectiveness of monetary policy is one explanation. Another is the differential impact of monetary policy on different countries facing unique challenges. For example, the PIIGS had far greater challenges than some of the other countries in our sample.

\footnotetext{
${ }^{1}$ The 2015 quantitative easing program launched by the ECB is expected to be halted by December 2018. This was announced by President of ECB, Mario Draghi, in a press conference on July 26, 2018 (https://www.ecb.europa.eu/press/pressconf/2018/html/ecb.is180726.en.html).
} 
In addition, we found that debt and deficits affect monetary policy transmission mechanism. High debt and deficits are linked with declining output. Fiscal vulnerability may put pressure on an economy and thus hurt output. It is also the case that a weaker economy strains the budget and causes rising deficits and debt. We believe that the link between fiscal vulnerability and output works both ways where declining output raises deficits and debt and when the Maastricht Treaty thresholds are breached it puts further pressure on output. Based on our empirical analysis we conclude that, for the Eurozone countries, if both the debt and the deficit thresholds established by the Maastricht Treaty are breached, this has a negative effect on output.

The differential results compared to earlier analysis and the impact of fiscal vulnerability suggest that the euro zone is at best, operating as only a partially integrated unit. This supports the evidence of some authors such as Poghosyan and de Haan (2007) and Barigozzi, et al. (2014) that there is asymmetry in monetary policy transmission in the euro zone. We offer another reason why there may be asymmetric effects, high deficits and debt burdens. It remains to be seen whether measures to impose further fiscal discipline to ensure that countries meet the Maastricht Treaty thresholds for debt and budget deficits lead to greater homogeneity in how monetary policy affects output.

\section{References}

Angeloni I, Ehrmann M (October 2003) Monetary Transmission in the Euro Area: Early Evidence. Economic Policy, CEPR, CES, MSH, 18(37): 469-501.

Angeloni I, Kashyap A, Mojon B, Terlizzese D (January 2002) Monetary Transmission in the Euro Area: Where do we Stand? European Central Bank Working Paper, 114: 383-412.

Anzuini A, Levy A (2007) Monetary Policy Shocks in the New EU Members: A VAR Approach. Applied Economics, 39(9): 1147-61.

Barigozzi M, Conti AM, Luciani M (2014) Do Euro Area Countries Respond Asymmetrically to the Common Monetary Policy. Oxford Bulletin of Economics and Statistics 76(5): 693-714.

Bernanke, Blinder (September 1992) The Federal Funds Rate and the Channels of Monetary Transmission. American Economic Review 82(4): 901-921.

Boivin J, Giannoni MP, Mojon B (2008) How has the Euro changed the Monetary Transmission Mechanism? NBER Macroeconomics Annual 23(1): 77-125. University of Chicago Press.

Buigut S (2009) Monetary Policy Transmission Mechanism: Implications for the proposed East African Community (EAC) Monetary Union. CSAE Oxford Conference Economic Development in Africa. Retrieved from https://bit.ly/2pqQ1qB.

Buigut S (2010) Is there a Bank Lending Channel of Monetary Policy in Kenya. International Research Journal of Finance and Economics, 45(August 2010): 183-192.

Cecchetti S (1999) Legal Structure, Financial Structure and the Monetary Policy Transmission Mechanism. NBER Working paper \#7151. 
Ciccarelli M, Maddaloni A, Peydró JL (2013) Heterogeneous Transmission Mechanism: Monetary Policy and Financial Fragility in the Eurozone. Economic Policy 28(75): 459-512. doi=10.1111/1468-0327.12015.

Clausen V, Hayo B (2002) Asymmetric Monetary Policy Effects in EMU. ZEI Working Paper, no. B 04-2002.Retrieved from https://bit.ly/2MLerV7.

Dedola L, Lippi F (2005) The Monetary Transmission Mechanism: Evidence from the Industries of Five OECD Countries. European Economic Review, 49(6): 1543-69.

Delivorias A (2014 December) Review of the 'Six-pack' and 'Two-pack. European Parliamentary Research Service EN PE 542.182.

Ehrmann (1998) Will EMU Generate Asymmetry? Comparing Monetary Policy Transmission across European Countries. EUI Working Paper, ECO No. 98/28.

Gerlach S, Smets F (1995) The Monetary Transmission Mechanism: Evidence from the G-7 Countries. BIS Working Paper 26. SSRN: http://ssrn.com/abstract=868427. doi=/10.2139/ssrn.868427.

Guiso L, Kashyap A, Panetta F, Terlizzese D (1999) Will a Common European Monetary Policy have Asymmetric Effects? Federal Reserve Bank of Chicago Economic Perspective 23(4): 56-75

Haug AA, Karagedikli Ö, Ranchold S (2005) Monetary Policy Transmission Mechanisms and Currency Unions: A Vector Error Correction Approach to a Trans-Tasman Currency Union. Journal of Policy Modeling 27(1): 55-74.

Hülsewig O, Winker P, Worms A (2004) Bank Lending in the Transmission of Monetary Policy: A VECM Analysis for Germany. Journal of Economics and Statistics 224(5): 511-529.

Ireland P (2005 November) The Monetary Transmission Mechanism. Federal Reserve Bank of Boston Working Papers 06-1.

Kashyap AK, Stein JC (1995) The Impact of Monetary Policy on Bank Balance Sheets. Carnegie-Rochester Conference Series on Public Policy 42(1): 151-195.

Kieler M, Saarenheimo T (1998) Differences in Monetary Policy Transmission? A Case not Closed. European Commission Economic Papers 132: 1-35.

Mihov I (2001) Monetary Policy Implementation and the Transmission in the European Monetary Union. Economic Policy 33(1): 369-402.

Mojon B, Peersman G (2001) A VAR Description of the Effects of Monetary Policy in the Individual Countries of the Euro Area. European Central Bank Working Paper 92: 56-74.

Peersman G, Smets F (2001 December) Monetary Policy Transmission Mechanism in the Euro Area: More Evidence from VAR Analysis. European Central Bank Working Paper 91: 36-55.

Poghosyan T, Haan DJ (2007) Interest Rate Linkages in EMU Countries: A Rolling Threshold Vector Error-Correction Approach. CESifo Working Paper 2060. SSRN: http://ssrn. com/abstract=1002868.

Sims C (1980) Macroeconomics and Reality. Econometrica 48(1): 1-48.

Sims C, Stock J,Watson M (1990) Inference in Linear Time Series Models with some Unit Roots. Econometrica 58(1): 113-44.

Van Els P, Locarno A, Morgan J, Villetelle JP (2001) Monetary Policy Transmission in the Euro Area: What do Aggregate and National Structural Models tell us? European Central Bank Working Paper Series 94: 91-106.

Verdun A, Zeitlin J (2018) Introduction: The European Semester as a New Architecture of EU Socioeconomic Governance in Theory and Practice. Journal of European Public Policy 25(2): 137-148. DOI=10.1080/13501763.2017.1363807. 